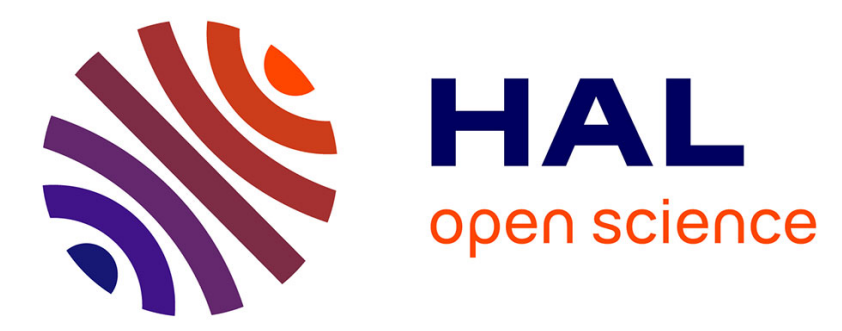

\title{
Progress on the preparation of nanocrystalline apatites and surface characterization: Overview of fundamental and applied aspects
}

Jaime Gómez-Morales, Michele Iafisco, José Manuel Delgado-López, Stéphanie Sarda, Christophe Drouet

\section{To cite this version:}

Jaime Gómez-Morales, Michele Iafisco, José Manuel Delgado-López, Stéphanie Sarda, Christophe Drouet. Progress on the preparation of nanocrystalline apatites and surface characterization: Overview of fundamental and applied aspects. Progress in Crystal Growth and Characterization of Materials, 2013, vol. 59, pp. 1-46. 10.1016/j.pcrysgrow.2012.11.001 . hal-00857502

\section{HAL Id: hal-00857502 https://hal.science/hal-00857502}

Submitted on 3 Sep 2013

HAL is a multi-disciplinary open access archive for the deposit and dissemination of scientific research documents, whether they are published or not. The documents may come from teaching and research institutions in France or abroad, or from public or private research centers.
L'archive ouverte pluridisciplinaire HAL, est destinée au dépôt et à la diffusion de documents scientifiques de niveau recherche, publiés ou non, émanant des établissements d'enseignement et de recherche français ou étrangers, des laboratoires publics ou privés. 


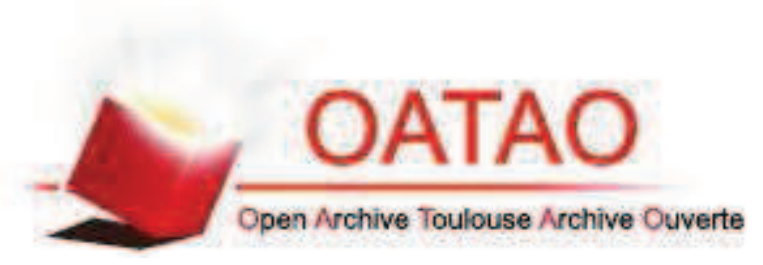

\section{Open Archive Toulouse Archive Ouverte (OATAO)}

OATAO is an open access repository that collects the work of Toulouse researchers and makes it freely available over the web where possible.

This is an author-deposited version published in: http://oatao.univ-toulouse.fr/ Eprints ID: 9162

To link to this article: DOI: $10.1016 /$ j.pcrysgrow.2012.11.001

URL: http://dx.doi.org/10.1016/j.pcrysgrow.2012.11.001

To cite this version: Gómez-Morales, Jaime and Iafisco, Michele and Delgado-López, José Manuel and Sarda, Stéphanie and Drouet, Christophe Progress on the preparation of nanocrystalline apatites and surface characterization: Overview of fundamental and applied aspects. (2013) Progress in Crystal Growth and Characterization of Materials, vol. 59 ( ${ }^{\circ}$ 1). pp. 1-46. ISSN 0960-8974 


\title{
Progress on the preparation of nanocrystalline apatites and surface characterization: Overview of fundamental and applied aspects
}

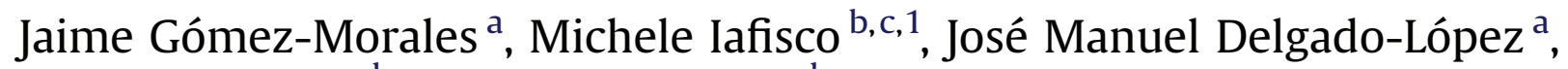 \\ Stéphanie Sarda ${ }^{\mathrm{d}}$, Christophe Drouet ${ }^{\mathrm{d}, *}$ \\ ${ }^{a}$ Laboratorio de Estudios Cristalográficos (IACT-CSIC-UGR), Avda. Las Palmeras, $n^{\circ}$ 4, 18100 Armilla, Granada, Spain \\ b Alma Mater Studiorum Università di Bologna, Dipartimento di Chimica “G. Ciamician", Via Selmi 2, 40126 Bologna, Italy \\ ${ }^{\mathrm{c}}$ Università del Piemonte Orientale, Dipartimento di Scienze Mediche, Via Solaroli 4, 28100 Novara, Italy \\ ${ }^{\mathrm{d}}$ CIRIMAT Carnot Institute, University of Toulouse, UMR CNRS/INPT/UPS, ENSIACET, 4 allée Emile Monso, 31030 Toulouse cedex 4 , \\ France
}

\section{Keywords:}

Biomimetic apatites and biomineralization Crystallization

Surface characterization and

reactivity (adsorption, ion exchange)

Bone tissue engineering

Drug delivery

Medical imaging

\section{A B S T R A C T}

Nanocrystalline calcium phosphate apatites constitute the main inorganic part of hard tissues, and a growing focus is devoted to prepare synthetic analogs, so-called "biomimetic", able to precisely mimic the morphological and physico-chemical features of biological apatite compounds. Both from fundamental and applied viewpoints, an accurate characterization of nanocrystalline apatites, including their peculiar surface features, and a deep knowledge of crystallization aspects are prerequisites to attempt understanding mineralization phenomena in vivo as well as for designing innovative bioactive materials that may then find applications in bone tissue engineering, either as self-supported scaffolds and fillers or in the form of coatings, but also in other domains such as drug delivery or else medical imaging. Also, interfacial phenomena are of prime importance for getting a better insight of biomineralization and for following the behavior of biomaterials in or close to their final conditions of use. In this view, both adsorption and ion exchange represent essential processes involving the surface of apatite nanocrystals, possibly doped with foreign elements or functionalized with organic molecules of

\footnotetext{
* Corresponding author. Tel.: +33 (0) 5343234 11; fax: +33 (0) 534323499.

E-mail addresses: jaime@lec.csic.es (J. Gómez-Morales), michele.iafisco@unibo.it (M. lafisco), jmdl@lec.csic.es (J.M. DelgadoLópez), stephanie.sarda@iut-tlse3.fr (S. Sarda), christophe.drouet@ensiacet.fr (C. Drouet).

1 Present address: Laboratory of Bioceramics and Bio-hybrid Composites, Institute of Science and Technology for Ceramics (ISTEC), National Research Council (CNR), Via Granarolo 64, 48018 Faenza, Italy.
} 
interest. In this review paper, we will address these various points in details based on a large literature survey. We will also underline the fundamental physico-chemical and behavioral differences that exist between nanocrystalline apatites (whether of biological origin or their synthetic biomimetic analogs) and stoichiometric hydroxyapatite.

\section{Introduction}

Nanocrystalline calcium phosphate apatites play an important role in biomineralization and in the biomaterials field. Biological nanocrystalline apatites are the main inorganic components of hard tissues in mammals (bone and tooth, with the exception of enamel which is closer to stoichiometric hydroxyapatite) and are involved in several pathological calcifications such as dental calculi, salivary stones, blood vessel calcification, etc [1-5]. In comparison with hydroxyapatite $\left[\mathrm{HA}, \mathrm{Ca}_{10}\left(\mathrm{PO}_{4}\right)_{6}(\mathrm{OH})_{2}\right]$ which is a stoichiometric apatitic phase that is the most stable and least soluble calcium phosphate at ambient conditions, nanocrystalline apatites are nonstoichiometric, calcium- (and $\mathrm{OH}-$ ) deficient and may incorporate substituted ions in their nanosized crystals. Their calcium and hydroxide deficiencies are responsible for a higher solubility than HA. Besides, they have the property of being able to mature when submitted to humid environments [5]. Due to this maturation process, "mature" bone crystals for vertebrates are less soluble and reactive than embryonic bone mineral crystals [6]. The small size and nonstoichiometry of apatite nanocrystals fulfill an important biological function in bone since they presumably bestow the mineral phase with the solubility needed for resorption of the bone by osteoclasts (bone resorbing cells), and enable bone mineral to act as an ion "reservoir" capable of either capturing or releasing ions (or small molecules) under the control of the body for ensuring homeostasis. Owing to these special properties, bone is thus a living tissue, far from being inert, which continuously undergoes remodeling and repair processes [7]. In addition, nanocrystalline apatites play a decisive role in the biological activity of implants (biomaterials) since the formation of a nanocrystalline bonelike apatite layer in their surface, when immersed in a simulated body fluid solution, can determine whether these materials can adequately integrate into the host living tissue [8].

Synthetic apatites exhibit excellent biological properties such as biocompatibility, bioactivity, lack of toxicity or inflammatory and immunitary responses, and also a relatively high bioresorbability. These properties can be significantly enhanced by improving their biomimetism [9], that is, by preparing them with similar dimensions, morphology, (nano)structural and chemical characteristics as for biological ones. Many different synthetic strategies have been employed to prepare nanosized apatite crystals [5]; however, the preparation of actually biomimetic nanocrystalline apatites may still be seen as a scientific and technological challenge [10]. It is important to underline that most important characteristics conferring the special properties to nanocrystalline apatites are the nanosized dimensions, their large surface-to-volume ratio, and the existence of a surface hydrated layer, nonapatitic in nature, which is essentially related to the formation process in solution. In fact this layer is bound to progressively disappear as the stable apatite domains (in the core of the crystals) develop with time (so-called maturation process). This hydrated layer exhibits a great ionic mobility, as well as ion exchange and adsorption capacities, and could participate in the interaction with macromolecules and drugs [4]. Thus, as mentioned above, this layer on bone mineral nanocrystals is thought to actively participate in homeostasis and other regulation processes [6]. Because of their excellent physicochemical and surface properties, nanocrystalline apatites then found applications as bio-inspired apatite-based bioceramics for bone substitution, repair or augmentation, or else as carrier vehicles for proteins, drugs and gene delivery $[4,11]$ or even in medical imaging.

The present paper reviews the recent progresses on the preparation of nanocrystalline apatites with tailored surface properties, which are based on the exploitation of their surface hydrated layer (as for biological apatites), as well as the characterization of nanocrystals surfaces and surface interactions with ions and macromolecules. 
The review is structured in five sections. Section 1 is devoted to the description of biologicallyrelated calcium phosphates and in particular to the recent studies and findings in terms of biomineralization related to the formation of bone and teeth. Section 2 deals with the latest published works regarding the preparation and crystallization mechanisms of biomimetic apatites with tailored surfaces properties. In Section 3 we report on the recent advances in the characterization of nanocrystalline apatite surfaces and their interactions with macromolecules and ions, of superior importance regarding their biological activity. Finally, Section 4 reviews some of the main advanced biomedical applications, related in particular to the emerging field of nanomedicine such as medical imaging, the setup of nano-carriers for drugs, proteins and gene delivery, or else bioactive coatings of metal implants.

Based on this review of the state-of-the-art in relation with biomimetic nanocrystalline apatites, there are excellent and exciting perspectives for the development of advanced bioactive bioceramics for bone tissue engineering, as well as for the setup of biomimetic nanoparticles with new applications based on the tailoring of their surface properties, for example by functionalizing the surface of the nanocrystals with specific molecules and ions or by using them to produce multifunctional engineered nanoparticles.

\section{Biologically-related calcium phosphates and recent advances in biomineralization related to bone and tooth formation}

As previously explained, in biological systems, calcium phosphates are the principal inorganic constituent of normal (bones, teeth, fish enameloid, deer antlers and some species of shells) and pathological (dental and urinary calculus and stones, atherosclerotic lesions) calcifications. Except for small portions of the inner ear, all hard tissues of the human body are formed of calcium phosphates. Structurally, with the exception of enamel, they occur in the form of poorly crystallized nonstoichiometric and carbonate-substituted nanocrystalline apatites [12,13].

\subsection{Bone mineralization}

Bones are rigid organs that form part of the endoskeleton of vertebrates. Their function is to move, support and protect the various organs of the body, produce red and white blood cells and store minerals [14,15]. Bones appear in a variety of shapes and have a complex internal and external structure; they are lightweight, yet strong and hard, in addition to satisfying their many other functions. Bone is a hierarchically-structured biomineral that has captivated scientists because of its particular structure and unique mechanical properties and remodeling capability. To understand its complex architecture, several hierarchical models have been proposed. The most known is the model of Weiner and Wagner [16] who described seven levels of hierarchy that range from the nanoscale to the macroscopic scale (Fig. 1).

The first level consists of molecular and crystalline components such as collagen, apatite, water and the rest of molecules. The second level is formed by the mineralized collagen fibrils. The third level is composed of arrays of mineralized collagen fibrils. These fibrils are almost always associated as bundles or other arrangements, often aligned along their long axis. The fourth level is composed of the different patterns of fibril arrays. These patterns can be parallel arrays, woven arrangements, plywood like structures, and radial arrays. Cylindrical structures called osteons make up the fifth level. The sixth level is formed by spongy (trabecular or cancellous) or compact (cortical) bone tissues. Cancellous bone is extremely porous (75-95 wt.\% porosity) and provides space for marrow and blood vessels, but has much lower compressive strength. Cortical bone is otherwise the dense outer layer (5-10 wt.\% porosity) that allows many functions of bone. The seventh level is simply the whole bone. S. Mann presented a similar structural hierarchy containing six levels [1].

Bone is made of about $65 \mathrm{wt} . \%$ of mineral phase (nanosized crystals of apatite), $25 \mathrm{wt} . \%$ of organic phase (basically type-I collagen, non-collagenous proteins (NCPs), minor organic molecules such as citrate) and $10 \mathrm{wt} . \%$ of water [2,11,16]. Apatite nanocrystals are calcium- (and hydroxide-) deficient, with a ratio of $\mathrm{Ca} / \mathrm{P}<1.67$, which is the theoretical value for the stoichiometric hydroxyapatite mineral $\left(\mathrm{Ca}_{10}\left(\mathrm{PO}_{4}\right)_{6}(\mathrm{OH})_{2}\right)$. Other interesting features of bone apatite are the poor crystallinity degree, the 

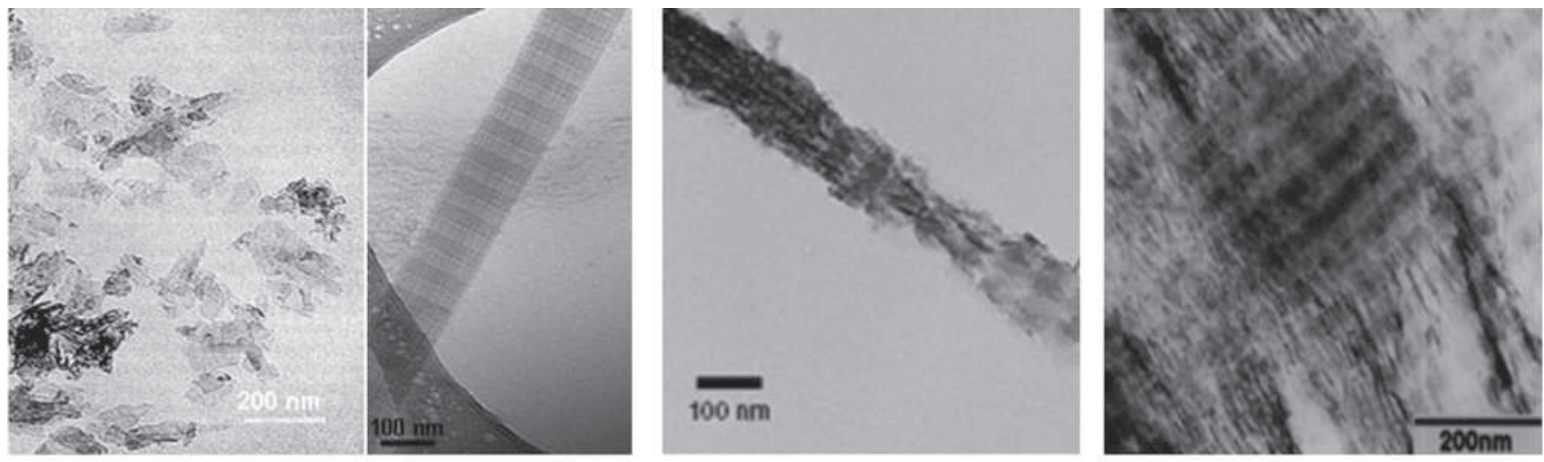

Level 1: Major components

Level 2: Mineralized Collagen

Level 3: Fibril Array

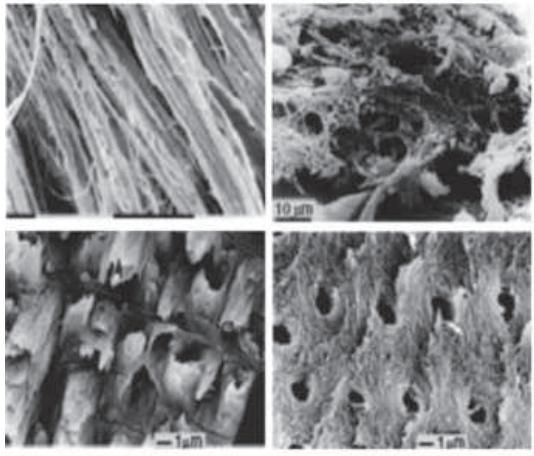

Level 4: Fibril Array Patterns
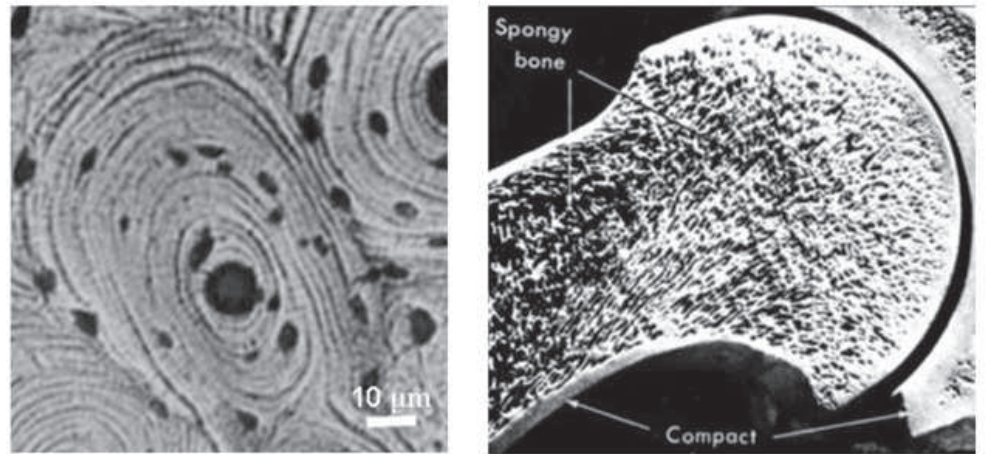

Level 5: Osteons

Level 6: Spongy vs Compact Bone

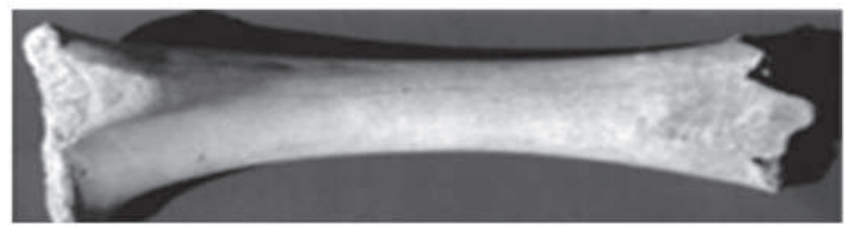

Level 7: Whole Bone

Fig. 1. Seven hierarchical levels of bone organization. Reprinted with permission from Ref. [13]. Copyright 2010 Dove Medical Press Ltd.

presence of ionic substituents in its crystalline structure (4-6 wt.\% carbonate, 0.9 wt.\% Na, $0.5 \mathrm{wt} . \% \mathrm{Mg}$ and others) and a typical plate-like morphology. The reported dimensions of nanocrystals vary according to the technique employed (Table 1). Using TEM, XRD and SAXS, the characterized dimensions vary in the following ranges: length $(20-50 \mathrm{~nm})$, width $(15-30 \mathrm{~nm})$ and thickness $(1.5-4 \mathrm{~nm})$ [2,17-21]. Studies by AFM, however, found that widths and lengths of bone crystals range from 30 to $200 \mathrm{~nm}$ [1]. Although apatite nanocrystals are usually presented as an inert single chemical compound with a passive role in the mechanical properties of bone, it must be underlined that the nanocrystals fulfill in fact a biological role, including through the "ion reservoir" function. It is thought that they may participate actively in homeostasis. This role has been attributed to their very high surface area and to

Table 1

Characterization of bone crystallites dimensions using different analytical methods.

\begin{tabular}{ll}
\hline Analytical method & Crystal dimensions \\
\hline TEM & $20 \mathrm{~nm}$ long $\times 3-6 \mathrm{~nm}$ wide \\
XRD & $10-35 \mathrm{~nm}$ long \\
$\mu$ XRD & $(14-17) \mathrm{nm} \times(3-5) \mathrm{nm}$ \\
SAXS & $50 \mathrm{~nm} \times 25 \mathrm{~nm} \times 1.5-4 \mathrm{~nm}$ \\
SAXS and TEM & $30 \mathrm{~nm} \times 20 \mathrm{~nm} \times 1.5-2 \mathrm{~nm}$ \\
AFM & $(200-30) \mathrm{nm} \times(200-30) \mathrm{nm} \times(3-10) \mathrm{nm}$ \\
\hline
\end{tabular}


the presence of a hydrated surface layer with strong abilities for ion exchange and adsorption of organic molecules. Due to their variable and complex composition, biological apatites were sometimes considered as a mixture of phases, which in consequence can be characterized by X-ray diffraction techniques. However, these techniques cannot provide information on the fine structural details of their surface. Recent progress on wet surface characterization of synthetic nanocrystalline apatites has occurred thanks to the use of spectroscopic methods. The data obtained by FTIR and solid state NMR revealed that freshly precipitated nanocrystals show specific lines that are lost after drying and are assigned to the existence of a hydrated structured surface layer, non-apatitic in nature. Some of their spectroscopic features are surprisingly analogous to those of triclinic octacalcium phosphate (noted OCP or, more precisely, $\mathrm{OCP}_{t}$ ). This layer becomes progressively transformed into the more stable apatitic lattice upon maturation in aqueous media. On the other hand the loosely-bound ions of this layer can be easily and reversibly substituted. Another feature is that the adsorption properties and reactivity of nanocrystalline apatites strongly depend on the composition of this layer [22].

Besides the above surface features, it is generally assumed that the very small particle size and the nonstoichiometry are bulk physicochemical features that presumably bestow the mineral phase with the solubility needed for resorption of the bone by osteoclasts, while their small thickness favors the mechanical properties, likely preventing crack propagation. Recently, citrate molecules strongly bound to the nanocrystalline apatite surfaces ( 1 molecule per every $2 \mathrm{~nm}^{2}$ ) have been identified by advanced solid-state NMR and proposed to be responsible for the inhibition of crystal thickening and also for the stabilization of nanocrystals within the collagen matrix [23]. NMR studies have revealed that citrate represents $5.5 \mathrm{wt}$.\% of the organic matrix of bone [23]. Due to its excellent chemical and biochemical properties, like its excellent Ca-complexing power and its bioavailability, some authors of the present review employed citrate molecules for the preparation of synthetic apatite nanoparticles that incorporated the molecules to their surfaces [24].

In addition to the recent interest for the characterization of surface properties of bone nanocrystals, the mineralization of collagen (the second level of hierarchy) has been the subject of intense investigation during the last decade. In this respect the description of bone nanostructure deserves some few words. Bone nanostructure is made of a self-assembled fibrillar collagen matrix mineralized with oriented apatite nanocrystals at both intrafibrillar and interfibrillar zones. During bone formation the collagen molecules self-assemble into triple helical structures called tropocollagen. The interaction between tropocollagen units leads to self-organization into fibrillar structures. Type I collagen molecules assemble their tropocollagen units giving rise to holes and overlapping areas that can be observed as a periodic banding pattern along the $67 \mathrm{~nm}$ repeat and a less dense $40 \mathrm{~nm}$-long gap zone (when stained for observation by TEM), the so-called D-band pattern (Fig. 2).

The holes appear mineralized and forming mineral bridges between them. The non-collagenous proteins (NCPs) appear linked to collagen and close to the mineralization front. Most of them are polyanionic and hold high amounts of carboxylate and phosphates groups which are arising from phosphoserine and aspartic and glutamic residues, with high affinity for Ca ions [26].

During many years there was controversy on whether it is collagen or NCPs that initiate intrafibrillar mineralization and on the mechanisms producing it at molecular level. It was thought that NCPs, while bonded to collagen fibers, could act as promoters of intrafibrillar nucleation. Such a hypothesis was supported by reports showing that NCPs appear during the formation of new bone in a very specific spatiotemporal timeline [27] and also that type-I collagen alone, dissociated from NCPs, is unable to produce bone mineralization [28]. On the other hand, it was proven that NCPs such as osteopontin, vitronectin and albumin, when they are dissociated from collagen, are inhibitors of calcium phosphate nucleation in solution [29-31].

Recently, in vitro intrafibrillar mineralization of collagen was achieved by substituting NCPs with polyaspartic acid (pAsp) [7,32]. Price et al. [33] proposed a mechanism for fibril mineralization based on inhibitor exclusion, by which macromolecular inhibitors of apatite growth favor fibril mineralization by selectively inhibiting crystal growth in the solution outside of the fibril. These authors tested this mechanism by using fetuin, a 48-kDa inhibitor of apatite growth. In the absence of fetuin, mineral growth occurred primarily in the solution outside of bone collagen, whereas in the presence of fetuin, mineral growth occurred almost exclusively within bone collagen. Only very recently, in 2010, the group of Sommerdijk [34] based on previous results [7,32] has shown that collagen functions in 

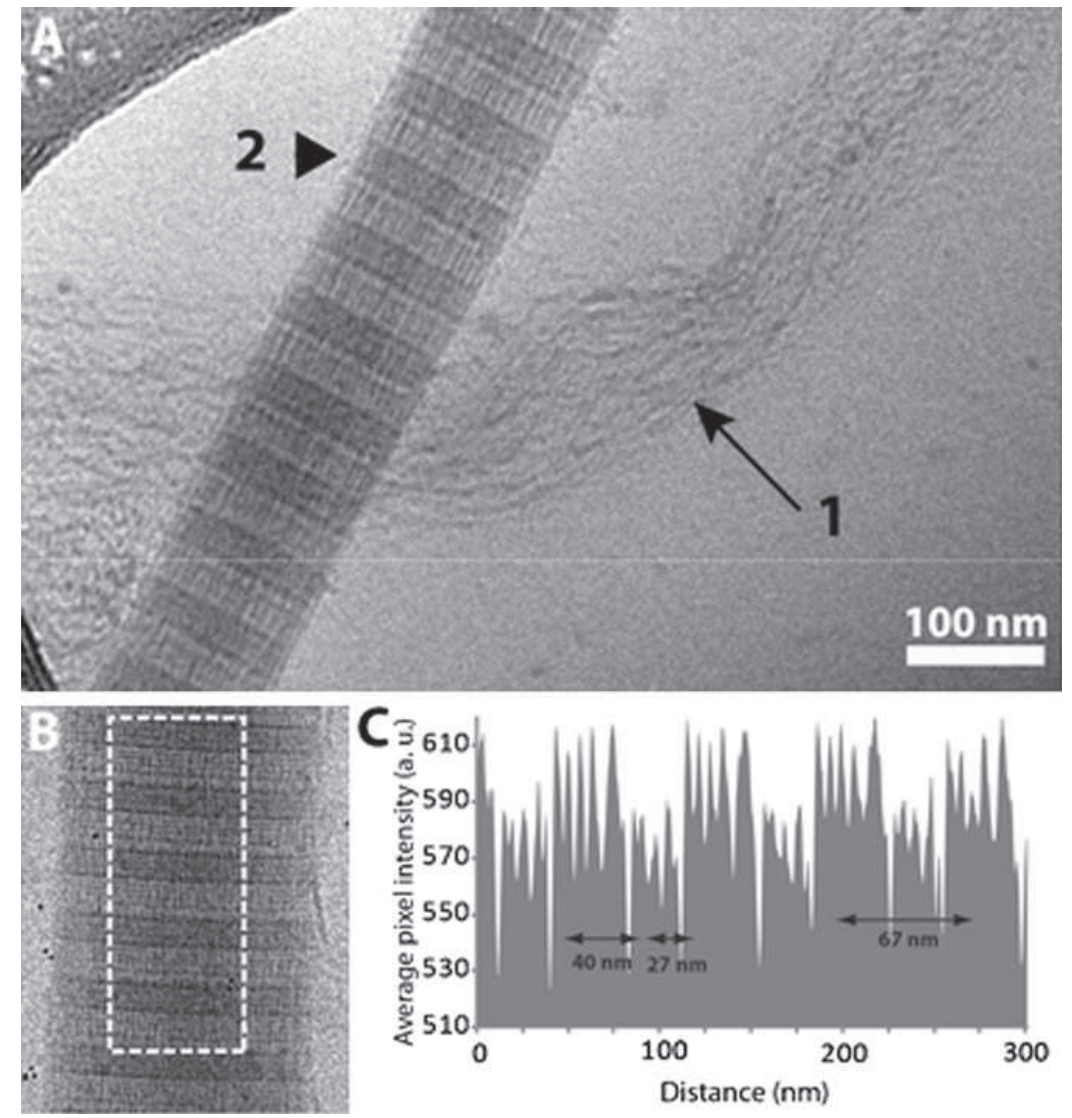

Fig. 2. Cryo-TEM images of (A) loosely packed collagen bundle (arrow, 1) and fully assembled fibril (arrowhead, 2) at pH 7.4. Scale bar: $100 \mathrm{~nm}$. (B) Assembled fibril showing clear D-band pattern. The dashed rectangle indicates the area used to calculate the profiles depicted in (C). (C) Intensity profile of the collagen fibril along the long axis, showing D-band pattern. Reprinted with permission from Ref. [25]. Copyright 2011 Royal Society of Chemistry.

synergy with inhibitors of hydroxyapatite nucleation to actively control mineralization by a mechanism of electrostatic interactions. These researchers used cryo-TEM and cryogenic electron tomography with molecular modeling to study this phenomenon and to follow the mineralization mechanism. In their experiments, Sommerdijk's group used type-I collagen and either polyaspartic acid (pAsp) or fetuin instead of NCPs as soluble inhibitors macromolecules. According to their results amorphous calcium phosphate (ACP) nucleate on polyaspartic acid forming negatively-charged ACPpAsp complexes. The mineral infiltration inside the fibrils is promoted by the net positive charge close to the C-terminal region of the collagen molecules at the gap and overlap areas. Furthermore, the charged aminoacids in these zones form nucleation sites controlling the conversion of ACP into a parallel array of oriented apatite nanocrystals. Although there are some open questions such as the role of the citrate molecules in this process, that could explain how these molecules participate in the biological regulation of nanocrystalline apatite formation, it can be said that these investigations have opened the door to the fabrication of intra-mineralized collagen bone analogs.

\subsection{Teeth mineralization}

Teeth consist of a bulk of dentin covered with (inorganic) enamel on the crown and cementum on the root surface [35]. Thick collagen bundles, called periodontal ligaments (PDL), attach to cementum at one end and the alveolar bone at the other end. The alveolar bone is supported by the jaw. These mineralized tissues are deposited by cells differentiating through interactions between inner neural crest-derived ectomesenchymal cells and overlying epithelial cells. Dentin and bone are similar in inorganic content (about $70 \mathrm{wt} . \%$ and $67 \mathrm{wt} . \%$, respectively), crystal size and crystallinity and organic composition, including the type-I and type-V collagen heterofibril framework [36,37], but these two 
tissues are histogenetically different. Dentin is characterized by closely-packed tubules extending throughout its entire thickness. These tubules contain cell processes of odontoblasts (dentin-forming cells), and their cell bodies are typically aligned along the inner edge of dentin, the dental pulp [35]. In contrast, bone usually has cells (osteocytes) within the matrix and either active or quiescent boneforming cells (osteoblasts) on the surface. On the contrary, enamel is distinct from bone and dentin in its tissue origin, mineralization matrix, and mode of mineralization [38]. Enamel is the hardest materials and with most robust mechanical properties formed by vertebrates and it is the most highly mineralized skeletal tissue present in the body. Mature enamel is composed of 95-97 wt.\% carbonated HA with less than $1 \mathrm{wt} . \%$ organic material. Compared to dentin, enamel is uniquely composed of extremely long and narrow crystals (around $100 \mu \mathrm{m} \times 50 \mu \mathrm{m}$, [39]), packed into parallel arrays, called enamel rods, which can form intricate interwoven patterns. The high degree of mineralization makes enamel a fascinating model for understanding fundamental mineralization processes and processes that occur within an extracellular matrix. It is distinct from bone in terms of architecture, pathology and the biological mechanisms mediating its formation [40]. Additionally, unlike other biomineralized tissues, mature enamel is acellular and does not resorb or remodel. As a result, enamel regeneration cannot occur in vivo following failure and is therefore an attractive target for future biomimetic and therapeutic approaches.

Enamel formation, or amelogenesis, is a highly regulated process involving precise genetic control as well as protein-protein interactions, protein-mineral interactions, and interactions involving the cell membrane. Enamel forms by HA crystallization on a non-collagenous protein matrix secreted from ameloblasts of epithelial origin, whereas bone and dentin form on a collagenous matrix deposited by cells of mesenchymal origin. The enamel matrix mineralizes immediately after secretion [41]. During the initial stages (secretory stage) of enamel formation, long thin ribbons of enamel mineral are formed almost immediately as the ameloblast lays down enamel matrix proteins [42,43], suggesting that enamel mineralization does not take place within a preformed matrix [41]. This process is in sharp contrast to bone and dentin, both of which mineralize on preformed unmineralized matrix, called osteoid and predentin respectively. Although these mineral ribbons are extremely long $(>100 \mu \mathrm{m})$ and may extend the full thickness of the enamel layer [39,44], they are only a few unit cells thick (i.e., in the order of $10 \mathrm{~nm}$ ) [45,46], if the initial mineral phase is considered to be HA or OCP. The $c$-axis of these crystals always coincides with their long axis [47], whereas, $a$ - and $b$-crystallographic axes coincide with two other (thickness and width) morphological axes of the crystal. The mineral phase of secretory enamel is approximately 10-20 vol.\%, with the remaining portion occupied by matrix protein and water [48]. It is important to notice that these ribbon-like crystals are organized in parallel arrays that ultimately dictate the highly-ordered arrangement of bundles of enamel crystals (i.e., enamel rods) found in mature enamel. In developing enamel [42,49], the $c$-axes (long axes) of these crystals are coaligned and generally run in parallel to the overall direction of the enamel rod. Subsequently, the enamel matrix matures into a hypermineralized inorganic tissue (about 96\% inorganic content). Specialized proteins, amelogenin, ameloblastin, and enamelin, constitute the mineralizing enamel matrix. During the maturation stage, coincident with the almost complete removal of enamel proteins by resident proteases, these mineral ribbons grow rapidly in thickness and width, resulting in a mineralized tissue that is $>95 \%$ mineral (by weight), with only $1-2 \%$ remaining protein (the missing percentage is mostly water), in a way that maintains the structural organization of the enamel crystals established during the secretory stage [50]. These findings suggest a functional relationship between organic matrix removal and subsequent mineral growth. The transient nature of the enamel matrix is unique and distinguishes enamel formation from other systems in biomineralization.

Similar to bone, enamel possesses a complex architecture, which can be broken into several hierarchical levels from the nanoscale to the macroscale [51] (Fig. 3). On the nanoscale, the protein-protein and protein-mineral interactions in the presence of supersaturated calcium phosphate solutions create a highly organized array of HA crystallites that grow preferentially along the $c$-axis [52]. The sizes of these crystallites depend on the stage of the mineralization. The crystallites grow primarily in length during the secretory stage and continue to grow in width and thickness during the maturation stage. The assembly of amelogenin has been shown to be crucial for the proper development of enamel crystallites [53,54]. Disruption of the assembly alters the formation process on the nanoscale, subsequently affecting larger length scales and giving rise to a diseased or malformed enamel phenotype. On 


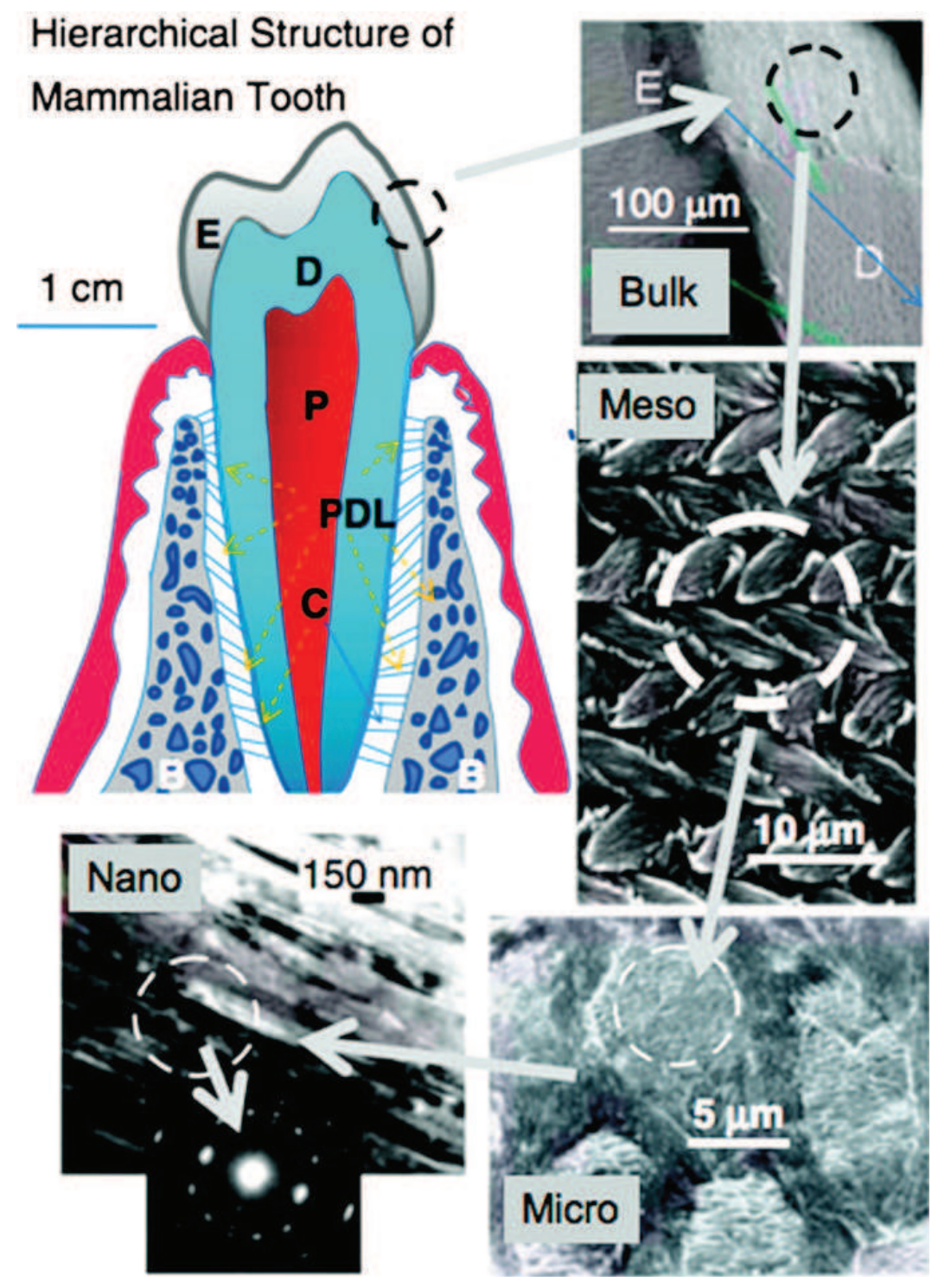

Fig. 3. Hierarchical architecture of mammalian enamel. Enamel (E) is the outermost layer at the crown of the tooth and resides above the dentin (D). The pulp (P) contains nerves and blood vessels, while the cementum (C) is the outermost layer of mineralized tissue surrounding the root of the tooth allowing the tooth to be anchored to the jawbone through the periodontal ligament (PDL). The bulk image depicts the $\mathrm{E}$ organ, the transition across the D-E junction, and the D below. On the mesoscale level, prismatic $\mathrm{E}$ consisting of weaving of rods (or prisms) that range from 3 to $5 \mu \mathrm{m}$ in diameter can be visualized. Upon further magnification, the micrometer scale shows the composition of a single rod. The nanometer scale reveals a highly organized array of individual HA crystallites (approximately $30 \mathrm{~nm}$ thick, $60 \mathrm{~nm}$ wide, and several millimeters in length), which are preferentially aligned along the $c$ axis. Reprinted with permission from Ref. [58]. Copyright 2008 Cambridge University Press.

the mesoscale level, there are three main structural components: the rod, the interrod and the aprismatic enamel. The main component of enamel on the mesoscale includes rods, which are bundles of aligned crystallites that are "woven" into intricate architectures that are approximately 3-5 $\mu \mathrm{m}$ in diameter [55]. The second structural component of the enamel matrix is the interrod (or interprismatic) enamel, which surrounds and packs between the rods. The difference between the rod and the interrod is the orientation of HA crystals; the rod contains aligned crystallites, whereas the mineral in the interrod is less ordered. These structures coalesce to form the tough tissue of enamel, which can withstand high forces and resist damage by crack deflection. The third structure, aprismatic enamel, refers to the structures containing HA crystals that show no mesoscale or macroscale alignment. The macroscale architecture includes specific zones of enamel that have unique characteristics, which contribute to the whole tissue. The enamel adjacent to the dentin-enamel junction (DEJ) exhibits a gradual transition from dentin to enamel. Aprismatic regions of enamel have been proposed to be primitive areas of the tooth serving as a toughening mechanism due to their flexible nature [56]. 
Several authors have identified these aprismatic areas to be located adjacent to the DEJ and at the incisal surface of both deciduous and permanent human enamel [57].

Over the last 40 years, a remarkable effort has been made to elucidate the mechanism by which enamel matrix proteins regulate the formation and organization of the enamel tissue. Although significant advances have clearly been made during this time, the complete mechanism of enamel formation is still unknown. Such progress has led investigators to suggest that the predominant enamel matrix protein, amelogenin, self-assembles to form organized supramolecular structures that facilitate crystal organization $[59,60]$, prior to its subsequent removal during tissue maturation. This suggestion was based, in part, on the detection of chains of nanometer-sized spheres by using TEM observations of both dehydrated resin-embedded [61] and non-dehydrated freeze-fractured sections of forming dental enamel [62]. It was further suggested that such aggregates, alone or in combination with other proteins, facilitate the nucleation and organization of mineral phases [41]. Although this conceptualization is very interesting, especially given its similarity to mineralization mechanisms in collagenbased tissues, the precise mechanism by which enamel matrix proteins regulate such processes is not well-understood. Nevertheless, evidences suggest that both protein-protein interactions and protein-mineral interactions (in particular amelogenin proteins) play crucial roles in the regulation of enamel mineral formation and organization.

To better comprehend the enamel formation in addition to the protein-mineral interactions, the role of fluoride has been investigated. In the last five decades, fluoride has been used for the treatment of dental erosion and caries prevention through different modalities [63]. In addition, the effect of fluoride on the nanostructure of remineralized apatite has been well documented [64]. However, despite its use in humans as remineralizing agent, its benefits are not still clear due to the fact that the optimal dose of fluoride resulting in a positive effect on enamel remineralization with minimum risk of toxicity has not been well documented. In this respect several recent studies have demonstrated the excellent properties as remineralizing agent of the apatite as such (especially nanosized apatite) [65-67].

Several works have suggested that enamel crystal growth comprises two events: the twodimensional growth of an OCP-like precursor in a narrow outermost zone adjacent to the ameloblasts and the subsequent overgrowth of apatite units on the template under discrete fluid environment in the underlying region distant from the cell layer. In this way, the presence of $0.1-2 \mathrm{mg} / \mathrm{l}$ fluoride in the mineralizing solution is known to promote hydrolysis of OCP to apatite $[68,69]$ and fluoride can accelerate epitaxial growth of apatite crystals on the OCP precursor, changing the crystal morphology. It has also been shown that at 0.1-1 ppm fluoride the ribbon-like OCP changes to an interlayered structure whereas at $2 \mathrm{mg} / \mathrm{l}$ needle-shaped apatite crystals were produced $[68,70]$. Fluoride was hypothesized to reduce growth of (100) face of OCP and to cause needle-like crystal structure formation. Recently Fan et al. have demonstrated that $1 \mathrm{mg} / \mathrm{l}$ fluoride was effective in altering the crystal nanostructure from porous plate-like OCP to a $20-50 \mathrm{~nm}$ diameter needle-like array of fluoridated apatite nanocrystals [71]. The biomimetic mineralization system used in this work (supersaturated calcification solutions were used to initiate the growth of calcium phosphate crystals on the etched enamel surfaces), at best of our knowledge, is a first step toward developing a clinicallyapplicable means of forming an enamel-mimicking mineralized layer, under minimal fluoride exposure, on eroded or damaged tooth enamel. However, direct evidence of the effect of $F$ ion on the morphology and nanostructure of crystal growth at a nanoscale level on an enamel surface has not been reported yet.

\section{Crystallization of apatites with tailored surface properties}

\subsection{Precipitation of amorphous calcium phosphate (ACP)}

Amorphous calcium phosphate is thermodynamically unstable which usually spontaneously transforms into crystalline calcium phosphate, mainly apatite. However, this instability and the easy transformation to crystalline phases are of a great biological relevance. Actually, ACP has been considered as a precursor phase of bone mineral in vertebrates which play a key role in intrafibrillar mineralization of collagen fibrils [72]. Recently, Weiner et al. reported that ACP is a major component of 
the first-formed mineral phase of bone [73]. Additionally, Nancollas et al. on the basis of the work of Hu et al. [23] have suggested that citrate can strongly influence early ACP formation [74]. They proposed that at an early stage of nucleation in the presence of citrate, only some citrate molecules can partly bind with the cluster surface, inhibiting their further aggregation, and thus increasing the induction time [74]. In the later nucleation stage, the ACP clusters aggregation can be promoted by the presence of non-collagenous protein. Although some citrate molecules can interact with the amorphous clusters, the binding area density is low, owing to the continuing mismatch between the spacing of the terminal carboxylate groups in citrate and the structural parameter of the amorphous clusters. In fact, the interaction of the citrate molecules and ACP clusters can slow down but not inhibit the transformation process to crystalline apatite. On the other hand, the area density of citrate binding on the crystal surfaces increases because the spacing of carboxylate groups in citrate matches that of calcium ions of the (1010) planes in apatite [23]. Thus, the crystal growth is inhibited along the [100] direction (reducing so the thickness of the nanoparticle) but it grows along the $c$-axis. Hence, it is clear that citrate and non-collagenous proteins play a key role on the tailoring of not only the transition from ACP to apatite but also the thickness and crystal orientation of apatite on the collagen fibrils.

\subsection{Crystallization methods of apatites}

Numerous methods have been used for the synthesis of apatite crystals. They can be classified into the following categories: wet chemical precipitation [75-77], sol-gel synthesis [78-80], coprecipitation [24,81], hydrothermal synthesis [82-84], rapid or continuous precipitation from solution [85], mechanochemical synthesis [86], microwave processing [87-90], vapor diffusion [91-93], silica gel template [94], emulsion-based syntheses [95], electrospraying [96], electrospinning [97], flux cooling [98] and other methodologies producing (nano)crystals of various shapes and sizes [99,100]. Dorozhkin [5] has recently produced a review of those methods producing nanocrystalline apatites and has underlined that the interest for nanocrystalline apatites was quite recent. In fact the systematic investigation on these materials did not commence until 1994.

Using as criteria the control of apatite structure and morphology, the crystallization methods can be divided into high and low temperature approaches. The synthesis at high temperature usually involves the homogenization of precursor compounds, such as $\mathrm{Ca}_{3}\left(\mathrm{PO}_{4}\right)_{2}$ and $\mathrm{Ca}(\mathrm{OH})_{2}$, and their annealing at about $1000{ }^{\circ} \mathrm{C}$. The advantage is the possibility to set the final stoichiometry of the product, whereas the main downsides are the long processing times and high annealing temperatures. In general, when using this method the $\mathrm{Ca} / \mathrm{P}$ ratio is a crucial parameter; in fact, if the initial molar ratio of $\mathrm{Ca} / \mathrm{P}$ is not well set to 1.67, extraneous phases could appear such as $\alpha$ - or $\beta$-TCP at values lower than the stoichiometric $\mathrm{Ca} / \mathrm{P}$ ratio and typically $\mathrm{CaO}$ at higher values. The $\alpha$-TCP phase is normally formed at temperatures around $1200^{\circ} \mathrm{C}$ whereas the $\beta$-TCP phase is formed at lower temperatures, up to $900{ }^{\circ} \mathrm{C}$. In addition to the high levels of energy consumption, another major downside of high temperature methods is the difficulty to produce uniform and nanosized crystals [101].

The synthetic methods at low temperature involving precipitation from solution offer the advantage that they can produce nanosized crystals, but a disadvantage may be in some cases the presence of transient and metastable phases in the final product. The samples produced by these methods are then generally nonstoichiometric and poorly crystallized. Indeed, the analyses carried out on several samples allow to assess that they have the typical features of biological apatites such as a poor degree of crystallinity, the existence of ionic surface disorder (non-apatitic surface layer) and surface compositions different from the bulk in nanocrystals, which consists on the presence of non-apatitic anionic and cationic chemical environments and sometimes labile carbonates.

As explained previously, biological apatites are known for their high content of defects, caused in part by a relatively large percentage of ionic substituents, all of which affect the lattice parameters, crystal morphology, crystallinity, solubility, and the thermal stability of the material. Biological apatite crystal surface is thus rarely smooth, which is also linked to biological significance. The exceptional roughness, comprising surface irregularities in the order of size of single unit cells, hypothetically corresponds to the tendencies to increase protein binding in the process of biomineralization. Moreover, recent studies have shown that rough surfaces improve biocompatibility of the material and have a positive effect on inflammatory reactions [102]. For this reason, evolution in the preparation 
techniques has led to methods for obtaining apatite in nanosized forms, mimicking those naturally occurring in bone. Structure is also important for biomimetism, as the mineral component of bone has well-defined features in relation to bone tissue function and age [103]. In this respect, the possibility to turn quite smoothly the bulk structure from highly to poorly crystalline by changing preparation conditions, such as temperature, $\mathrm{pH}$, presence of anionic and/or cationic substituents, or else nucleation on a substrate such as collagen fibers, is well-known [104].

To investigate the effect of temperature on nanosized apatite, Sakhno et al. compared two types of samples synthesized at $40{ }^{\circ} \mathrm{C}$ and $95{ }^{\circ} \mathrm{C}$ [105]. The apatite synthesized at low temperature displayed platelet-like morphology and are constituted by a crystalline core coated by an amorphous surface layer 1-2 nm thick (Fig. 4). By increasing the preparation temperature, the platelet morphology was retained but apatite nanoparticles exhibited a higher degree of crystallinity (evaluated by X-ray diffraction techniques). HRTEM observations revealed that, in this case, the crystalline order was extended up to the particles surfaces, exhibiting the planes (010), (100), and (001). IR spectroscopy was used to investigate the surface hydration of both materials, in terms of adsorbed $\mathrm{H}_{2} \mathrm{O}$ molecules and surface hydroxyl groups, as well as the Lewis acidity of surface cations, by removing water and adsorbing CO [106]. For both features, strong similarities between amorphous and crystalline surfaces were found. However, interestingly the apatite synthesized at $95^{\circ} \mathrm{C}$ with crystalline surfaces appeared able to physisorb multilayers of water in a larger extent than less crystallized samples.

Nowadays, the interest for nanocrystalline apatites is still rising thanks to their new applications in biomedicine requiring control of shape and size distribution as well as tailored surface properties (see in particular Section 4). Although there are numerous methods to produce nanocrystalline apatites in a controlled manner, the preparation of actually biomimetic and surface- or bulk-tailored nanocrystals is still a scientific and technological challenge. In this sense variations of already established methodologies such as the method based on precipitation from metastable $\mathrm{Ca} /$ citrate/phosphate solutions [24] or new methodologies, not yet explored, are being investigated to get these materials.

Delgado-López et al. have prepared citrate-functionalized carbonate-apatite nanoparticles with mean lengths ranging from 20 to $100 \mathrm{~nm}$ by a thermal-decomplexing batch method [107]. This crystallization method consists on the thermal decomplexing of metastable calcium/citrate/phosphate/carbonate solutions that produces a gradual and homogeneous release of $\mathrm{Ca}^{2+}$ ions in the solution producing, thus the precipitation of nanocrystalline apatites. They also studied the effect of the maturation time and the presence of sodium carbonate in the solution on the physico-chemical and structural properties of the nanoparticles. They found these two experimental conditions play an important role in tailoring both the physicochemical and the morphological properties of nanocrystalline apatites such as size, composition, and crystallinity. At short precipitation time, poorly crystalline $100 \mathrm{~nm}$-mean length apatites with low carbonation degree $(1.5 \% \mathrm{w} / \mathrm{w}$, mainly as B substitution) and high citrate content $(5.9 \% \mathrm{w} / \mathrm{w})$ were precipitated. Interestingly, this citrate content is close to that recently measured on bone apatite [23]. When increasing the precipitation time up to $96 \mathrm{~h}$ the mean length and the citrate content progressively decrease and at the same time the nanoparticles
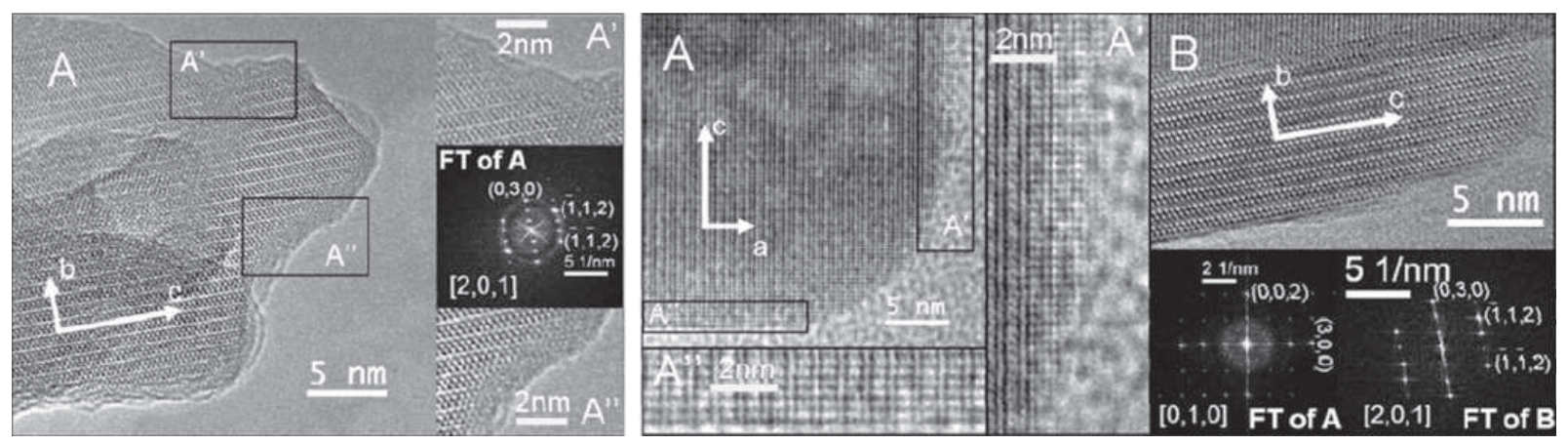

Fig. 4. (Left) High resolution TEM image of a portion of apatite synthesized at $40{ }^{\circ} \mathrm{C}$ (main panel, left), related FT and zoomed view of two border regions (right panels). Original magnification: $800 \mathrm{k} \times$. (Right) High resolution TEM image of a portion of apatite synthesized at $95{ }^{\circ} \mathrm{C}$ (main panels A and B), related FT (right, bottom). Panels A, $\mathrm{A}^{\prime}$ : zoomed view of two enframed border regions in panel A. Original magnification: $800 \mathrm{k} \times$. Reprinted with permission from Ref. [105]. Copyright 2010 American Chemical Society. 
become more crystalline. The presence of carbonate in the solution favors its incorporation in the crystal lattice up to $3.1 \%$ (both, in A and B positions) giving rise also to shorter and more isometric nanoparticles. Hence, this work provides new insights on the role of citrate to tailor the apatite nanocrystal size. The nanoparticles were composed of a well-ordered carbonate-substituted apatitic core embedded in a non-apatitic hydrated layer containing citrate ions. This layer progressively transforms into more stable apatite domain upon maturation in aqueous media. Moreover, the nanoparticles prepared by this method displayed excellent compatibility properties in cell biology systems, since they were not cytotoxic to a mouse carcinoma cell line, when added until a final concentration of $100 \mu \mathrm{g} \mathrm{mL}^{-1}$.

One of the most interesting system to produce apatite nanocrystals at low temperature is the mechanochemical-hydrothermal $(\mathrm{M}-\mathrm{H})$ method. The main advantages of this kind of synthesis of ceramic powders are simplicity and low cost since conventional milling equipment can be used. The $(\mathrm{M}-\mathrm{H})$ technique is located at the intersection of hydrothermal and mechanochemical processing. Mechanochemical powder synthesis is a solid-state synthesis method that uses the perturbation of surface-bonded species by pressure to enhance thermodynamic and kinetic reactions between solids. Pressure can be applied at room temperature by milling equipment ranging from low-energy ball mills to high-energy stirred mills. M-H synthesis (sometimes called "wet" mechanochemical), takes advantage of the presence of an aqueous solution in the system. The aqueous solution actively participates in the mechanochemical reaction by acceleration of dissolution, diffusion, adsorption, reaction rate, and crystallization. The mechano-chemical activation of slurries can generate local zones of high temperatures (up to $700{ }^{\circ} \mathrm{C}$ ) and high pressures due to friction effects and adiabatic heating of gas bubbles, while the overall temperature is close to the room temperature. The $\mathrm{M}-\mathrm{H}$ technique produces comparable amounts of calcium phosphates powder as the hydrothermal processing, but it requires lower temperature than the hydrothermal process. Shuk et al. crystallized for the first time agglomerates of nanocrystalline apatite (about $20 \mathrm{~nm}$ in size) from heterogeneous reaction between $\mathrm{Ca}(\mathrm{OH})_{2}$ powders and $\left(\mathrm{NH}_{4}\right)_{2} \mathrm{HPO}_{4}$ solutions via the $\mathrm{M}-\mathrm{H}$ route [108]. More recently, several authors improved the basic knowledge about this method and investigated the effects of $\mathrm{pH}$, surfactant and polymer on the features of synthesized apatite nanocrystals [109-111]. Moreover the possibility to produce substituted apatites with carbonate, magnesium and fluoride by $\mathrm{M}-\mathrm{H}$ technique was also studied $[112,113,114]$.

Recently, Iafisco et al. reported a new methodology, based on the vapor diffusion sitting drop micromethod, to precipitate carbonate-substituted apatite nanoparticles [91,92] (Fig. 5a). The method was developed by using an innovative device called the "crystallization mushroom" [115,116], which offers the advantage of a reduced consumption of reagents, since the volume of micro-droplets is around $40 \mu \mathrm{L}$ and the high reproducibility due to the possibility of running 12 batches for each experiment. Therefore, this setup is suitable to evaluate interactions and/or the co-crystallization of apatite with small amounts of proteins, polymers, or drugs for studies in the fields of biomineralization and biomaterials. By using this methodology it has been found that mixtures containing $50 \mathrm{mM} \mathrm{Ca}\left(\mathrm{CH}_{3}-\right.$ $\mathrm{COO})_{2}$ and $30 \mathrm{mM}\left(\mathrm{NH}_{4}\right)_{2} \mathrm{HPO}_{4}$ in micro-droplets and $3 \mathrm{~mL}$ of a $40 \mathrm{mM} \mathrm{NH}_{4} \mathrm{HCO}_{3}$ solution in the gas generation chamber were the optimal concentrations to precipitate carbonate-apatite nanocrystals after 7 days of reaction. The nanocrystals were produced by solvent mediated phase transformation of octacalcium phosphate (OCP) to apatite, with OCP most probably acting as a temporal template for the heterogeneous nucleation of apatite nuclei. The obtained crystals displayed nanometric dimensions, carbonate ions in the crystal lattice, plate-like morphology, and low crystallinity degree, closely resembling the inorganic phase of "young bones". Nassif et al. [93] also precipitated carbonate-apatite by the vapor diffusion method. They used $\mathrm{CaCl}_{2}-\mathrm{NaH}_{2} \mathrm{PO}_{4}$ mixed solutions in the volume range of milliliters (macro-method) and either a $\mathrm{NH}_{4} \mathrm{OH}$ and $\mathrm{NaHCO}_{3}$ solution or solid $\left(\mathrm{NH}_{4}\right)_{2} \mathrm{CO}_{3}$ to generate the gas phase, which led respectively to the precipitation of B- or A-type carbonate-apatite phases. They concluded that the best similarity between synthetic and natural apatite was obtained by using an aqueous carbonate precursor. This result agrees with those obtained by lafisco et al. [92].

The analysis of the existing literature reveals that optimal routes to synthesize nanocrystalline apatites analogous to biogenic apatites are the low temperature methods, and also that in order to optimize their specific biomedical applications the particle dimensions, porosity, morphology and surface properties are major physical-chemical features that should be tailored. An approach consists 

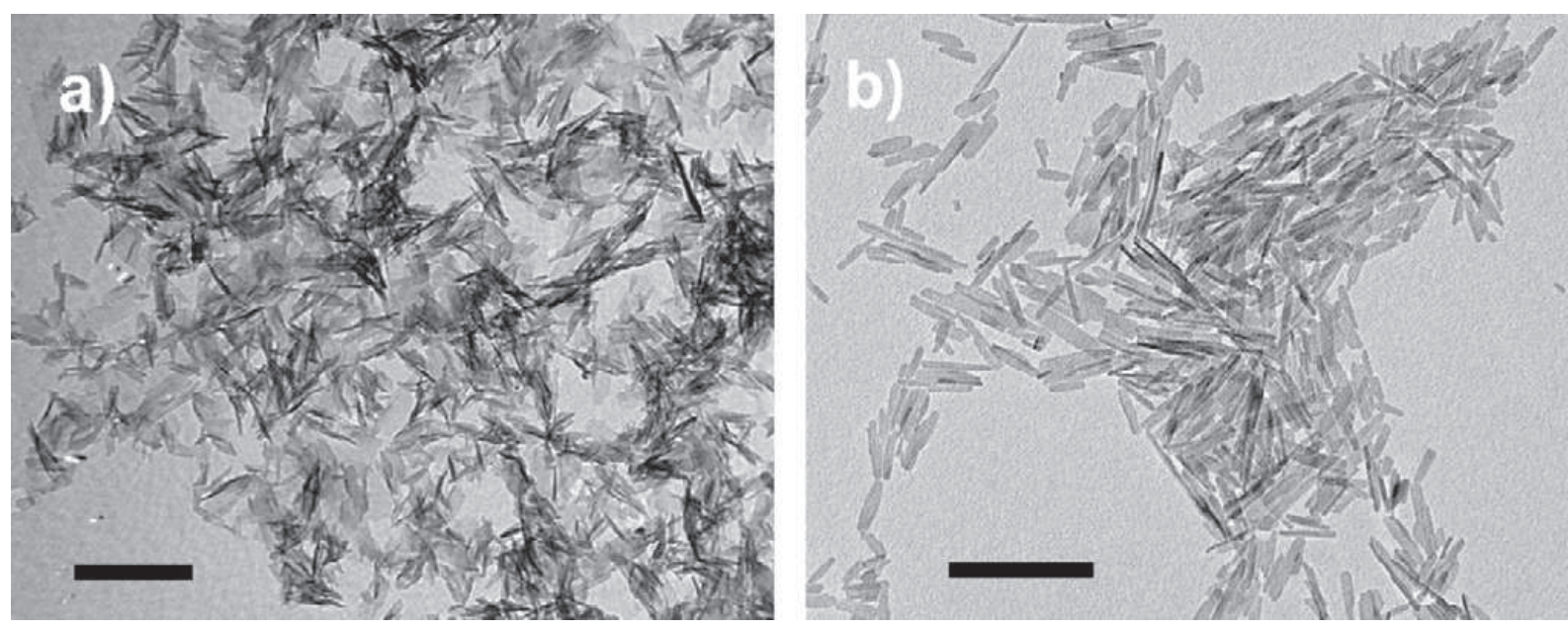

Fig. 5. TEM images of carbonate-hydroxyapatite crystals grown by the sitting-drop vapor diffusion (a) and by the batch precipitation from metastable Ca/citrate/phosphate solutions. (b) Scale bars are $200 \mathrm{~nm}$.

in using methods of precipitation in the presence of small amounts of additives [117,118]. The interactions between the growing inorganic particles and certain additives are governed mainly by electrostatic forces which can be tuned by controlling the zeta potential of colloidal particles. These forces are crucial for setting the optimal conditions for the growth of nanocrystals in different sizes and morphologies. Elongated apatite particles were for example obtained in the presence of poly(L-lysine), whereas in the presence of more charged poly(L-glutamic acid), small nanocrystals were precipitated [119]. These additives thus act as inhibitors for the crystallization of apatitic crystals. A similar inhibiting effect was found for other molecules such as dimethyl acetamide [120], polyvinyl alcohol [121] and several other (bio)polymers [122], among others (more details on this matter are also given on Section 4).

Among the additives, aminoacids are biological molecules of particular interest since they are the smallest molecular components of proteins. The effects of hydroxyproline, tyrosine, serine, glycine, cysteine, cystine, glutamine and lysine on apatite crystallization have been studied by the "Chemo-stat method" by Koutsopoulos et al. [123-125]. Diverse inhibiting activities were then observed as a function of the different aminoacid side groups. All these studies have utilized biomolecules as simple growth inhibitors of HA crystallization, rather than considering their use as a strategy to fine-tune the bioactivity of the apatite crystals. In fact, considering that the presence of proteins in biological materials is intrinsic to the bioactivity of apatite, aminoacids can be considered as agents that can increase the bioactivity of synthetic apatites. This idea was first developed by Gonzalez-McQuire et al. [126], who obtained, by hydrothermal crystallization, stable aqueous colloids of positively charged aminoacid-functionalized apatite nanorods of less than $80 \mathrm{~nm}$ in length and ca. $5 \mathrm{~nm}$ in width. Greatly elongated apatite nanorods, of ca. $150 \times 3.5 \mathrm{~nm}$, were prepared with aspartic acid. The above work inspired further investigations into the nature and stability of the interaction of a series of aminoacids with apatite [127-129]. Together with the "Chemo-stat method", these studies also suggested that crystallization kinetics is affected through the inhibition by aminoacids of the active growth sites of the apatite crystals surface. These sites could be constituted by surface calcium or phosphate ions (often protonated), and less probably by a few exposed hydroxyl groups. These experiments suggest that there may be a complex multi-site adsorption process, that may be "switched" on or off by changing the $\mathrm{pH}$, since it affects the formation of different surface complexes between $\mathrm{COO}^{-}$and $\mathrm{Ca}^{2+}$ at different sites.

Biomimetic nonstoichiometric apatite nanocrystals with aminoacid (alanine, arginine and aspartic acid) surface functionalities and different morphologies (depending on the aminoacid used as coreagent during the synthesis) have been obtained by Palazzo et al. [130]. A self-assembly mechanism could be supposed, considering that the crystals domain size appeared slightly decreased by the aminoacid presence, while the nanocrystal grows unidirectionally. Zeta potential measurements then showed that the aminoacid-functionalized apatite surface charge is inverted, being shifted toward neutrality with respect to that of the apatite (Table 2). 
Table 2

Zeta potential measurements for nonstoichiometric apatite synthesized in the absence of aminoacids and aminoacidfunctionalized nonstoichiometric apatite nanocrystals.

\begin{tabular}{llc}
\hline & $\mathrm{pH}$ of suspensions & Zeta potential $(\mathrm{mV})$ \\
\hline Not-stoichiometric apatite & 7.5 & $-21.2 \pm 1.4$ \\
Alanine-apatite & 7.8 & $-5.8 \pm 1.5$ \\
Aspartic acid-apatite & 7.6 & $-6.9 \pm 1.2$ \\
Arginine-apatite & 7.6 & $-4.1 \pm 1.0$ \\
\hline
\end{tabular}

This chemical surface modification is found to dramatically affect the biological properties of the apatites, and should thus offer the potential for the nanocrystals to be used as carriers of bioactive molecules linked to the aminoacidic residue. Aminoacid is the anchoring agent between apatite and bioactive molecules, dramatically affecting the adsorption and release kinetics. It was found that, while the introduction of the aminoacids during the apatite nanocrystal synthesis induces a modification in the primary crystallite domains along the $c$ direction and along its transverse directions, only polar aminoacids induce a morphological and dimensional variation in the apatite nanocrystals. Considering that the crystal domains sizes appear slightly decreased by the presence of the aminoacid while the nanocrystal grows unidirectionally, a self-assembly mechanism of nanocrystal formation can be supposed.

As was said earlier, zeta potential measurements showed that the surface charge of aminoacidfunctionalized apatite was inverted compared to the unfunctionalized apatite shifting toward neutrality. The role of the lateral residue in the binding mechanisms, involving either the carboxylate group (in the case of alanine and aspartic acid) or the amino lateral group in the case of arginine, has been underlined.

Although each of the reported approaches to produce nanosized apatites has both a scientific and a practical relevance, only little attention has been dedicated to-date to the physico-chemical aspects involved in the careful control of the particle size distribution and particle shape. Indeed, in the case of particle size distribution, most of the reported ways to synthesize nanosized apatites really produce a mixture of particles with a wide size distribution from tens to hundreds of nanometers. In fact, the control of nanoparticle shape is another problem for these methods, which commonly result in pin-like or irregular particles. The size-controlled synthesis of materials can be achieved by using limited reaction spaces; namely microemulsions [131], micelles [132] and reverse micelles [133] have been successfully applied to the synthesis of nanosized apatites. In some cases, special polymers can be used as spatial reaction vessels for their fabrication. Mann et al. pioneered the use of organized molecular systems such as microemulsions to mimic the basic biomineralisation process in which mineral phase nucleation and growth is coupled with self-organized construction [134]. The micrometer-sized droplets of supersaturated solution stabilized in oil by surfactant molecules consist of microreactors where the reactions take place, and the nucleation and growth of mineral phase occurs specially at the surfactant headgroups segregated at the oil-water interface. Such systems can be used for the synthesis of apatitic nanocrystals, their growth (from about $10 \mathrm{~nm}$ thickness), occurred in a preferential direction oriented on the organized molecular support [131,135].

\subsection{Crystallization mechanisms of nanocrystalline apatites}

When using low temperature synthetic methods to produce nanocrystalline apatites, a disadvantage in some cases is the presence of transient phases in the final precipitates. To explain the possible presence of these extraneous phases the already published solubility phase diagrams can be considered. The one published in 1992 by Johnsson and Nancollas [136] was performed at $37{ }^{\circ} \mathrm{C}$ and ionic strength $0.1 \mathrm{M}$. According to this diagram, the calcium phosphates phases decrease their solubilities with the increase of $\mathrm{pH}$. At $\mathrm{pH}$ above $4.0 \mathrm{HA}$ is the most stable phase followed by TCP and OCP, whereas at $\mathrm{pH}$ values lower than 4.0 the DCPD phase is more stable than HA. The position of the curves will change with the change in temperature and the ionic strength. On the other hand, the one published in 2009 [H.B. Pan and B.W. Darvell, Crystal Growth Des, 2009, 9, 2, 639-645] considers that DCPD is not the most stable phase below $\mathrm{pH} \sim 4.2$, since calcium-deficient $\mathrm{HA}$ is less soluble. The 
misunderstanding arises from the metastability of DCPD, which nucleates much more easily than HA at low $\mathrm{pH}$. This fact highlights the importance of kinetic factors when defining the $\mathrm{pH}$ domains in which a certain $\mathrm{CaP}$ phase can be formed in a precipitation experiment.

Thus, parameters such as $\mathrm{pH}$, ionic strength, temperature, aging time, concentration and type of additives, $\mathrm{Ca} / \mathrm{P}$ molar ratios and supersaturation have to be considered for the control of the formation of apatites [137]. The $\mathrm{pH}$ significantly affects the precipitation of HA because of its influence on the amount of free $\mathrm{OH}^{-}$groups and on the balance of phosphate species. A shift to low $\mathrm{pH}$ will decrease the saturation level by diminishing the concentration of free $\mathrm{OH}^{-}$groups and shifting the balance of phosphate species from $\mathrm{PO}_{4}{ }^{3-}$ to $\mathrm{HPO}_{4}{ }^{2-}$ to $\mathrm{H}_{2} \mathrm{PO}_{4}{ }^{-}$to $\mathrm{H}_{3} \mathrm{PO}_{4}$. Hence, at low $\mathrm{pH}$, the phosphate groups are protonated, and the precipitation is less favored. Moreover, the $\mathrm{pH}$ can shift the surface charge of the interacting particles by changing the distribution of proton and hydroxyl groups at the interface. Although $\mathrm{H}_{3} \mathrm{O}^{+}$and $\mathrm{OH}^{-}$are usually considered as charge-determining ions in the case of HA particles, other ions can adjust the surface charge, and in particular, in calcium-containing solutions, $\mathrm{Ca}^{2+}$ ions may bind to the negatively-charged HA surface at $\mathrm{pH}>$ IEP (isoelectric point), leaving the surface neutral rather than negative. The opposite effect can take place in phosphate-rich solutions when binding of $\mathrm{HPO}_{4}{ }^{2-}$ species at $\mathrm{pH}<$ IEP may result in a negatively-charged HA particle surface rather than the positive.

One of the best accepted models for the crystallization of HA is the Ostwald-Lussac model which predicts the highest nucleation rate for the least stable phase for which the supersaturation limit is exceeded under given conditions. This model implies that an amorphous calcium phosphate (ACP) will be the first phase to precipitate, followed by the solid state transformation to OCP and then to HA. $\mathrm{Ca}(\mathrm{OH})_{2}$ or TCP may be secondary phases depending on the exact stoichiometric ratio between the precursor $\mathrm{Ca}^{2+}$ and phosphate ions in the solution. However, the exact chemical pathways, the transformation mechanism (dissolution/recrystallization or bulk rearrangement of ions within the prime crystal lattice), the transient compounds, and time frames for the nucleation and growth of each one of the phases are still subject to uncertainty.

The most important parameter used to describe the precipitation of HA (at a given temperature) is the supersaturation ratio $S=Q / K_{\mathrm{sp}}$, where $Q$ is the product of ionic activities of precursor ions in the solution for the given stoichiometry (for half a unit cell of $\mathrm{HA}, Q=\left[\mathrm{Ca}^{2+}\right]^{5}\left[\mathrm{PO}_{4}^{3-}\right]^{3}\left[\mathrm{OH}^{-}\right]$), and where $K_{\mathrm{sp}}$ is the product of ionic activities for the given compound at the saturation level (solubility product). In view of the continuous transfer of the matter across the solid/liquid interface in both directions, $K_{\mathrm{sp}}$ could be also defined as the product of activities of dissolved ions of a solid substance in equilibrium between the dissolved ions precipitating and the precipitated ions dissolving. Ostwald-Lussac rule postulates that the most soluble phase (i.e., the least stable) for which $S>1$ is the first to precipitate, which will be successively followed by precipitation of less soluble phases. The reason for this is that the thermodynamic barrier between the state occupied by dissolved ionic species and the solid phase will be the lowest for the thermodynamically most unstable phase (Fig. 6) [138,139].

An important contributor to this effect is the surface/interfacial energy, that is, the work required to increase the surface area of a substance by one area unit, which is the obstacle that must be overcome when forming a solid phase. An amorphous phase is less ordered than a crystalline phase and it has a lower interfacial energy (particularly if it is hydrated, it is most similar in chemistry to the surrounding aqueous environment) which implies that it tends to be the first to precipitate prior to subsequently transforming into a more stable, crystalline modification. In the case of the precipitation of calcium phosphates, this means that HA could be the last phase to form. The initial precipitation of ACP is normally followed by nucleation of OCP at a certain stage. However, only the phases with $S>1$ are involved in this successive precipitation. Those for which $S<1$ are assumed not to be precipitated at any stage of this process, and their appearance may only be transitory during phase transitions that involve rearrangements of ions in the solid state. This kinetic rule was empirically observed, although it can be nowadays supported by theoretical arguments. In one such calculation [140], it was shown that in simulated body fluid (SBF), whose $S$ normalized per growth unit ( $n=9$ for HA) equals 19.5 with respect to $\mathrm{HA}$, the nucleation rate of OCP is higher than the one for $\mathrm{HA}$, implying that OCP would be the preceding crystalline phase to form.

Intermediate phases are thus expected to play a crucial role in defining the morphology, the interfacial properties and the growth mechanism of the HA. Hence, the first phase that should form 


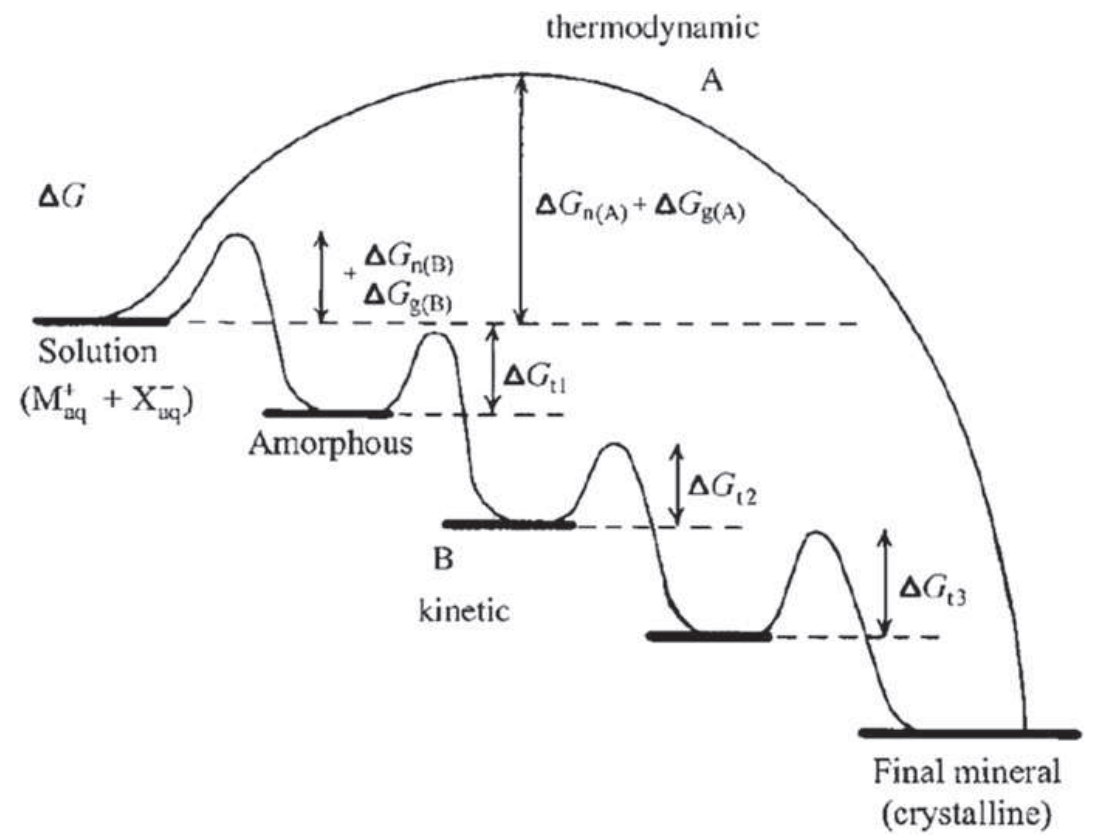

Fig. 6. Crystallization pathways under thermodynamic and kinetic control. Whether a system follows a one-step route to the final mineral phase (pathway A) or proceeds by sequential precipitation (pathway B), depends on the free energy of activation (DG) associated with nucleation $(n)$, growth $(g)$, and phase transformation $(t)$. Amorphous phases are common under kinetic conditions. Reprinted with permission from Ref. [138]. Copyright 2003 John Wiley \& Sons, Inc.

upon precipitation of calcium phosphates is an amorphous phase. The particles initially formed would be agglomerates of amorphous calcium phosphates units. Only in the following stage, the transformation of this phase into apatite and any other phase with $S>1$ under the given conditions would take place. Under the conditions that resemble the physiological ones ( $\mathrm{pH}$ about 7.4 and $T=37^{\circ} \mathrm{C}$ ), the precipitated phases change over aging time (OCP is generally accepted to be the transient phase in physiological conditions and at $\mathrm{pH}<9$, whereas the mechanism at higher $\mathrm{pH}$ is not clearly defined yet). The solubility isotherms for brushite (DCPD) and OCP at room temperature and for Ca/P molar ratio of 1.16 (resembling the $\mathrm{Ca} / \mathrm{P}$ ratio within the initially precipitated amorphous phase) interconnect at $\mathrm{pH}$ 6.7 (above this value OCP is a more stable phase and the trend is inverted at lower $\mathrm{pH}$ ). This implies that according to Ostwald-Lussac rule, the transformation of the amorphous phase to apatite should follow the OCP to DCPD to apatite route at $\mathrm{pH}<6.7$, and the DCPD to OCP to apatite route at $\mathrm{pH}>6.7$ [141].

The formation mechanisms of HA in pure solutions have been deeply investigated in the last years. An aggregation model of roughly spherical units of composition $\mathrm{Ca}_{9}\left(\mathrm{PO}_{4}\right)_{6}$ called "Posner's clusters" (PC) was proposed in the 60's to explain the formation of HA via an amorphous precursor, when working in neutral to basic conditions. The chemical analysis of the precursor amorphous phase indicated to be a hydrated calcium phosphate $\left(\mathrm{Ca}_{3}\left(\mathrm{PO}_{4}\right)_{2} \cdot x \mathrm{H}_{2} \mathrm{O}\right)$ with a $\mathrm{Ca} / \mathrm{P}$ ratio 1.50 , consisting of close-packed Posner's clusters to form larger spherical particles with water in the interstices [142-144].

After these pioneering works several researchers found evidences that strongly support an aggregation mechanism to explain HA formation. The mechanism proposed by Melikhov [145] can be divided into the following steps: (i) homogeneous nucleation of ACP; (ii) aggregation of primary ACP particles into typically spherical units; (iii) aggregation of spheres into chain-like structures; (iv) growth of these structures; (v) secondary precipitation and phase transformation. The initially precipitated particles of the amorphous phase were observed to be round-shaped with $20-30 \mathrm{~nm}$ in size (although they can reach $120 \mathrm{~nm}$ in size) [145], but composed of smaller particles of $4 \mathrm{~nm}$ in size on average. It was also observed that an increase in the ripening time implied aggregation of spherical singlets and formation of needle-shaped calcium phosphates particles of about $20 \mathrm{~nm}$ in length [146].

Rodríguez Clemente et al. [147] proposed a model of nucleation-directed aggregation-agglomeration-growth mechanism to explain the formation HA with micrometer size. The mechanism is based on empirical results of the precipitation of HA in batch and continuous process at $85{ }^{\circ} \mathrm{C}$ as well as 
HRTEM characterizations of the microparticles and the inconsistency of the classical nucleationgrowth-agglomeration mechanism to explain the crystal size distributions of the HA obtained in their precipitation experiments. According to this model, the formation mechanism of particles starts with a nucleation episode, followed by the aggregation of supercritical nuclei ruled by surface energy excess, which counterbalance the repulsive forces between particles. The aggregates agglomerate, forming solid bridges, and these agglomerates continue to grow as distinct particles due to repulsive forces. This model allows to explain, for example, the precipitation of nanocrystalline apatites from complexed Ca-citrate-phosphate solutions. The specific surface area measurements (BET method), XRD, FTIR and microscopy analyses (TEM and SEM) showed that in the case of precipitation from Ca/ citrate/phosphate using sodium salts as reagents, the particle formation mechanism involves the initial precipitation of $\mathrm{Na}_{3} \mathrm{cit} .4 \mathrm{H}_{2} \mathrm{O}$, which acts as a temporary template. The heterogeneous nucleation of nanosized apatite in this system is interpreted in terms of surface free energy excess minimization by the interaction of the supercritical nuclei with this template. Afterwards, these supercritical nuclei grow to their final nanometer size, the template-particle interaction prevents the formation of apatite aggregates and, thus, allows the formation of primary nanosized particles at the time that the template dissolves. When using potassium salts or EDTA instead of sodium citrate as complexing agent, there was not an initial precipitation of a template and then apatite particles grew to final submicrometer or micrometer sizes. It is interesting to note that precipitation of a metastable phase which later dissolves, or the coprecipitation of both phases simultaneously, offers a unique way to obtain nanosized solid phases in natural and artificial crystallization from solution, which would otherwise be impossible to obtain due to surface energy excess.

Very recently the group of Sommerdijk revealed that ACP formation proceed via aggregation of prenucleation clusters before the development of oriented apatite crystals. High-resolution cryoTEM demonstrated that at $25{ }^{\circ} \mathrm{C}$ the simulated body fluid (SBF) solution that they employed contained isolated nanometer-sized prenucleation clusters. After increasing the temperature to $37{ }^{\circ} \mathrm{C}$ these clusters were present partially as individual entities or as small aggregates, but mainly as loosely aggregated networks within the bulk solution [148]. Size analysis of the observed clusters showed an average diameter of $0.87 \mathrm{~nm}$, in line with previously reported cluster sizes $(0.70-1.00) \mathrm{nm}$ [149] and the theoretical size of Posner's clusters $(0.95 \mathrm{~nm})$ [144].

\section{Advances in the characterization of nanocrystalline apatite surface - study of surface interactions}

\subsection{Introductive remarks on the need for precise and complete characterization data}

Generally surfaces are difficult to characterize since they are easily contaminated and often exhibit great ion mobility, reactivity or metastability. This holds especially with calcium phosphate-based biomaterials. Therefore, great care has to be dedicated to the characterization of such systems. Indeed, significant departure from stoichiometry can be evidenced and is bound to have a noticeable impact on most of the sample properties. The full description of titration methods is not the object of this paper and has been addressed elsewhere [4], however we will summarize here the main aspects.

The determination of calcium, total phosphate and carbonate ions can be performed nowadays with good accuracy using various methods. All these methods are based on the dissolution of the apatitic powder in acidic solution before the analysis (calcium and orthophosphate ions determination) or during the analysis (carbonate ions). Calcium contents can be assessed chemically by way of complexometry with EDTA [150] and orthophosphate ions contents $\left(\mathrm{PO}_{4}{ }^{3-}\right.$ and $\left.\mathrm{HPO}_{4}{ }^{2-}\right)$ using a yellow phosphovanadomolybdenum complex formed in acidic conditions [150]. The Ca/P mole ratio of apatite compounds is then the result of these analyses, and this ratio is often used to compare samples. Relative uncertainties on calcium and phosphorus concentrations obtained this way are of the order of $0.5 \%$. Alternative methods as for example ICP or atomic absorption can measure lower ionic concentrations than the current chemical methods, but phosphate concentrations are more difficult to asses on an ICP basis due to possible matrix effects in the presence of other ions in the systems. The titration of $\mathrm{HPO}_{4}{ }^{2-}$ ions only is, on the contrary, an indirect method exploiting the condensation of $\mathrm{HPO}_{4}{ }^{2-}$ ions into pyrophosphates $\mathrm{P}_{2} \mathrm{O}_{7}{ }^{4-}$ upon heating (e.g. $600{ }^{\circ} \mathrm{C}, 1 \mathrm{~h}$ ), since the latter cannot form the yellow 
complex [151]; and the $\mathrm{HPO}_{4}{ }^{2-}$ content is then reached by comparison with the data obtained without heating. The relative error is then again of about $0.5 \%$. It shall be noted however that this method cannot be used to accurately quantify the $\mathrm{HPO}_{4}{ }^{2-}$ content in bone and in synthetic carbonated apatites due to the presence of carbonate ions which can interfere with the formation of pyrophosphate ions. The carbonate content of apatites can be determined using a $\mathrm{CO}_{2}$ coulometer that measures the $\mathrm{CO}_{2}$ released during sample dissolution in acidic conditions. It should be added here that the mole ratio $\mathrm{Ca} /$ $(\mathrm{P}+\mathrm{C})$, where $\mathrm{C}$ denotes the amount of carbonates, should replace $\mathrm{Ca} / \mathrm{P}$ for assessing the global (non) stoichiometry of carbonated apatite samples.

The materials should not only be investigated in their dry state (i.e. as produced), but also, insofar as possible, in humid conditions close to the conditions of use. In this last case, the in-situ characterization of the biomaterial/living system interface is then an important complement for drawing an accurate picture of the situation of the biomaterial and its surface after implantation.

Table 3 summarizes the main characterization techniques suitable for a detailed physico-chemical characterization of calcium phosphate-based biomaterials, where the techniques particularly suited for in-situ analyses have been underlined. Spectroscopic techniques (solid state NMR, FTIR and Raman) are in particular extremely useful for characterizing calcium phosphate systems, possibly carbonated, since the constitutive phosphate (whether in the form of $\mathrm{PO}_{4}{ }^{3-}$ or $\mathrm{HPO}_{4}{ }^{2-}$ ions), carbonate $\left(\mathrm{CO}_{3}{ }^{2-}\right.$ ) and hydroxide ions $\left(\mathrm{OH}^{-}\right)$give very specific signals depending on their local chemical environment(s). For in-situ analyses, vibrational spectroscopies (FTIR and Raman) are then a good choice for deriving physicochemical and structural features of synthetic and/or biological nanocrystalline apatites. Indeed, these techniques are non-invasive, can be used under a broad range of experimental conditions (temperature, pressure, etc...) and can prove to be surface-sensitive, e.g. with an ATR setup. This latter setup additionally strongly reduces the strong absorption of IR radiation by the solvent (water) that allows for the in-situ characterization of the HA interface in contact with biological molecules under study [152,153]. Information on the behavior of the apatite nanocrystals, especially related to the nature of adsorbed species, adsorption sites, adsorbate functional groups interacting with the surface and adsorbate-adsorbate interactions at the apatite interface can for instance be obtained $[152,153]$. Moreover, the combination of IR and Raman spectroscopies provide a complete overview of the vibrational behavior of the system under study. In fact, both spectroscopies are among the most useful techniques for the in-situ characterization of interfaces at a molecular/ionic level in different fields [154-157].

In the following section, we will summarize the main characteristics of nanocrystalline apatites (whether of biological nature or for biomimetic synthetic analogs), based on most of the techniques cited in Table 3, and we will underline major differences with respect to stoichiometric hydroxyapatite (HA). The peculiarities of the surface of apatite nanocrystals will also be stressed.

\section{Table 3}

Main analytical techniques used for the study of calcium phosphates, especially nanocrystalline apatites, including techniques used for in-situ interfacial characterization.

\begin{tabular}{|c|c|c|}
\hline Compositional analyses & $\begin{array}{l}\text { Phosphate }\left(\mathrm{PO}_{4}{ }^{3-}, \mathrm{HPO}_{4}{ }^{2-}\right) \\
\text { Carbonate }\left(\mathrm{CO}_{3}{ }^{2-}\right)\end{array}$ & $\begin{array}{l}\text { Complexometry (e.g. with EDTA) } \\
\text { Atomic absorption, ICP, ion } \\
\text { chromatography... } \\
\text { Colorimetry } \\
\text { Coulometry }\end{array}$ \\
\hline Diffraction & X-Ray diffraction (XRD) & \\
\hline Nuclear magnetic resonance & Solid-state NMR & \\
\hline Thermal analyses & $\begin{array}{l}\text { Thermogravimetry (TG) } \\
\text { Differential scanning calorimetry (DSC) }\end{array}$ & \\
\hline \multirow[t]{2}{*}{ Vibrational spectroscopies } & Infrared (FTIR) & $\begin{array}{l}\text { Attenuated total reflection (ATR) } \\
\text { Microspectroscopy }\end{array}$ \\
\hline & Raman scattering & $\begin{array}{l}\text { Confocal Raman microscopy } \\
\text { FT-Raman spectroscopy }\end{array}$ \\
\hline \multirow[t]{2}{*}{ Microscopies } & Atomic force microscopy (AFM) & \\
\hline & Electronic microscopy & Cryo-transmission electron microscopy \\
\hline
\end{tabular}




\subsection{Characterization aspects of nanocrystalline apatites and overview of their peculiar surface features}

The peculiar physicochemical and morphological features of nanocrystalline calcium phosphates have been explored in details in the last years. This has been in particular made possible thanks to drastic technological evolutions of materials characterization techniques. Additionally, the possibility to prepare synthetic biomimetic analogs to bone mineral (more or less mature) also enables one to consider them as excellent bone mineral "models" (replacing the poorly-suited model initially considered, based on stoichiometric HA). Such models can then be exploited for investigating interactions between bone-like apatite nanocrystals and the components of surrounding fluids (ions, proteins...) or with drugs (e.g. anti-osteoporotic agents).

Contrarily to stoichiometric HA, biological apatites or their synthetic biomimetic analogs (prepared under physiological-like conditions of $\mathrm{pH}$ and temperature) exhibit a plate-like morphology (with the large dimension in the $c$-axis direction). Also, their constitutive crystals are nanosized (with a mean length of the order of 15-30 $\mathrm{nm}$ and an average width of 6-9 $\mathrm{nm}$ [158]), as opposed to the much larger, micron-sized HA crystals. It is also worth mentioning that the crystallinity degree of nanocrystalline apatites is rather low, as shown by the powder XRD patterns represented in Fig. 7. These compounds are thus generally referred to as "poorly-crystalline" apatites in the literature. However, it is important to note that this low degree of crystallinity is perfectly comparable with that of biological apatites from bone or dentin. This is another criterion for considering synthetic nanocrystalline apatites as good models for mimicking bone mineral, as opposed to stoichiometric well-crystallized HA (Fig. 7) which is better suited for mimicking dental enamel.

From a chemical perspective, the composition of nanocrystalline apatites also greatly differs from that of HA, and this has been an object of controversy during the 20th Century. Taking advantage of the recent major evolutions in materials science characterization techniques, as mentioned above, it has however been possible to show $[159,160]$ that bone mineral was composed of nonstoichiometric single-phased nanocrystalline calcium phosphate apatites (more or less matured as a function of bone remodeling stage) responding to the global chemical composition:

$\mathrm{Ca}_{10-x}\left(\mathrm{PO}_{4}\right)_{6-x}\left(\mathrm{HPO}_{4} \text { or } \mathrm{CO}_{3}\right)_{x}\left(\mathrm{OH} \text { or } \frac{1}{2} \mathrm{CO}_{3}\right)_{2-x}$ with $0 \leq x \leq 2$

(except maybe for very immature nanocrystals which may depart from this generic formula). This formula underlines in particular the presence of vacancies in both $\mathrm{Ca}$ and $\mathrm{OH}$ sites, and Legros et al. [161] reported the following, rather constant formula from the analysis of various cortical bone specimens:

$\mathrm{Ca}_{8.3}\left(\mathrm{PO}_{4}\right)_{4.3}\left(\mathrm{HPO}_{4} \text { or } \mathrm{CO}_{3}\right)_{1.7}\left(\mathrm{OH} \text { or } \frac{1}{2} \mathrm{CO}_{3}\right)_{0.3}$

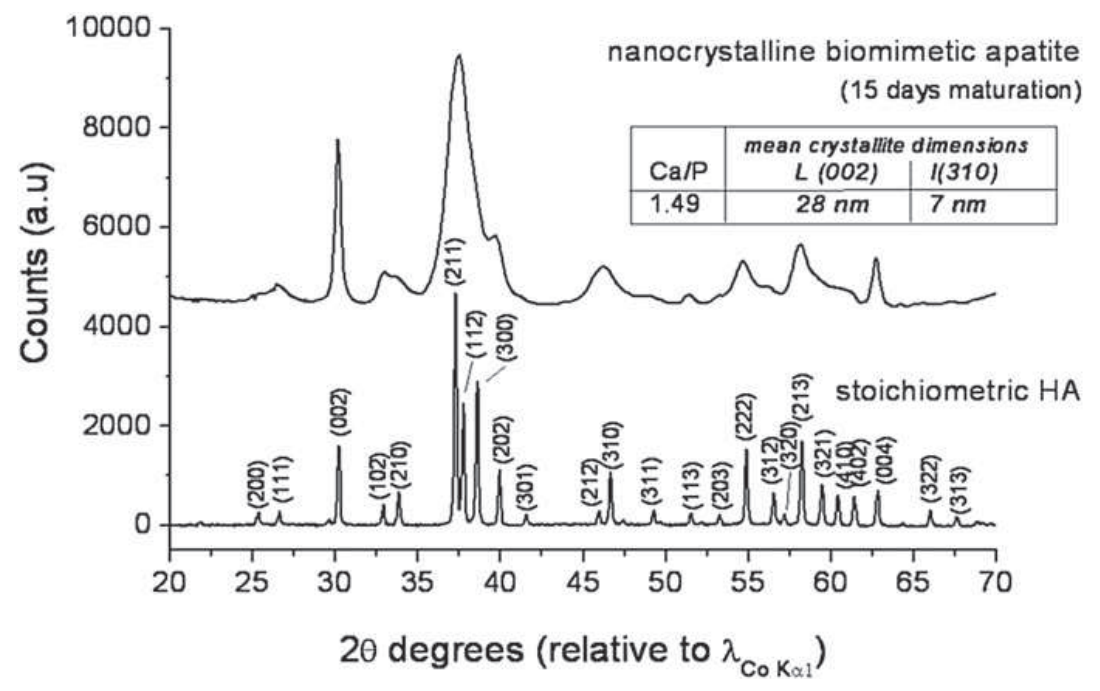

Fig. 7. XRD pattern for a nanocrystalline biomimetic apatite sample (maturation time in solution: 15 days, RT) and for stoichiometric HA. Inlet table: Ca/P molar ratio and mean crystallite dimensions (drawn from Scherrer's formula) for the nanocrystalline apatite sample shown. 
It may however be added that, beside calcium, phosphate, carbonate and hydroxide ions, the presence of other incorporated ionic substituents as "traces" is also found in biological apatites, such as sodium or magnesium ions substituting part of $\mathrm{Ca}^{2+}$ ions in the apatitic lattice, or else fluoride ions in $\mathrm{OH}$ apatitic sites [1,2].

It is nevertheless essential to remind that such chemical formulas only refer to the "global" composition of such nanocrystalline apatite compounds. Indeed, it does not reflect local variations among the nanocrystals (e.g. within osteons [162]), that are bound to exist due to localized bone remodeling phenomena for example. Also, it does not take into account the sub-structure within the individual nanocrystals.

As was previously mentioned, vibrational techniques may be of particular assistance for characterizing phosphate- and/or carbonate-containing systems. FTIR has thus been widely applied to obtain information about structural and/or physico-chemical properties of apatite [157,163,164]. It allows in particular to identify the chemical environment(s) of phosphate and carbonate ions and, at the same time, provides structural details of the particles such as crystallinity (to some extent), carbonation type and carbonation content. Fig. 8 represents a typical FTIR spectrum collected for carbonated nanocrystalline apatite precipitated by a thermal-decomplexing batch method [24]. The main absorption band which appears between 1184 and $970 \mathrm{~cm}^{-1}$ is related with the triply degenerated asymmetric stretching mode $\left(\nu_{3}\right)$ of the $\mathrm{O}-\mathrm{P}-\mathrm{O}$ bonds of the HA phosphate groups. The symmetric stretching mode $\left(\nu_{1}\right)$ of the same groups appears as a shoulder at $960 \mathrm{~cm}^{-1}$ whereas the triply degenerated bending mode $\left(\nu_{4}\right)$ can be distinguished between 630 and $570 \mathrm{~cm}^{-1}$. The peak position of these vibrational modes depends on the compositional features of the material $[164,165]$ whereas the bandwidths are related to both the crystalline domain size and degree of ion ordering into the unit cell; thus, wellcrystallized HA will display well-defined bands whereas a main broad band will be typical for poorly-crystalline apatites [22,165]. In this context, the full width at half maximum (FWHM) of the $604 \mathrm{~cm}^{-1}$ band $\left(\nu_{4}\right)$ is commonly used to estimate the crystallinity index of the mineral part of bone [166], although this method should remain associated to XRD crystallographic analyses.

Recent advances in the characterization of apatite nanocrystals by FTIR spectroscopy have however shown the presence of some chemical environments for phosphate and for carbonate ions (in both biological apatite compounds and their synthetic biomimetic analogs) that could not be attributed to regular apatitic ones. For example, detailed analyses of the phosphate groups by FTIR have enabled to

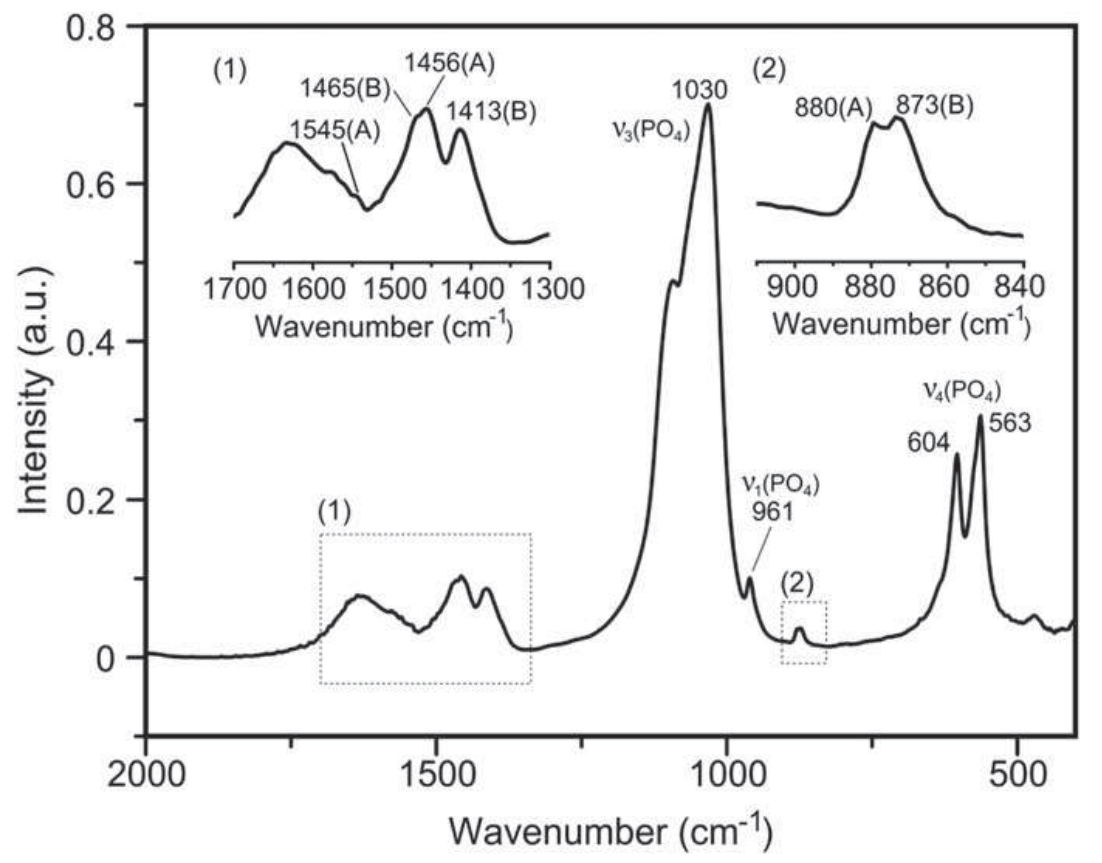

Fig. 8. FTIR spectrum collected for carbonated nanocrystalline apatite precipitated by thermal-decomplexing batch method. The insets (1) and (2) represent an enlarged view of the typical carbonate spectral region: A-type (marked with A) and B-type (marked with B) bands. 
distinguish (see for example Fig. 9 for the $\nu_{4}\left(\mathrm{PO}_{4}\right)$ vibration region) in nanocrystalline apatites the presence of "additional" bands (as compared to HA) that are not present for regular apatite environments [167,168]. These chemical environments were then referred to by Rey as "non-apatitic" environments.

At least two main "non-apatitic" vibrational bands can indeed be visualized for $\mathrm{PO}_{4}{ }^{3-}$ ions (around $617 \mathrm{~cm}^{-1}$ ) and for non-apatitic $\mathrm{HPO}_{4}{ }^{2-}$ ions (around $535 \mathrm{~cm}^{-1}$ ), this last assignment to hydrogen phosphate ions being confirmed by chemical analysis [169]. The presence of such non-apatitic environments is thought to be linked to the conditions of formation of apatite nanocrystals (either in vivo or under physiological-like synthetic protocols).

The presence of non-apatitic ionic environments in biomimetic apatites has also been pointed out from solid-state NMR. In stoichiometric HA, the ${ }^{31} \mathrm{P}$ chemical shift of all phosphate groups is the same and leads to a single peak at 2.3-2.9 ppm with respect to $\mathrm{H}_{3} \mathrm{PO}_{4}$ [170-172]. In contrast, in bone or bonelike apatite, NMR data suggest phosphate environments different from those of regular HA [173-175]. In addition, an asymmetrical broad ${ }^{31} \mathrm{P}$ peak of the main phosphate is often observed [175-177], and this was related to $\mathrm{HPO}_{4}{ }^{2-}$ ions, which can be evidenced using 2-D ${ }^{1} \mathrm{H} \leftrightarrow{ }^{31} \mathrm{P}$ cross-polarization [175].

The analysis of the FTIR $\nu_{3}\left(\mathrm{PO}_{4}\right)$ vibration domain is also found to be of interest, in particular in the case of apatites studied in the wet state (e.g. freshly precipitated, which are not degraded by drying processes) and where a fine structuration of the $\nu_{3}\left(\mathrm{PO}_{4}\right)$ band can be witnessed by FTIR (Fig. 10). In these conditions, the presence of several fine details can be evidenced in the form of successive shoulders in the $\nu_{3}\left(\mathrm{PO}_{4}\right)$ domain (which is not the case for stoichiometric $\mathrm{HA}$ ). It is then interesting to remark that this band structuration resembles to some extent the case of (triclinic) octacalcium phosphate (OCPt) [4,177], whose structure can be described as a "multi-layered" structure involving stacked "apatitic" and "hydrated" layers (in a multiple sandwich-like structure) and where the hydrated layers contain calcium ions as well as all the $\mathrm{HPO}_{4}{ }^{2-}$ content of the OCPt unit cell and several water molecules [177].

It can nonetheless be noted that some bands present on the spectrum of OCPt (e.g. around 916 and $1195 \mathrm{~cm}^{-1}$ ) are not detected for nanocrystalline apatites, and thus nanocrystalline apatites should not be confusively mixed up with octacalcium phosphate. It is also interesting to point out that XRD is also a way to distinguish these two systems, as the typical (100) XRD peak observed at low $2 \theta$ angles for OCPt is not observed for nanocrystalline apatites. Also, it is not possible to incorporate carbonate ions in the OCPt structure, contrarily to nanocrystalline apatites. Nevertheless, this rather high resemblance between the FTIR spectral features of OCPt and biomimetic apatites may suggest some degree of similarity regarding some non-apatitic chemical environments, and these aspects are still under investigation.

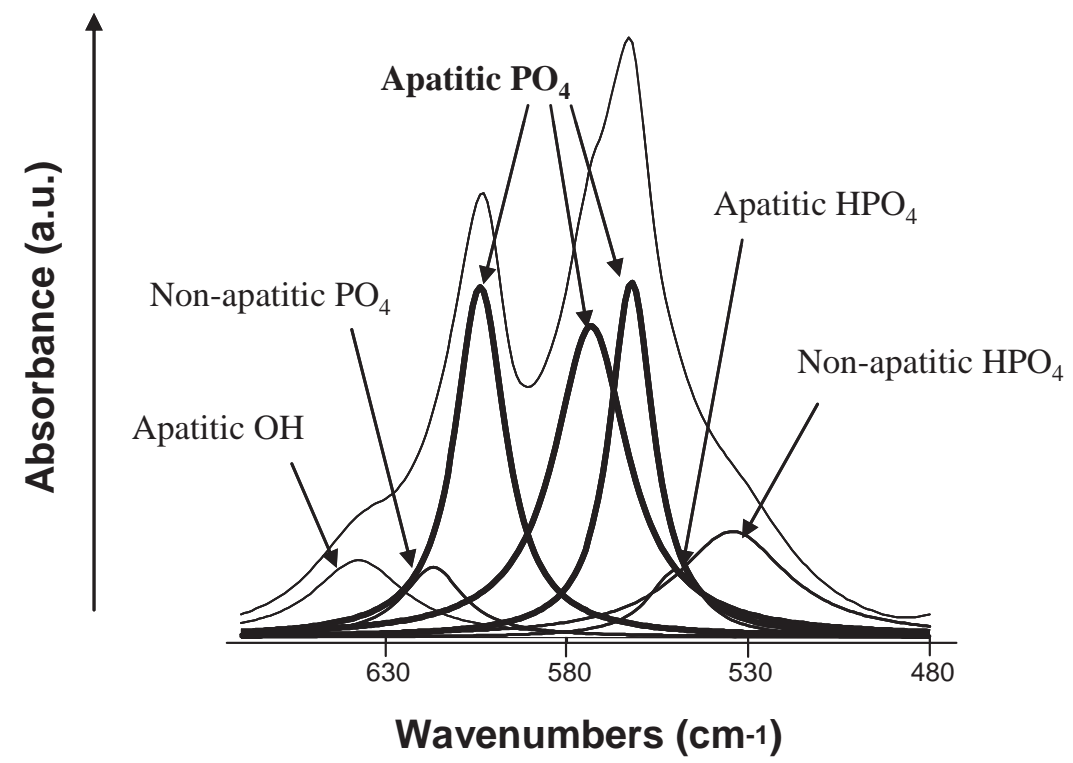

Fig. 9. FTIR spectrum for a nanocrystalline apatite sample, around the $\nu_{4}\left(\mathrm{PO}_{4}\right)$ vibrational region. 


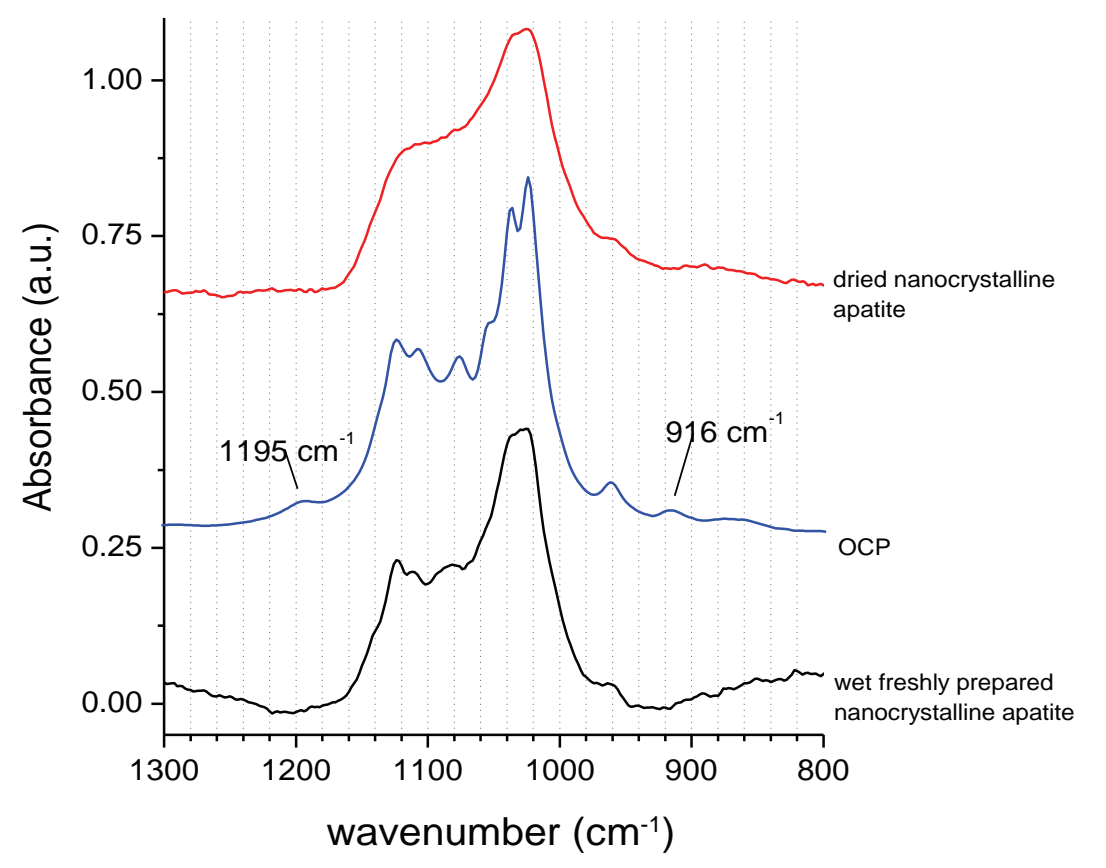

Fig. 10. Details of the $\nu_{3} \mathrm{PO}_{4}$ FTIR band for nanocrystalline apatites (wet and dried) and for OCPt.

In a similar way as mentioned above, the FTIR analysis of carbonate ions in apatites can also be interesting. The amount of carbonate groups associated to the bone mineral nanocrystals (knows as carbonation degree) can be measured as the area ratio of the $\nu_{2} \mathrm{CO}_{3}\left(894-862 \mathrm{~cm}^{-1}\right)$ over $\nu_{3} \mathrm{PO}_{4}(1184-$ $910 \mathrm{~cm}^{-1}$ ) regions [166]. Additionally, FTIR data provide not only the amount of carbonate ions present in the system, but also the carbonate environment(s). Concerning the incorporation of carbonate ions in the apatite lattice, two "extreme" cases can be distinguished: on the one hand, when carbonate ions replace tetrahedral $\mathrm{PO}_{4}$ sites (leading to the so-called B-type carbonation), the infrared spectrum shows bands at $\mathrm{ca} .1465,1413$ and $873 \mathrm{~cm}^{-1}$ assignable to the doubly degenerated stretching $\left(\nu_{3}\right)$ and bending $\left(\nu_{2}\right)$ modes of carbonate groups, respectively [164,165,178]; on the other hand, in A-type carbonation (where carbonate groups occupy $\mathrm{OH}$ positions) the $\mathrm{CO}_{3}$ stretching mode $\left(\nu_{3}\right)$ shifts to 1546 , $1456 \mathrm{~cm}^{-1}$ and the bending mode $\left(\nu_{2}\right)$ appears at $880 \mathrm{~cm}^{-1}$ [165] (insets in Fig. 8). As for phosphate chemical environments, in the case of carbonated nanocrystalline apatites an "additional" (non-apatitic) vibrational band can be detected around $866 \mathrm{~cm}^{-1}$ in biological or synthetic biomimetic apatites, and the presence of this band indicates that some carbonate ions are not localized in regular apatitic environments [179]. Also, ion exchange experiments have shown the possibility to exchange these non-apatitic carbonate species with non-apatitic $\mathrm{HPO}_{4}{ }^{2-}$ ions.

Such ion exchange experiments were found to be fast phenomena (generally taking few minutes to stabilize) and mostly reversible, therefore strongly suggesting surface rather than bulk processes. Most importantly, 2D ${ }^{13} \mathrm{C}-{ }^{1} \mathrm{H}$ solid-state NMR analyses run on biomimetic apatites [172] showed the existence of a clear correlation between the non-apatitic carbonate species and water molecules [22]. Taking into account the circumstances of formation of apatite nanocrystals in biomimetic conditions, a strong interaction of the nanocrystals surface with water molecules is indeed quite probable. ${ }^{1} \mathrm{H}$ solid-state NMR data could indeed be related to water molecules associated with bone apatite nanocrystals - or their synthetic analogs [180,181]. This interaction may in fact play a role in the thermodynamic stabilization of the nanocrystals surface (e.g. lowering of surface energy).

Complementary characterization information can also be obtained by Raman spectroscopy. This information is then given by scattered photons of different wavelengths after the interaction between the incident visible light and the sample [154,182]. A vibrational transition is Raman active if the molecule/functional group changes its polarizability (i.e. tendency of the electron cloud of the molecule/group to be distorted by an external electric field) whereas the selection rules for IR establish a change on the dynamic dipole moment during the vibration [154,182,183]. Thus, in general, some vibrational modes will be active in both spectroscopies, but others will be only Raman- or IR-active. 
Therefore, the combination of both spectroscopies can provide a complete vibrational description of the system under study. Additionally, the use of dispersive Raman spectrographs $[154,182]$ equipped with a confocal microscope enables a very small sample area or volume to be analyzed (down to the micron scale). Hence, this technique will be surface-sensitive when focusing with confocal microscope to the surface of the sample $[184,185]$. In addition, for in situ experiments, Raman spectroscopy has some advantages over FTIR including minimal sample preparation, the possibility of remote sensing, and a low sensitivity to interference from water (since water molecules are weak scatterers of visible light). This fact makes the technique particularly suitable for in-situ characterization of samples in aqueous solutions $[156,157]$.

Raman spectroscopy has then been demonstrated to be a powerful tool to analyze the structural, compositional and physico-chemical properties of both synthesized nanocrystalline apatite and biological ones [163,186-188]. Raman spectra collected for a nanocrystalline apatite grown by thermaldecomplexing batch precipitation [24] are represented in Fig. 11. As can be seen, the main peak appearing at $961 \mathrm{~cm}^{-1}$ corresponds to $\nu_{1} \mathrm{PO}_{4}$ mode [165] which, as described previously, was observable as a weak shoulder in the IR spectra (Fig. 8). Conversely, the most intense IR absorption band corresponding to the $\nu_{3} \mathrm{PO}_{4}$ mode is practically negligible in the Raman spectra $\left(1000-1110 \mathrm{~cm}^{-1}\right)$. Degenerated bending modes of phosphate groups, $\nu_{4} \mathrm{PO}_{4}$ and $\nu_{2} \mathrm{PO}_{4}$, emerge between $610-580 \mathrm{~cm}^{-1}$ and $450-420 \mathrm{~cm}^{-1}$, respectively [165]. An interesting additional Raman feature in the case of highlynonstoichiometric nanocrystalline apatites is the presence around $955 \mathrm{~cm}^{-1}$ of a shoulder to the $\nu_{1} \mathrm{PO}_{4}$ peak [165,189-192], and this secondary peak is thought to be due to the signature of the nonapatitic phosphate chemical environments as already evidenced by FTIR.

The presence of carbonate ions in the case of carbonated apatites is witnessed, by Raman spectroscopy, by the symmetric stretching of carbonate groups $\left(\nu_{1} \mathrm{CO}_{3}\right)$ appearing at 1070 (B-type) $[187,191]$ and $1103 \mathrm{~cm}^{-1}$ [187] (as a shoulder, A-type) in the spectrum b collected for particles grown in the presence of $50 \mathrm{mM}$ of sodium carbonate in the initial solution mixture. It can be clearly seen that Btype carbonate substitutions are strongly favored instead of A-type. The type of carbonate site in apatite is also distinguishable in Raman spectra through the $\nu_{4} \mathrm{CO}_{3}^{2-}$ mode (between 600 and $720 \mathrm{~cm}^{-1}$ ) [191] although the signal is very weak in this example. Awonusi et al. demonstrated that the area ratio of the band at $1070 \mathrm{~cm}^{-1}\left(\nu_{1} \mathrm{CO}_{3}^{2-}\right)$ and that at $960 \mathrm{~cm}^{-1}\left(\nu_{1} \mathrm{PO}_{4}\right)$ is strongly correlated to the carbonate content of apatite [191]. Moreover, the peak position and width of the $\nu_{1} \mathrm{PO}_{4}$ band $\left(960 \mathrm{~cm}^{-1}\right)$ strongly depends on, respectively, the compositional characteristics of the synthetic HA and the degree of ionic

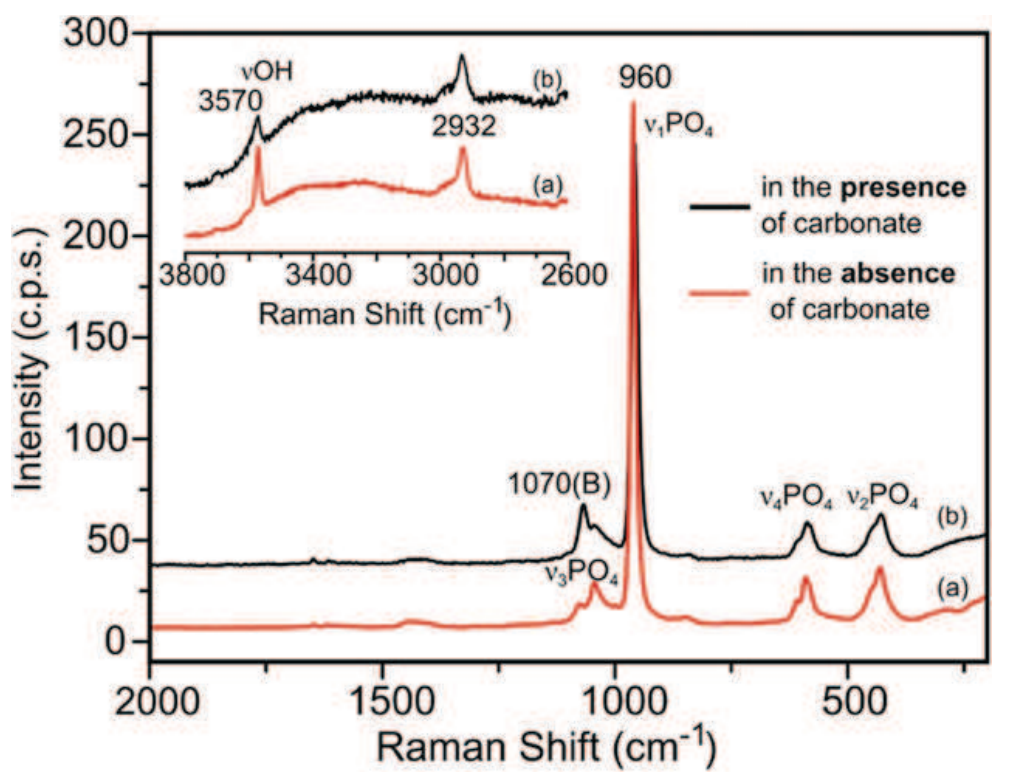

Fig. 11. Raman spectra collected for apatite nanoparticles precipitated by the thermal-decomplexing batch method without (a) and adding (b) $50 \mathrm{mM} \mathrm{Na}_{2} \mathrm{CO}_{3}$ to the initial solution. The inset represents an enlarged view of the high-energy $\mathrm{OH}$ vibrations spectral region. Bands at 1070 and $1103 \mathrm{~cm}^{-1}$ in spectrum b are related with carbonate ions occupying $\mathrm{PO}_{4}$ (B-type) and $\mathrm{OH}$ (A-type) positions within the apatitic crystal lattice (see Refs. [165,187]). 
ordering within the apatite unit cell [188,191]. In the example of Fig. 11 (spectrum b), the carbonate incorporation causes a red-shift from $962 \mathrm{~cm}^{-1}$ (frequency reported for standard not-carbonated HA, NIST [188,191]) to $958 \mathrm{~cm}^{-1}$. Raman spectra also provide valuable information about apatite hydroxyl groups as well as aliphatic groups of organics molecules adsorbed and/or incorporated to the apatite crystal lattice. In Fig. 11, the stretching vibration of $\mathrm{OH}$ groups $(\nu \mathrm{OH})$ can be clearly seen at $3570 \mathrm{~cm}^{-1}$. The intensity of this band decreases in spectrum $b$ due to the replacement of some $\mathrm{OH}^{-}$by carbonate groups. From the characterization of several biological apatites by Raman spectroscopy, it has been concluded that the degree of ionic order in the apatite unit cell increases when increasing the degree of hydroxylation, estimated as the area ratio of the $\nu \mathrm{OH}$ over the $\nu_{1} \mathrm{PO}_{4}$ bands [188].

Considering all the above data, originating from complementary characterization techniques, apatites nanocrystals (whether biological or their synthetic analogs prepared under physiologicallyinspired conditions) may most probably be described by an apatitic core (often nonstoichiometric) and a structured "non-apatitic" surface hydrated layer containing water molecules and rather labile ions (e.g. $\mathrm{Ca}^{2+}, \mathrm{HPO}_{4}{ }^{2-}, \mathrm{CO}_{3}{ }^{2-} \ldots$ ) [4,105], as illustrated in Fig. 12.

The presence of this hydrated surface layer is thought to be responsible for most of the properties of biomimetic apatites, and in particular their high surface reactivity in relation with surrounding fluids (which is probably directly linked to a high mobility of ionic species contained within this layer, as witnessed by fast surface ion exchange reactions). This reactivity may then explain, from a physicochemical viewpoint, the role of bone mineral in homeostasis in vivo.

One property linked to this peculiar surface state is the compound apparent solubility. Indeed, experimental solubility studies shower that the determination of a constant solubility product $\left(K_{\mathrm{sp}}\right)$ for nanocrystalline apatites was not possible, as it was found to depend on the amount of apatite dissolved, and this peculiar behavior is known under the appellation "metastable equilibrium of solubility" (MES) [193]. Each sample is thus in fact characterized by a series of $K_{\mathrm{sp}}$ values. Although the origin of this behavior has not yet been clearly identified, the heterogeneity of composition within crystals (with a surface composition different from that of the bulk) and the presence of strains (related to ion substitutions and the presence of defects in the lattice) are most probably involved.

It is worthwhile remarking that the typical non-apatitic features were shown to progressively disappear during the aging of the nanocrystals in solution [194,195]. This process was referred to as "maturation" and has been related to the progressive growth of apatite domains at the expense of the surface hydrated layer [194], which is probably thermodynamically-driven. It is thus possible to prepare synthetic analogs to either "young bones (more precisely bone mineral)" or "more mature" ones by selecting adequately the conditions of maturation, especially in terms of duration, temperature, relative concentrations and $\mathrm{pH}$. This maturation process is indeed thought to be linked to the metastability of such poorly-crystallized nonstoichiometric apatites, which may steadily evolve, in solution, toward stoichiometry and better crystallinity [195-197]. Such evolutions then lead to limited potentialities to undergo ion exchanges [194] or adsorption phenomena [198-200].

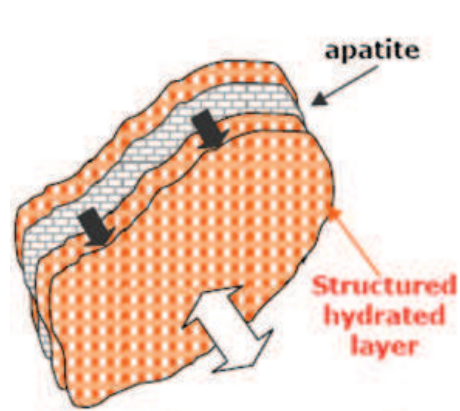

a) Apatite nanocrystal (3D view)

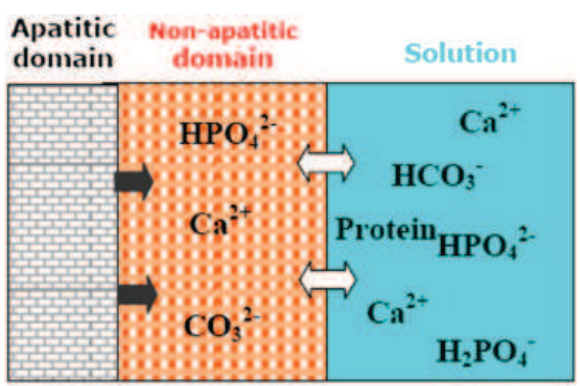

b) Apatite nanocrystal in solution (profile)

Fig. 12. Schematic model of a biomimetic apatite nanocrystal (a) and interaction with surrounding fluids (b). Reprinted with permission from Ref. [4]. Copyright 2007 Nova Science Publishers. 
This high surface reactivity of apatite nanocrystals can be exploited for the setup of innovative bioactive materials, for bone tissue engineering applications and even beyond. The high ionic mobility within the hydrated layer has for example been recently shown to allow the preparation of a new generation of bioceramics by consolidating biomimetic apatites at "low" temperatures (e.g. at $150^{\circ} \mathrm{C}$ by spark plasma sintering, SPS), while preserving most of the characteristics of the initial powders, and in particular their nanometric size, hydrated characters and nonstoichiometry [192,195,201]. Also, the high surface reactivity of apatite nanocrystals can be exploited for enriching biomimetic apatite-based materials with biologically-active ions like $\mathrm{Mg}^{2+}$ or $\mathrm{Sr}^{2+}[104,177,202]$ or with active molecules [203,204], either using the bioceramic by itself (self-supported) or as a bioactive coating on bone repair scaffolds or prostheses.

All the above statements show that the use of several complementary techniques is needed for gaining an accurate idea of nanocrystalline apatites, whether biological or their synthetic analogs, and many differences with stoichiometric HA can clearly be evidenced. Of special interest is the peculiar surface state of apatite nanocrystals, which can be described as a hydrated organized but non-apatitic metastable layer, and the presence of this layer (sometimes inappropriately called "amorphous" since clear reproducible features can be observed by spectroscopy techniques) is thought to play a key role in the high reactivity of bone mineral or of synthetic biomaterials based on apatite nanocrystals.

Beside spectroscopies, additional features on such nanocrystalline apatites can also be attained through other techniques. AFM in particular allows imaging the surface of many samples (including biomaterials) at the atomic scale in ultrahigh vacuum (UHV), ambient air and even liquids environments. It therefore may lead to complementary characterization details.

This microscopy is not based on the current as the Scanning Tunneling Microscope (STM), but on the detection of the tip-sample interaction force that allows to study non-conductive samples and substrates [205]. The simplest imaging set-up is the contact mode, where the repulsive force between the tip and the sample is kept constant. Then, the tip follows the sample surface giving a map of its topography [205]. However, non-contact modes are commonly applied to very soft samples (such as biological systems) and to true atomic resolution studies even in liquid environments [206].

In recent years, in situ AFM has been used to study the growth thermodynamics and kinetics of several mineral systems such as calcite [207], barite [208] and gypsum [209] among others including hydroxyapatite [149,210,211]. Onuma et al. proposed a cluster growth model for hydroxyapatite under similar conditions as in the human body [149,211]. The authors estimated, as a function of supersaturation, the step kinetic coefficient and the edge free energy from the velocity of growth steps and the variation in the normal growth rate, respectively. Since both values were found to be close to those of protein crystals [211], authors concluded that the growth units of apatite crystals are clusters rather than simple ions [211]. In situ AFM has also provided information about the hydrolysis processes of other calcium phosphates such as dicalcium phosphate dehydrate (DCPD) and OCP $[212,213]$ to HA in the presence of aminoacids and/or citrate ions.

Surface structural properties of nanocrystalline hydroxyapatite/titanium coatings such as roughness and porosity can also be analyzed by AFM at the nanometer level [214,215]. In addition, AFM can be especially useful to measure the thickness of the HA films deposited on Ti substrates. The step height between the HA film and the Ti substrate can be measured from the AFM images of partially covered HA/Ti samples. In another case, these measurements have allowed to measure a thickness lower than $10 \mathrm{~nm}$ for nanostructured silver thin films partially deposited on flat Germanium substrates [216].

AFM also provides the unique opportunity to "visualize" in situ the interactions between biological macromolecules and HA surface in aqueous environments at the nanometer scale [217]. For instance, Jiang et al. demonstrated that AFM is a powerful tool to explore in detail the HA interface in contact with citrate-containing solutions [218]. From in situ high-resolution AFM images, they proposed that only a side carboxylate of citrate anions interacts with a calcium ion of the (100) HA face. Furthermore, they observed that adsorbed citrate molecules are self-assembled on the HA surface by using their free carboxylate and hydroxyl groups [218]. In the same way, AFM has been used to investigate the interactions between HA surface and extracellular matrix proteins (i.e. bovine serum albumin (BSA) and recombinant mouse amelogenin (M 179), which play an important role in the enamel apatite crystals development [219]). AFM images collected before and after proteins adsorption are shown in Fig. 13. The size of the adsorbed proteins indicated that albumin is bound to the HA surface as a monomer 

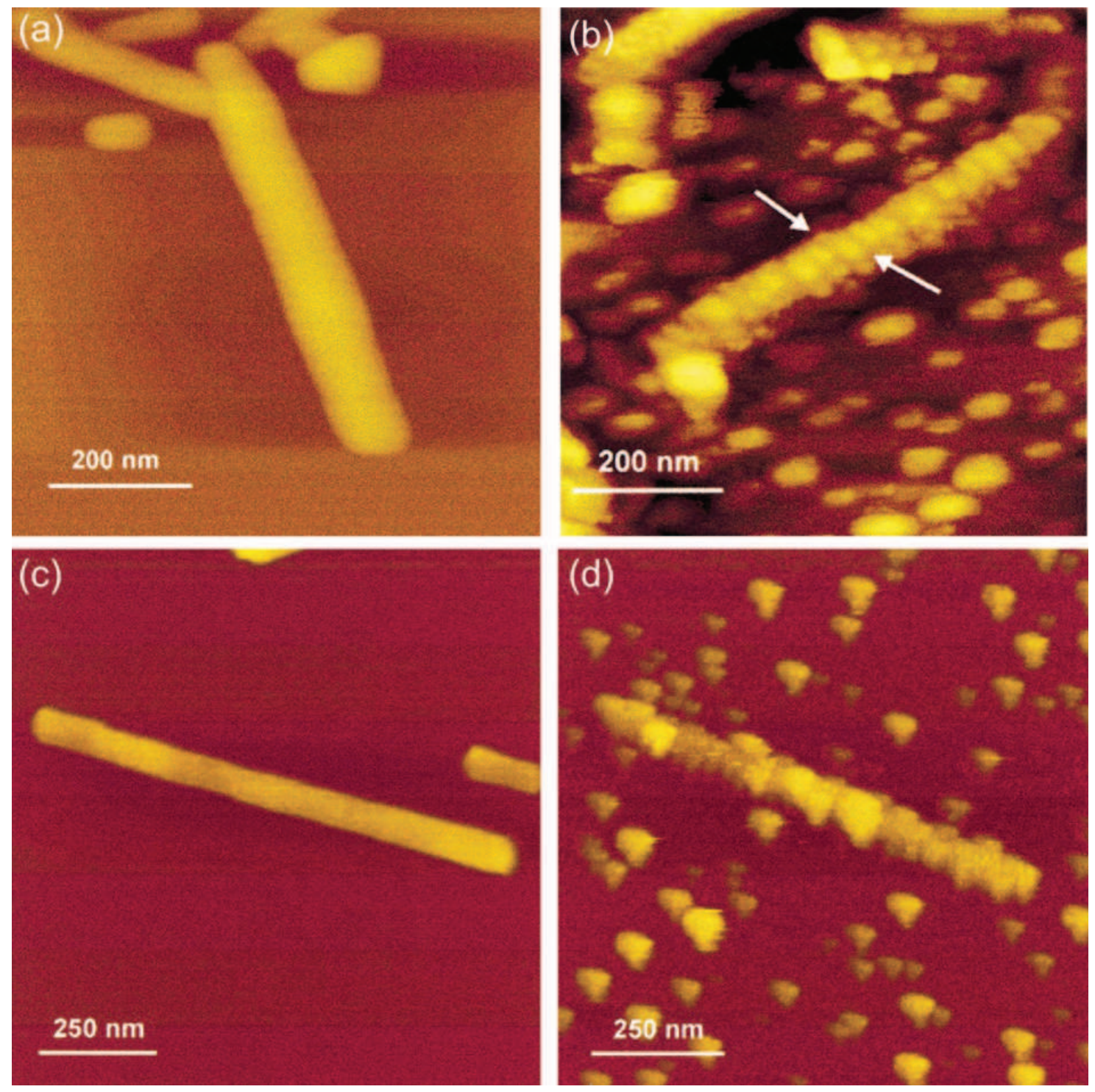

Fig. 13. Tapping mode AFM images of maturation stage enamel crystals before and after the binding of BSA (b) and amelogenin (a) and (c) crystals imaged under distilled water prior to the introduction of proteins to the fluid cell. Appearance of a typical crystal 5 min after the introduction of BSA (b) and aminogenin (d) proteins solution. Bands of BSA protein on the crystal surface are visible and are indicated by the arrows. Reprinted with permission from Ref. [219]. Copyright 2001 American Chemical Society.

whereas amelogenin is adsorbed forming bigger aggregates [219]. Furthermore, desorption process using phosphate buffer has been also followed by AFM (Fig. 14). The images show that amelogenin was bound more strongly to certain crystal faces suggesting a more specific role for this protein in the control of crystal morphology and growth [219]. Vázquez-Hernández et al. studied the adsorption of bovine serum albumin (BSA) and fibrinogen (FGN) on nanocrystalline apatite synthesized by hydrothermal method [220]. In this case, AFM images showed ovoid-shaped adsorbed BSA molecules whereas adsorbed FGN molecules were elongated with dimensions around $525 \mathrm{~nm} \times 130 \mathrm{~nm}$. Therefore, they concluded that both proteins are denatured in the adsorption process since they change their original shape and size [220].

\subsection{Study of surface interactions}

The non-apatitic environments of the hydrated layer of nanocrystalline apatites have been shown to be responsible for several properties of the nanocrystals, especially their alteration upon ageing in solution, as well as their ion exchange and adsorption abilities. Adsorption phenomena onto 

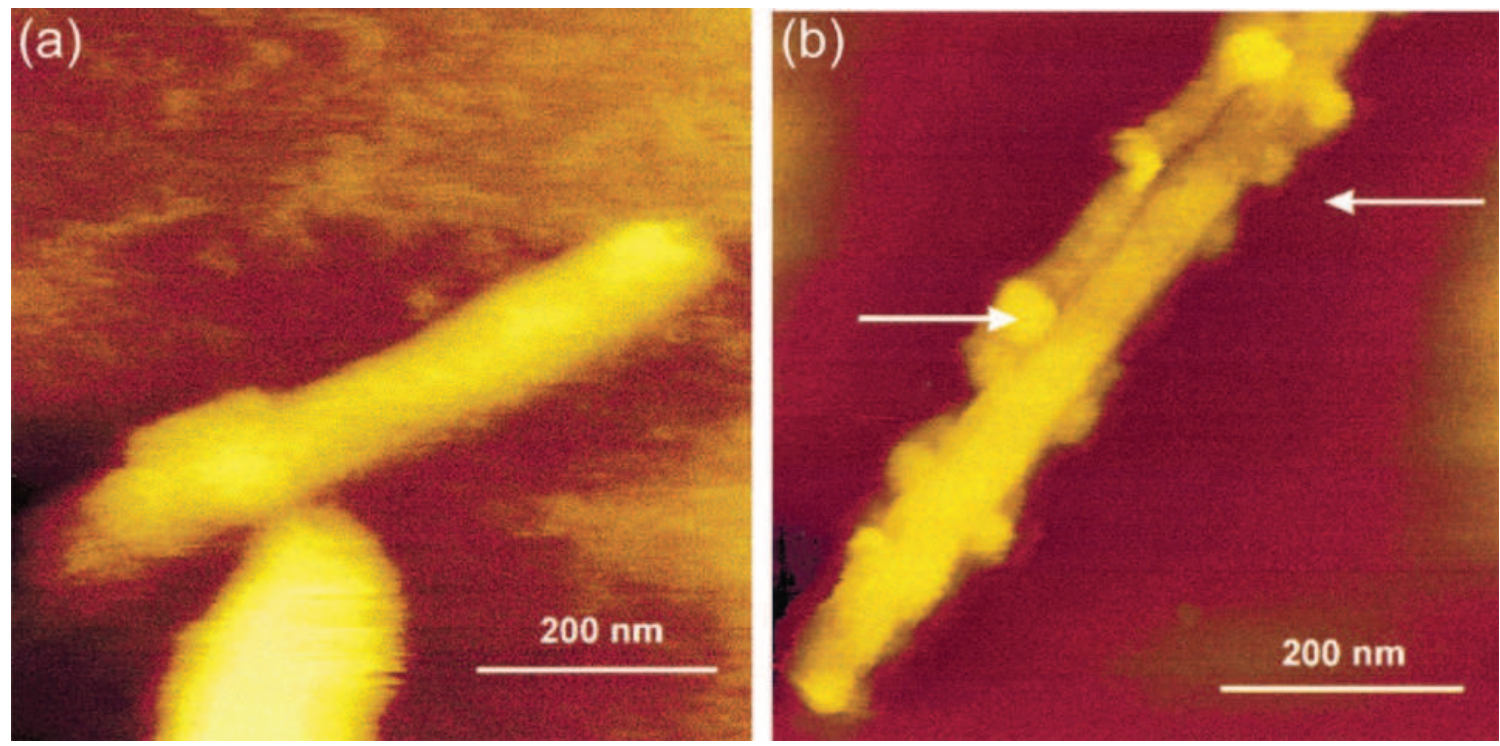

Fig. 14. Tapping mode AFM images of same crystals imaged $10 \mathrm{~min}$ after the exchange of the BSA (a) and aminogenin (b) protein solutions with phosphate buffer solutions. In the case of BSA, there is no evidence for proteins remaining on the mineral surface, however, despite of the aminogenin protein has been removed from the upper surface of the crystal, it remains bound to the sides (marked with arrows). Reprinted with permission from Ref. [219]. Copyright 2001 American Chemical Society.

biomimetic nanocrystals play in particular an important role in the biomineralization process in living organisms and in the regulation of bone mineral turnover through protein and drugs adsorption and release. Adsorbate-mineral interactions at the surface can be, for instance, well evidenced using different spectroscopic methods such as FTIR, solid state NMR or Raman.

\subsubsection{Ion exchange on nanocrystalline apatites}

Concerning ionic mobility of the nanocrystalline apatites surface, the ions of the hydrated layer constitute a pool of loosely bound mineral ions which can be easily replaced by other ions from the surrounding solution. The ionic mobility in the surface of apatitic nanocrystals appears to be strongly dependent on the nature of the ions, on the composition of the apatite and on its maturation stage [22]. The exchange reactions result from the replacement of one ion of the hydrated layer by one ion from the solution, sometimes observable by FTIR spectroscopy, without major other alteration of the solid composition (especially no change in apatite stoichiometry and XRD patterns [177]). These reactions are very rapid, and the exchange equilibrium is reached within few minutes. They can generally be mathematically modeled using a Langmuir-type isotherm. The exchange reactions do not however appear as a reversible equilibrium like in regular Langmuir-type adsorption, as the exchanged ions cannot be removed from nanocrystals surface by simple dilution of the exchange solution, or subsequent washing of the solids. However, the exchanged ions can be almost totally removed (backexchanged) by contacting the nanocrystals with calcium or phosphate solutions (or other mineral ions which may replace them in the hydrated layer such as anions like carbonate or cations like magnesium or strontium for example) $[22,177,196]$.

The affinity constant and the maximum adsorbed amount depend on the nature of the ions. Both anionic and cationic species can be exchanged [22] but not all the possibilities of these exchange reactions are known yet. The first experiments to be reported concerned essentially bivalent cations and anions. Moreover, it has been found that some monovalent ions like $\mathrm{Na}^{+}$and $\mathrm{K}^{+}$could not be incorporated [158,221]. As an example of anionic exchange, $\mathrm{HPO}_{4}{ }^{2-}$ ions from nanocrystalline apatites can be replaced by carbonate ions from a surrounding solution. The exchange of $\mathrm{HPO}_{4}{ }^{2-}$ by $\mathrm{CO}_{3}{ }^{2-}$ results in a decrease of the intensity of the FTIR band observed at $534 \mathrm{~cm}^{-1}$ and attributed to $\mathrm{HPO}_{4}{ }^{2-}$ labile ions localized in non-apatitic environments, these results confirm that only non-apatitic (surface) species participate in the exchange reaction [196,222]. Cationic exchanges are also possible and exhibit similar characteristics as the anionic exchanges. For example cationic substitution of $\mathrm{Mg}^{2+}$ and $\mathrm{Sr}^{2+}$ has been studied by several authors, according to the particular biological interest of such 
ions. Ionic exchanges of such ions with calcium within the hydrated layer have been suggested with a substituting ratio close to $1: 1$. A greater affinity of both carbonated and non-carbonated apatites was found for strontium as compared to magnesium [177,194].

Moreover the ion exchange properties of nanocrystals appear to be strongly dependent on the composition of the hydrated layer and on ageing. The ability to exchange surface ions with ions from the solution decreases considerably with the maturation state of the apatitic nanocrystals. The hydrated layer progressively decreases in proportion to the crystals maturation, and so does the amount of exchangeable ions $[22,196]$. The ion exchange mechanism depends also on the composition of the nanocrystals hydrated layer. It has been published that for a given exchanging ion such as magnesium and strontium, a greater exchanged amount can be reached on carbonated nanocrystalline apatites compared with non-carbonated one. $\mathrm{CO}_{3}{ }^{2-}$ ions are well known to act as apatite-growth inhibitors [223] which could explain the more developed hydrated layer on carbonated nanocrystals surface [177].

Another characteristic of nanocrystalline apatites is their ability to progressively incorporate several elements into the apatitic lattice (bulk), depending on the composition of the surrounding solution. Thus concerning ionic exchange on nanocrystalline apatites, two types of ions can be distinguished. Some ions, like $\mathrm{Mg}^{2+}$, may exchange easily with calcium ions from the hydrated layer but they cannot massively penetrate in apatite domains: therefore such ions always remain exchangeable independently of the maturation stage of the apatites. On the contrary, other ions like $\mathrm{Sr}^{2+}$ can be incorporated into the surface layer and progressively penetrate in the apatite domains (bulk) and then cannot be removed without destruction of the crystals $[4,22,196]$. Strontium substitution for calcium leads to a linear variation in the cell parameters and in the infrared adsorption bands positions of the hydroxyl and phosphate groups, coherent with the increase of the ionic radius. The position of the Raman band attributed to $\nu_{1} \mathrm{PO}_{4}{ }^{3-}$ at around $963 \mathrm{~cm}^{-1}$ in strontium-substituted apatites decreased linearly to $949 \mathrm{~cm}^{-1}$ at full Sr-substitution [224,225].

\subsubsection{Organic molecules adsorption on nanocrystalline apatite}

In addition to these aspects on ion exchange abilities, nanocrystalline apatites have the ability to adsorb organic molecules such as proteins or drugs. Organic molecules (e.g. bioactive ones) often exhibit a high binding affinity for calcium phosphate surfaces, but if adsorption studies of such molecules on well-crystallized HA are well described [226-229], very few studies have been performed on the adsorption of organic molecules on nanocrystalline apatites despite physico-chemical features much closer to those of bone mineral. As for ion exchanges, the adsorption isotherms are generally well described by the Langmuir model, as it has been published for proteins as bovine serum albumin (BSA) [200,230], or o-phosphoserine [231], although the adsorption on apatitic surface of some aminoacids as serine, or simple molecules weakly interacting with apatite, can be more adequately described by a Freundlich type isotherm [231]. The adsorption process is explained by the replacement of some ions from nanocrystals surface by some charged/polarized end groups of organic molecules from the surrounding solution. Negatively-charged molecules are considered to bind to calcium sites (generally with simultaneous release of phosphate ions from the hydrated layer to the solution) while positivelycharged ones bind to phosphate sites (generally with simultaneous calcium release). For example, the adsorption reaction of bisphosphonates molecules as antiresorptive agents can be described by an ion exchange process between phosphate ions on the surface of the apatitic nanocrystals and phosphonates groups of the active adsorbing molecules. Solid state NMR provides information on the nature and state of the adsorbed species at the apatite surface [232,233]. The very high affinity of phosphoserine for apatite surface compared to that of serine can be explained by the existence of the phosphate endgroup on the molecule which can interact strongly with the apatite surface, as evidenced by FTIR spectra of the samples after adsorption, where a change in FTIR bands position associated with carboxylate vibrations indicate the strong interaction with the apatitic surface (Fig. 15) [231]. The surface adsorption reaction of organic molecules is obviously influenced by several solution parameters such as temperature, $\mathrm{pH}$, and ionic contents in the surrounding solution. Several processes can disturb the adsorption equilibrium on apatitic nanocrystals: the possible precipitation of calcium (or phosphate) salts formed with the adsorbed molecule, the dissolution equilibrium of the solids and/or hydrolysis reactions of apatitic surface. For example, the mechanisms involved in protein and peptides 


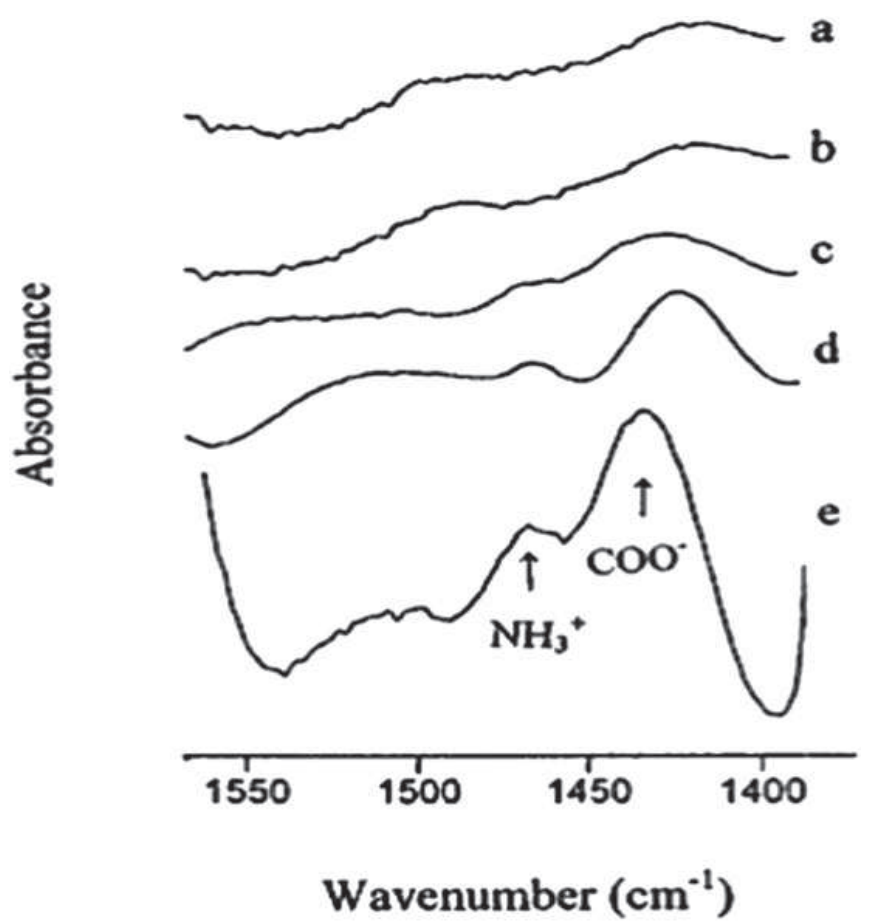

Fig. 15. FTIR spectra of poorly crystalline apatitic samples adsorbing serine and phosphoserine at $\mathrm{pH}=7$ and $20^{\circ} \mathrm{C}(\mathrm{a})$ untreated (b) treated with deionized water (c) treated with $0.1 \mathrm{M}$ serine solution (d) treated with $0.1 \mathrm{M}$ phosphoserine solution (e) phosphoserine calcium salt. Reprinted with permission from Ref. [231]. Copyright 2001 Elsevier.

adsorption on inorganic substrate is in fact a complex process consisting of many events, including protein conformational changes and protein-protein interactions [230,234].

Apart from the associated ion exchange phenomenon, the process of adsorption of organic molecules on nanocrystalline apatites does not differ strongly from well-crystallized hydroxyapatite; however an interesting aspect is the variation of the adsorption parameters with the characteristics of the nanocrystals. As for ion exchange, the adsorption properties of the organic molecules are strongly dependent not only on the chemical properties of such molecules, but also on the nature of apatitic nanocrystals and maturation stage, as could be observed for proteins as BSA [200] or drugs as bisphosphonates molecules [232]. Experimental results indicate an increase of the affinity constant and a decrease of the amount adsorbed as maturation time increases. The increase of the affinity constant with maturation may be correlated with an increase of interfacial energy of nanocrystals during maturation in aqueous media. Indeed, the hydrated layer probably reduces the surface energy of the nanocrystals in aqueous media, and thus molecules adsorption for more mature systems should be energetically favored [22,232]. The decrease of the number of adsorption sites with maturation time can be interpreted as a decrease of potentially exchangeable ions in the hydrated layer or a change in the equilibrium constants [22]. It can be seen that the ability of a poorly-crystalline apatite to adsorb is related to the number of its non-apatitic surface sites and its low crystallinity. As the adsorption process can be explained by ion exchange process at the surface of the apatitic support, the amount of organic molecules adsorbed could be related to the amount of labile mineral ions available in the hydrated layer and then to the extent of the hydrated layer. As the maturation proceeds, the amount of such exchangeable species diminishes and the adsorption capacity of the solid decreases.

As for ion exchange, the reaction appears irreversible with respect to dilution, as observed for proteins or active agents [232]. After the adsorption event, no desorption should be expected by simple dilution of the adsorption solution or even upon washing of the samples, except for faint release effects due to the dissolution of the apatite. This behavior could be useful in view of the controlled release of such agents from apatitic biomaterials in vivo. Indeed, generally, bioactive molecules such as growth factors or drugs are incorporated in biomaterials by simple impregnation followed by drying, and such associations do not allow the chemical bonding of the organic molecules and thus the release rate from the solids is often difficult to control [235]. On the contrary, adsorption leads to stable association and 
control of the amount of bioactive molecules contained in the solid implant, and thus of the dose released [199,204,236-238]. Moreover as adsorption properties of the organic molecules are strongly dependent on the chemical and structural characteristics of apatitic nanocrystals, the release rate is also related to the physico-chemical properties of the apatite samples. For example some authors show that the coating of sintered biphasic calcium phosphate granules (hydroxyapatite and $\beta$-tricalcium phosphate) with nanocrystalline apatites improves growth factors adsorption, such as with bone morphogenetic protein BMP-2 [204], and controls its release rate, as only a low quantity of protein is spontaneously released in cell culture medium during the first weeks. Similarly Palazzo et al. [239] show that adsorption and release kinetics of three drugs (cisplatin, alendronate and di(ethylendiamineplatinum)medronate) are controlled by the surface properties of the nanocrystalline apatitic support such as surface area and surface charge, as well as the charge on the adsorbed molecules and their mode of interaction with the apatitic surface. These properties of biomimetic nanocrystalline apatites suggest the possibility to functionalize the surface of such nanocrystals with different linking agents, such as bisphosphonates for example, to anchor biologically active molecules for specific therapeutic application [237], or to improve the biocompatibility of bone-implantable biomaterials for hard-tissue engineering and regeneration technologies [240]. The use of nanocrystalline apatites as drug delivery carriers will be further discussed in Section 4.1.

\section{Advanced biomedical applications of nanocrystalline apatites}

\subsection{Drug delivery and surface functionalization}

Materials can interact with biomolecules as well as with living systems and these interactions can be used to develop new materials and technologies [241]. The main driving force behind the use of apatites as materials for health care is their chemical similarity to the mineral component of mammalian bones and teeth, as previously explained in details. As a result, in addition to being nontoxic, they are biocompatible, not considered as noxious foreign materials in the body and, most importantly, they both exhibit a bioactive behavior and may integrate into living tissues by the same processes as the ones that are active in remodeling healthy bone. This leads to an intimate physicalchemical bond between the implants and bone, termed osteointegration. More to the point, calcium phosphates are also known to support osteoblast adhesion and proliferation. Even so, the major limitations to use apatites as load-bearing biomaterials are their mechanical properties; namely, they are brittle with a poor fatigue resistance [12]. The poor mechanical behavior is even more evident for highly porous ceramics and scaffolds, as porosity greater than $100 \mu \mathrm{m}$ is considered a requirement for proper vascularization and bone cell colonization [12]. That is why, in bone-related applications, calcium phosphates are used primarily as fillers and coatings [242]. Moreover, apatites may find several other biomedical applications such as for drug delivery [243]. Numerous bioactive molecules can indeed be associated to calcium phosphates, including proteins, aminoacids, antibiotics, growth factors, anticancer and antiosteoporosis drugs [130,237,239,240,243-245]. However, so far, only very few studies have been carried out to understand the adsorption behavior of therapeutic molecules on apatitic calcium phosphates, especially nanocrystalline apatites.

As drug carriers, apatite nanoparticles exhibit some advantageous properties: i) favorable biodegradability and biocompatibility properties in general; ii) soluble and less toxic than silica, quantum dots, carbon nanotubes, or magnetic particles [246]; iii) more stable/robust than liposomes, which predisposes them for a more controlled and reliable drug delivery. Contrary to liposomes and other micelle-based carriers, which are subject to dissipation below specific critical concentrations (which presents a clear obstacle upon injecting them into the bloodstream), calcium phosphates-based systems and particularly those with $\mathrm{Ca} / \mathrm{P}$ molar ratio close to the one of $\mathrm{HA}$, are negligibly soluble in blood, which is naturally supersaturated with respect to HA; iv) higher biocompatibility and pHdependent dissolution compared to polymers [247].

Furthermore, nanocrystalline apatite nanoparticles may hold larger load amounts of drugs because of their larger specific surface areas than coarse particles. The dissolution of calcium phosphates is accelerated at low $\mathrm{pH}$ media, which are typically found in endolysosomes and in the vicinity of tumors, providing an advantage in the delivery of drugs into malignant zones or cell organelles. They are also 
able to permeate the cell membrane and dissolve in the cell, which makes them an attractive candidate for gene delivery agents [248,249].

Another important advantage of calcium phosphates is the low production costs and excellent storage abilities (not easily subjected to microbial degradation). As previously explained, the preparation of nanosized calcium phosphates is not a complicated task, although it should be undergone with care. Unlike most other ceramics, nanosized calcium phosphates can be prepared in situ, under ambient conditions, in a wide array of morphologies, from spheres to platelets to rods to fibers. Calcium phosphates can also be prepared with a variety of phase compositions thereby enabling fine tuning of the dissolution properties in vivo.

Bioactive molecules often exhibit a high binding affinity for calcium phosphate surfaces. Generally the adsorption equilibrium of such drugs strongly interacting with an apatitic surface can be satisfactorily described by a Langmuir isotherm, a behavior similar to that presented by proteins and aminoacids [119,200,219,220,250,251], as explained in Section 2. Negatively-charged molecules are considered to bind to calcium sites and positively-charged ones to phosphate sites. The interaction of organic molecules and calcium phosphate surfaces depends on the nature of the molecules. For example, it has been published that, in the case of antibiotics, those containing carboxylic groups like cephalothin interacted better with the apatite coating applied onto titanium implants [252]. Some studies have shown that carboxyl-containing molecules are good binders of calcium sites [250,253]. In the same way, adsorbate-adsorbent interactions can take place during protein adsorption, depending on the protein structure and the nature of the surface of the adsorbent [228]. Few works show a strong affinity of growth factors for apatitic surfaces, enhanced in the simultaneous presence of calcium ions in the solution as in the case of the adsorption of other proteins [254,255].

The study of interactions between bone morphogenetic proteins (BMPs) growth factors and apatitic surfaces is of great biological and medical interest as BMPs have been attempted to be applied for the reconstruction of bone defects resulting from trauma, surgical resection of tumors, and congenital anomalies in orthopedic and maxillofacial surgery. A computed theoretical modeling based on the interactions of the (001) HA surface with functional groups of BMP-2 growth factor [227] has evidenced three types of interactions: an electrostatic interaction of charged $\mathrm{COO}^{-}$groups from the protein with $\mathrm{Ca}^{2+}$ ions on the apatite surface, and water-bridged $\mathrm{H}$-bonds between $\mathrm{OH}$ and $\mathrm{NH}_{2}$ residues of BMP-2 and with phosphate ions from the apatite crystal surface [204].

\subsubsection{Nanocrystalline apatites: application to drug delivery}

As previously mentioned, one of the most efficient ways to improve the bone forming ability of biomaterials is their association with bone morphogenetic proteins [204]. Generally, bioactive molecules such as growth factors are incorporated in biomaterials by simple impregnation followed by drying, and the type of bonding with the substrate and the release rate are often undetermined [252]. It is suspected that such associations do not allow the chemical bonding of the growth factor to the biomaterial and thus the release rate is often difficult to control. For example, precipitation and clustering of the growth factor molecules may occur and the release is only determined by local dissolution and diffusion rules [204]. In some cases, the uncontrolled release of growth factors has been related to an accelerated resorption of bone tissue and of the implant [204]. Since growth factors agents can stimulate the degradation as well as the formation of bone (depending on their local concentrations), they could impair the osteoconductivity of the coated-implant surface [256]. In the same way, local and slow administration of antineoplasic drugs like methotrexate (MTX) is also useful to avoid systemic side effects, and because its time effect (the sensitivity of cells to this drug increases with time) is greater than its dose effect [257].

On the contrary, adsorption on apatitic surfaces (as opposed to simple impregnation) leads to a stable association and control of the amount of bioactive molecules contained in the solid implant, and thus of the dose released. Generally, the release is rather low because most of the bioactive molecules adsorbed are irreversibly bound and they are not spontaneously released in a cell culture medium [226] as explained above. They can only be displaced by mineral ions and/or soluble proteins with a stronger affinity for apatite surfaces but in a predicable manner (following an ionic backexchange process already discussed), or by cell activity [226]. This characteristic has been observed for various growth factors like bone morphogenetic protein (BMP-2) or vascular endothelial growth 
factor (VEGF) [204,257], and for others bioactive molecules such as antiosteoporosis agents [258,259] and anticancer drugs [236,260]. Fig. 16 illustrates antibiotics release incorporated in apatitic calcium phosphate coatings on titanium implant using biomimetic method [252]. A local release system of antibiotics could be used to prevent post-surgical infections favoring early osteointegration of prosthesis. Some of the antibiotics containing carboxylic groups in their chemical structure, like cephalothin, were better adsorbed than others into calcium phosphate biomaterials. These molecules are slowly released from the carrier [253]. Moreover the high binding capability of the apatitic support for a wide range of therapeutic agents allows its surface functionalization with linking agents, such as bisphosphonate molecules, to anchor biologically active molecules which can be released, breaking the linkage as a consequence of external stimuli or internal chemical factors, such as $\mathrm{pH}$ and ionic force variation due to physiological or pathological biological process [103,240]. For example, some works have investigated the adsorption and "smart release" of antitumoral platinum complexes containing bisphosphonate molecules onto apatitic nanocrystals as bone specific drug delivery devices to be used for the treatment of bone tumors upon local implantation [237].

The adsorption and release of bioactive molecules are strongly affected not only by the chemical properties of the drug molecule, but also by the chemical and structural characteristics of the apatitic substrates. For example the release rate of cisplatin anticancer drug can be controlled by use of a better crystallized apatite phase for a faster release rate or a less crystalline material for a slower rate [236]. Similarly the coating of sintered biphasic calcium phosphate granules (HA and $\beta$-TCP) with nanocrystalline apatite increases the rate of BMP-2 growth factors adsorption [204]. Only a low quantity of protein was spontaneously released in cell culture medium during the first weeks (Fig. 17).

Palazzo et al. have compared the behavior of metal-based drugs to that of a classical organic drug (alendronate), evaluating the effect of the drug molecule overall charge in influencing the drug affinity for apatite nanocrystals with variable structural and chemical different properties [239]. The adsorption and release of cisplatin, alendronate and di(ethylendiamineplatinum)medronate have been investigated using two biomimetic synthetic apatite nanocrystals materials with either plate-shaped or needle-shaped morphologies and with different physico-chemical surface properties. The apatite surface area and surface charge (as well as other parameters such as $\mathrm{Ca} / \mathrm{P}$ ratio etc.), as well as the charge on the adsorbed molecules and their mode of interaction with the apatite surface, influence the

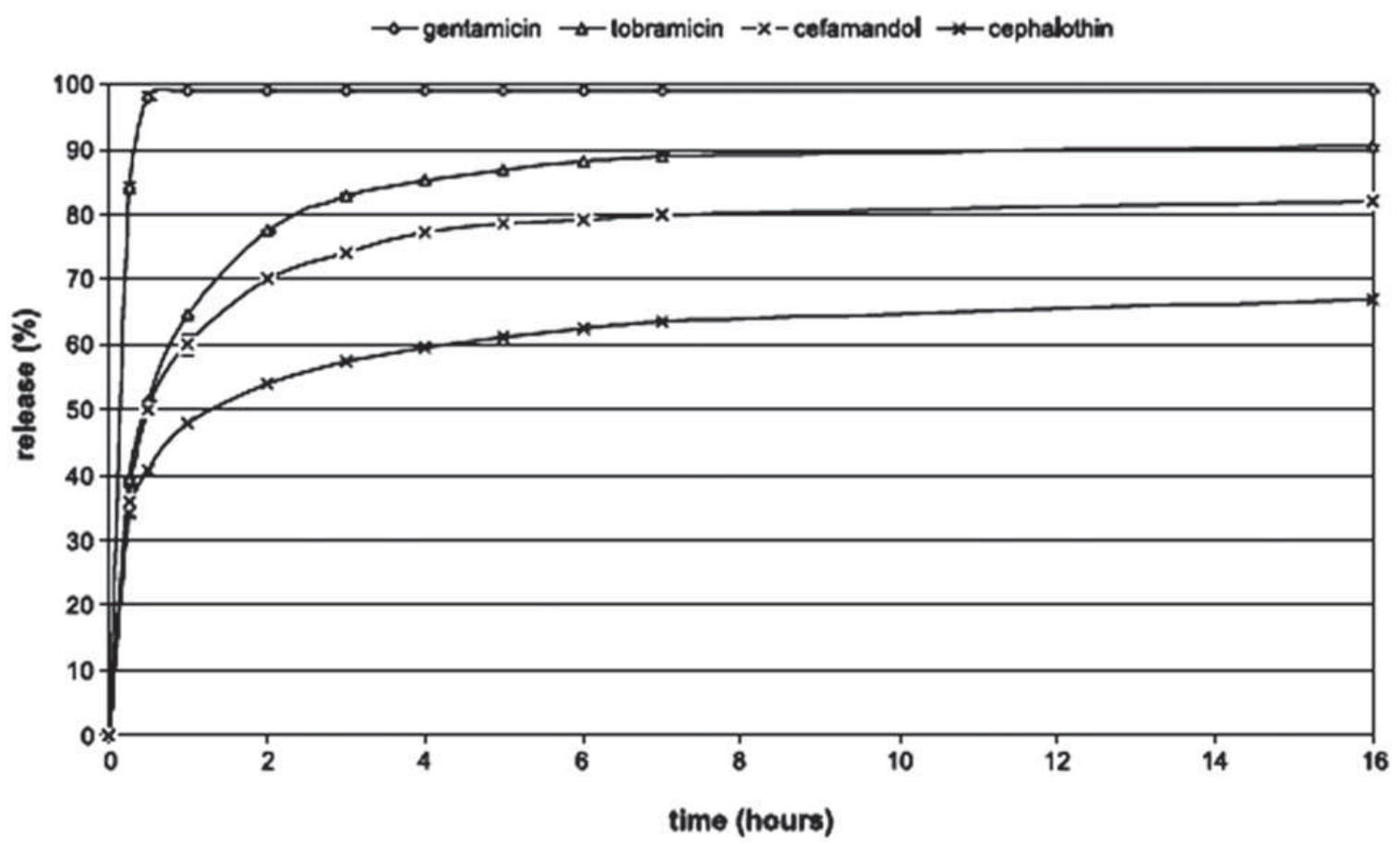

Fig. 16. Antibiotic release from carbonated apatitic calcium phosphate coatings on titanium implants into phosphate buffered saline at pH 7.3. Reprinted with permission from Ref. [252]. Copyright 2004 Elsevier. 


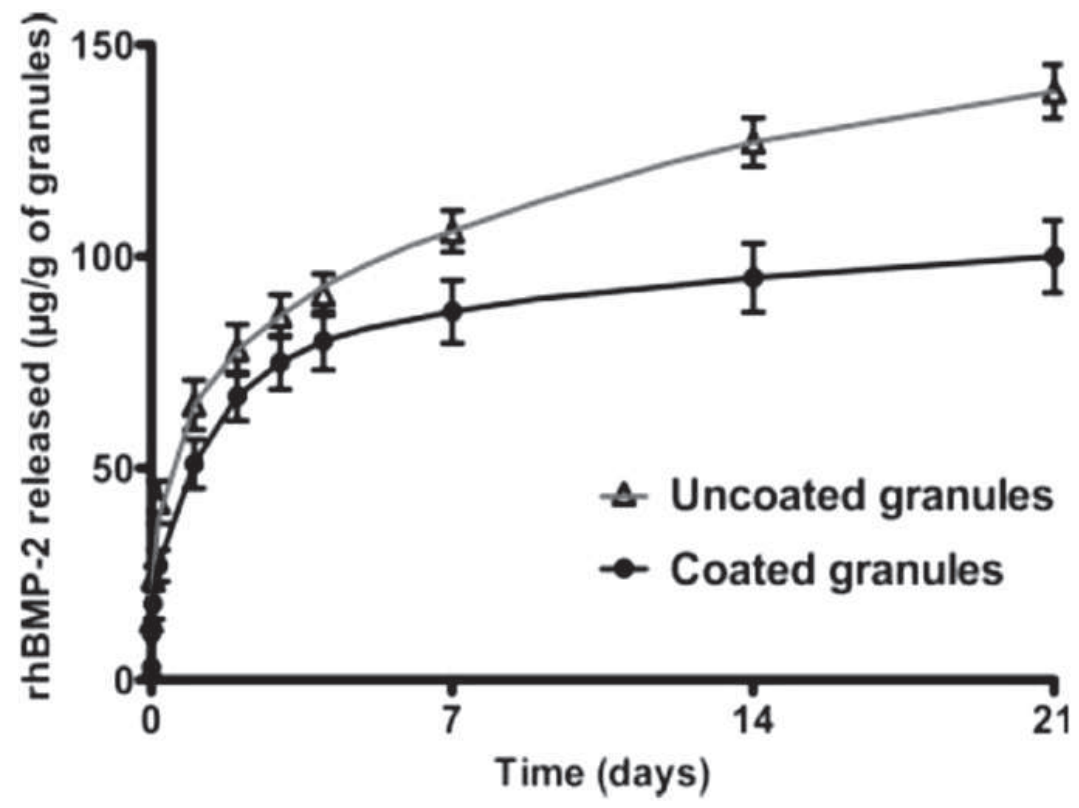

Fig. 17. Cumulative release of BMP-2 in DMEM complete culture medium from adsorbed BMP-2 on nanocrystalline-apatite coated and uncoated biphasic calcium phosphate. Reprinted with permission from Ref. [204]. Copyright 2009 John Wiley \& Sons, Inc.

adsorption and release kinetics of the three drugs investigated. The results demonstrated that apatite nanocrystals and antitumor drugs can be selected in such a way that the bioactivity of the drug-apatite conjugate could be tailored for specific therapeutic applications.

The adsorption of two different platinum complexes with cytotoxic activity, \{ethylenediamineplatinum(II)\}-2-amino-1-hydroxyethane-1,1-diyl-bisphosphonate (A) and bis-\{ethylened iamineplatinum(II)\}medronate (B), on the synthesized biomimetic nanocrystals has been investigated by lafisco et al. [237]. Both complexes contain a geminal bisphosphonate but, in addition, complex A contains a charged ammonium group.

This structural difference dramatically affects the affinity of A and B toward apatite nanocrystals, complex A having a greater affinity for calcium phosphate nanocrystals. The release profiles of the platinum complexes from the apatite nanoparticles follow an inverted trend (complex B > complex A) when compared with the adsorption process. Most probably the less effective desorption in the case of complex A could be due to the aminic group present on the bisphosphonate which remains anchored to the apatite matrix, coordinating and holding some of the ethylenediamineplatinum ( $\mathrm{Pt}(\mathrm{en}))$ residues. Unmodified and apatite-adsorbed Pt complexes were tested for their cytotoxicity toward human cervix carcinoma cells (HeLa). The apatite-loaded Pt complexes were more cytotoxic than the unmodified compounds $\mathrm{A}$ and $\mathrm{B}$ and their cytotoxicity was comparable to that of dichloridoethylenediamineplatinum $\left[\mathrm{PtCl}_{2}(\mathrm{en})\right]$ thus indicating a common active species. The above results demonstrate that apatite nanocrystals and antitumor drugs can be conjugated in such a way to yield a smart bone filler delivery system, acting both as bone substitutes and as platinum drug releasing agents with the final goal of locally inhibiting the tumor re-growth and reducing the systemic toxicity. The one here described not only can ensure a prolonged release of active species but also improve the performance of the unmodified drug. Moreover, these results suggest the possibility of using the chemical-physical differences of apatite nanocrystals, above all degree of crystallinity, crystal size and surface area, in order to strongly tailor the Pt complex release kinetics.

Considering the biomimetic apatite nanocrystals functionalization effects, an attracting goal could be to obtain a drug delivery process characterized by a stimuli responsive kinetic. This aim induces to functionalize the surface of apatite nanocrystals with different linking agents, such as bisphosphonates, to anchor biologically active molecules which can be released breaking the linkage as a consequence of external stimuli or internal chemical factors, such as $\mathrm{pH}$ and ionic force variation due to physiological or pathological biological process. 


\subsubsection{Example: bisphosphonates interaction with nanocrystalline apatites}

Bisphosphonates (BPs) are well established as an important class of drugs for the treatment of common skeletal disorders including osteoporosis. BPs were first studied over 30 years ago as synthetic analogous stable of inorganic pyrophosphate in which the oxygen bridge has been replaced by a carbon with various side chains (P-C-P) (Fig. 18). This substitution makes bisphosphonates resistant to biological degradation and therefore suitable for clinical use [261,262]. Their mode of action are at the same time physico-chemical effects and cellular effects: like pyrophosphate, BPs present a high affinity to adsorb onto bone mineral, and thereby prevent mineral dissolution and bone resorption, inhibiting osteoclasts activity directly and/or indirectly. BPs have two additional substituents in their molecule not present in pyrophosphate, R1 and R2, attached to the germinal carbon (Fig. 18), which may significantly affect both the mineral affinity and the pharmacological activity [263]. The ability of BPs to bind to bone mineral is increased when the R1 functional group is able to co-ordinate to calcium, as hydroxyl group (OH) [261,262]. Varying the R2 functional group can influence antiresorptive potency, those containing a nitrogen atom within a heterocyclic ring (such as risedronate, zoledronate) have the most potent antiresorptive effect [229,264]. Although the detailed mechanism of action of BPs has not been fully elucidated, it is clear that at the tissue level all active BPs inhibit bone resorption, bone turnover, and therefore, bone loss [261].

The classic BPs treatment is the systemic way by oral administration or intravenous injection. However, undesirable side-effects like fever [265], ulcers [266,267] or osteonecrosis of the jaw $[267,268]$ are commonly observed by systemic use of BPs. Moreover low bioavailability is commonly observed for oral administration [269]. In order to avoid these adverse effects and to increase BPs bioavailability, the development of strategies for local administration of BPs within osteoporotic sites becomes even more interesting.

While calcium phosphate ceramics are commonly used for biocompatible drug carriers, very few studies have been focused on the development of bioactive implant based nanocrystalline apatites for BPs local release. Some authors have recently shown that calcium deficient apatites were appropriate carriers for such antiresorptive drugs, in which the apatitic nanocrystals/BP association can be

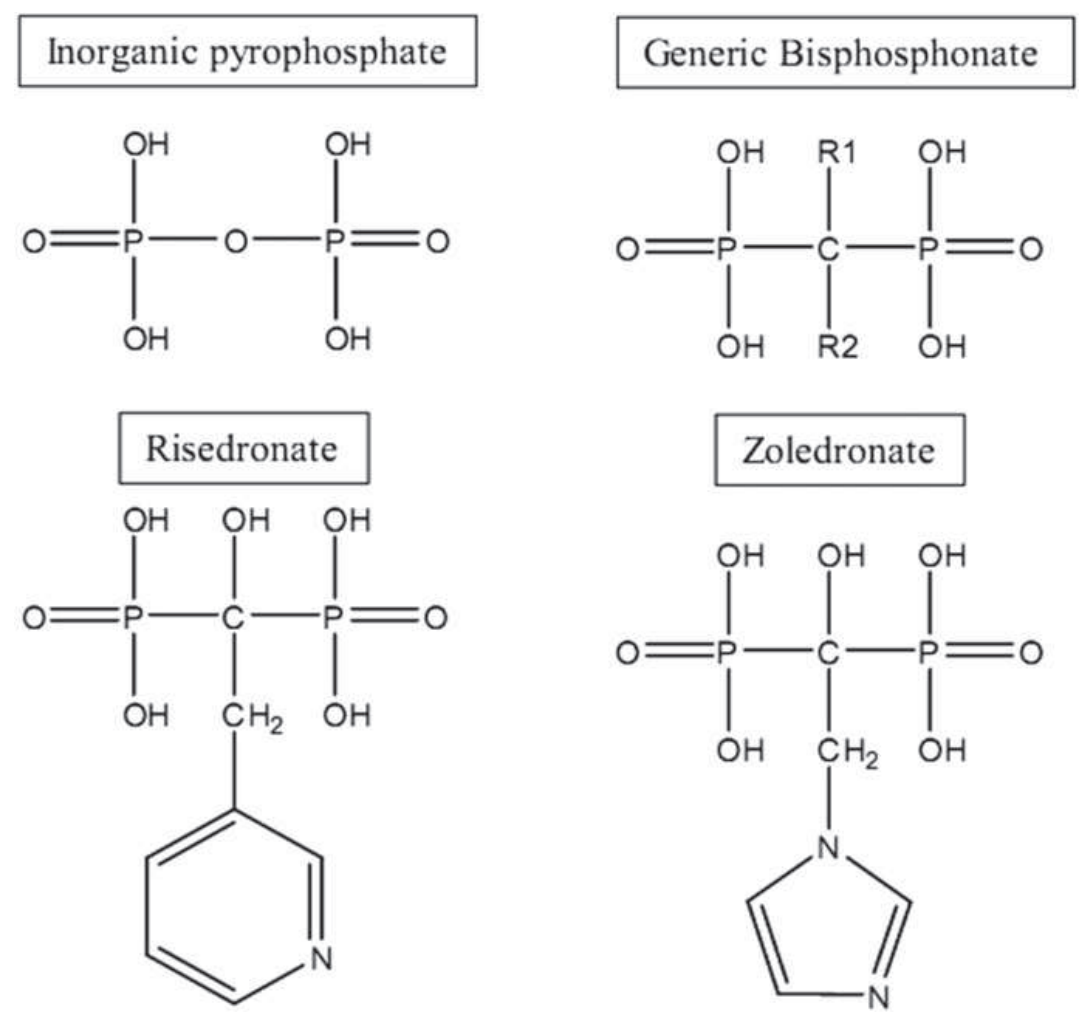

Fig. 18. Structure of the inorganic pyrophosphate and its synthetic (organic) analog bisphosphonate (BP). Examples of bisphosphonates, risedronate and zoledronate: well established antiresorptive agents for the prevention and treatment of postmenopausal osteoporosis. 
chemically controlled and well evidenced by spectroscopic method [270,271]. Osteointegration of association calcium phosphate matrices and BP was found to be BP concentration-dependent [272,273], thus nanocrystalline apatite has been shown to be effective for loading and releasing BP at doses that can inhibit excessive bone resorption without affecting osteoblasts [274]. For example recent studies report on the adsorption of risedronate molecules in solution on nanocrystalline apatites powders [271]. NMR studies confirm the uptake of risedronate adsorbed by the solid surface. The change observed for the ${ }^{31} \mathrm{P}$ environment of the adsorbed phosphonates, with respect to the native species, could be due to a local disorder induced by a strong interaction with the apatite surface, particularly calcium ions. The analysis of the solutions obtained after adsorption revealed that the binding of risedronate ions was accompanied by the displacement of phosphate ions from the mineral surface. Similar observations were noted for zoledronate bound calcium deficient apatites [270]. When zoledronate was grafted onto calcium phosphate powders, the adsorption process was associated with the release of phosphate ions in the solution from the apatitic surface. The ${ }^{31} \mathrm{P} \mathrm{CP}-\mathrm{MAS}$ solid state NMR spectra recorded for nonstoichiometric apatite phases showed the presence of the BPs moiety as a large peak (Fig. 19). On the basis of these observations, it can be postulated that BPs species in solution participate to an ionic exchange process with active mineral ions on the nanocrystals surface, particularly phosphates and/or carbonates, which share the same ionic sites [270,271]. The higher adsorption capability observed for the nanocrystalline apatites, compared to well-crystallized HA, was attributed to the presence of a well developed hydrated layer with relatively-mobile mineral ions at the surface of the nanocrystals corresponding to non-apatitic environments (phosphates and carbonate groups) at their surface [271], as explained in Section 2. In this context, the main parameter governing the release of BPs adsorbed onto nanocrystalline apatites seems to be phosphate concentration in the desorption medium, or other mineral ions which may replace them in the hydrated layer with release kinetics compatible with the inhibition of bone resorption [233]. This suggests that nanocrystalline apatites based delivery systems are able to precisely control BPs release by adjusting the properties of the carriers. Thus nanocrystalline apatites based biomaterials appear to be good candidates for hard tissue repair with a local action of these antiresorptive agents at the main osteoporosis induced fracture. Such strategies open the door to entire classes of new treatments.

\subsection{Coatings}

Commercially pure titanium (cpTi) and Ti-6Al-4V alloys are the most commonly used metallic implant materials, as they are highly biocompatible materials with good mechanical properties and corrosion resistance $[275,276]$. The biocompatibility of titanium implants is attributed to the stable

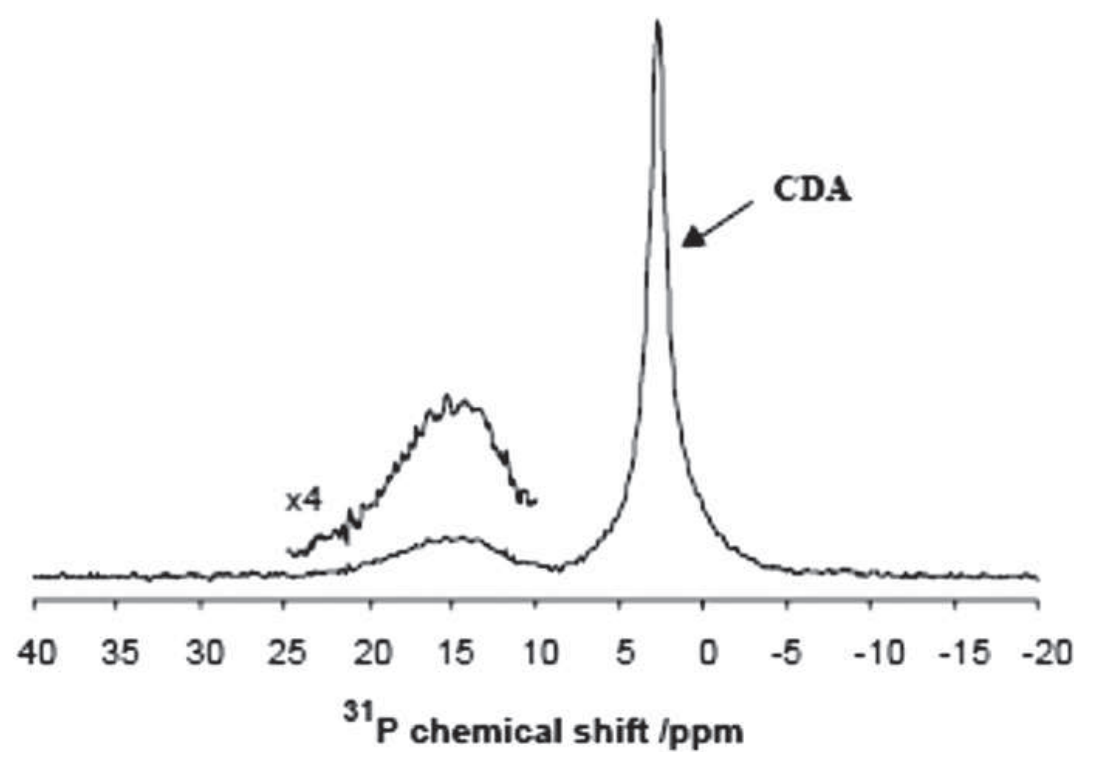

Fig. 19. ${ }^{31} \mathrm{P}$ CP-MAS NMR spectrum of zoledronate-modified calcium deficient apatite (CDA). Reprinted with permission from Ref. [270]. Copyright 2005 Elsevier. 
oxide layer (with a thickness of 3-10 nm) that spontaneously forms when titanium is exposed to oxygen [277]. This reaction prevents the formation of fibrous tissue around the implant, and creates direct contact to osseous tissue. However, when applying $\operatorname{Ti}\left(\mathrm{O}_{2}\right)$ as implant material, a nonphysiological surface is exposed to a physiological environment. Nevertheless, by generating a coating onto a titanium surface that mimics the organic and inorganic components of living bone tissue, a physiological transition between the non-physiological titanium surface and surrounding bone tissue can be established. In this way, the coated titanium implant functions as scaffold for improved bone cell attachment, proliferation and differentiation. Such a coating is supposed to further enhance early and strong fixation of a bone-substituting implant by stimulating bone formation starting from the implant surface. As such, a continuous transition from tissue to implant surface can be induced. Consequently, research efforts have focused on modifying the surface properties of titanium to control the interaction between the implant and its biological surrounding. As mentioned previously, apart from the living cells and the collagenous extracellular matrix the main constituent of bones and teeth is nonstoichiometric calcium phosphate apatite and the ideal surgical implant would be made from the same materials. However (hydroxy)apatite is weak and brittle, making them unsuitable for replacing parts of the body. To eliminate this problem, it was suggested that the titanium implants could be improved by coating them with apatite. This approach would combine the mechanical strength of titanium with the biological properties of biomimetic apatite.

Calcium phosphates coatings for orthopedic and dental implants were introduced by de Groot and Geesink $[278,279]$. Since then numerous reports have been published about the osteoconductive properties of calcium phosphates -coated implants (osteoconduction refers to the ability of a biomaterial to support the growth of bone over its surface). These apatite coatings are described to induce an increased bone-to-implant contact [280,281] to improve the implant fixation [282], and to facilitate the bridging of small gaps between implant and surrounding bone [283]. The calcium phosphates-layer guides bone growth along the implant surface, and as a result bone formation now occurs from both the surrounding tissue and the implant surface, in which calcium phosphates functions as a physiological transition between the non-physiological titanium surface and surrounding bone.

The application of apatite on titanium is restricted because of failure at the metal-coating interface leading to loosening of implants [284]. To improve the bonding strength of the coating, many methods have been tested. So far, the most successful method to apply calcium phosphates coatings to implants has been the plasma-spraying technique, due to its high deposition rate and the ability to coat large areas $[285,286]$. Plasma-spraying is a technique in which a so-called plasma gun creates an electric arc current of high energy between a cathode and an anode. An inert gas is directed through the space between these electrodes and subsequently the arc current ionizes the gas and plasma formed. The electrons and ions in this plasma are separated form each other and are accelerated toward the cathode and anode, respectively. These rapidly moving particles then collide with other atoms or molecules in the gas, which results in expansion owing to the temperature increase. Then, a plasma flame is formed that emerges form the gun toward the substrate at velocities approaching or exceeding the speed of sound. After, hydroxyapatite ceramic powder particles are fed into plasma flame. The particles melt and are deposited on the substrate at which the gun is aimed. The quality of plasma-sprayed coatings can be influenced by several parameters, such as the temperature of the plasma, the nature of the plasma gas, the particle size of the powder and the chemical nature of the ceramic powder. In this way the apatite coating deposited is quite different from bone mineral apatite. In fact, during this procedure the overheating and melting can change the synthetic apatite powder [287], leading for example to its partial decomposition.

The osteoconductive and bone-bonding behavior of plasma-sprayed coatings was assessed by numerous studies. However, it should be noted that, despite recent advances especially with low-energy plasmas which were not much reported as yet, the chemical composition of plasma coatings generally involve a mixture of several phases (including amorphous calcium phosphate in particular), not always in a reproducible manner. Therefore, researchers have been continuously inspired in the past two decades to explore alternative or complementary techniques for deposition of coatings onto an implant surface. Various deposition methods have been proposed, including magnetron sputtering [288,289], electrophoretic deposition [290], hot isostatic pressing, sol-gel deposition [291], pulsed laser deposition [292], biomimetic deposition [293], ion beam dynamic mixing deposition [294], electrospray deposition [281], electrolytic deposition induction heating deposition from solution [285]. Other methods 
involving hydrothermal treatment have also been used, but its accomplishment commonly needs a twostep treatment. First, a surface containing calcium and phosphorus ions is produced by any other techniques such as anodic oxidation [295], micro-arc oxidation [296] or plasma spraying [297]. Then the obtained samples are hydrothermally treated in an aqueous medium (water or SBF) to form apatite phase. Such hydrothermal treatment method is complicated and increases cost and time. To overcome these problems Hu et al. reported a one-step hydrothermal process with apatite suspension to realize stable and uniform coating on a titanium surface [298]. Change of surface chemistry, surface morphology of samples, and structure of formed nano-apatite were investigated. The concentration of hydroxyl groups increased after hydrothermal treatment and the ability of the titanium surface to form nano-apatite was enhanced by increasing the hydrothermal treatment temperature and time. The bonding strength of the formed nano-apatite coating, examined by an ultrasonic cleaning process, was higher than that of apatite coating generated directly by suspension deposition.

In addition to pure calcium phosphates, many different biologically functional molecules can be immobilized onto titanium surfaces to enhance bone regeneration at the interface of implant devices. However, most techniques used to prepare (inorganic) hydroxyapatite coatings are performed either at extremely high temperatures or under non-physiological conditions, which preclude the incorporation of biomolecules. The recent investigation trend has attempted to avoid this difficulty by adsorbing biological agents onto the surfaces of preformed inorganic layers [299,300]. However, these superficially adsorbed molecules will be rapidly released in an uncontrollable single burst upon implantation [301]. Hence, coating procedures that incorporate biomolecules into the apatite coating create a more sustained release profile and are therefore of high interest [302]. In this way, the molecules can both sustain their biological activity for a considered period of time and support the mechanical properties of the coating in case of structural ECM components such as collagen [303]. Both the biomimetic and electrospray deposition (ESD) process are among the most promising techniques, for generating organic-inorganic composite coatings on implant materials, and for depositing a nanostructured apatite coating due to their physiological process conditions [304,305]. ESD involves atomization of a precursor solution by applying a high voltage to the liquid surface, which then disperses into an aerosol spray of micro-sized charged droplets $(<10 \mu \mathrm{m})$. This is accomplished by pumping the solution through a nozzle. Usually a spherical droplet is formed at the tip of nozzle, but when a high voltage is applied between nozzle and substrate, this droplet transforms into a conical shape and fans out form a spray of highly charged droplets. These charged droplets are attracted towards a grounded substrate, where a thin biofilm is formed after solvent evaporation. ESD technique has several advantages: very simple and cheap set-up; high deposition efficiency, since the electric field directs charged droplets to the substrate; control over the coating composition and the possibility to tailor the morphology of the deposited coatings [306-308]. Leeuwenburgh et al. [281,308] demonstrated moreover the ability of ESD to produce calcium phosphates coatings, using Ca and P precursor salt solutions by mixing them at the spraying nozzle. Thian et al. [309] used the ESD for the deposition of biomimetic apatite nanocrystals onto titanium substrates as uniform coatings at room temperature, using an apatite suspension as the precursor solution. These apatite coatings triggered early apatite precipitation process in acellular simulated body fluid and furthermore human osteoblast cells were observed to attach well on these coatings, with clear evidence of well-formed actin stress fibers and vinculin adhesion plaques. Thus, these results indicated the enhanced in vitro bioactivity of nanocrystalline apatite thin coatings.

It is worth noticing that caution should always be taken when directly comparing the success rates of these coating techniques without a proper understanding of the physicochemical nature of the specific calcium phosphates coatings. Generally, the conclusions about the biological/clinical performance of coatings cannot be made without a complete set of characterizations that enable correlation of material properties to biological response [310]. Clinically, each application demands specific requirements, and in that respect the wide range of available coating techniques offers the possibility to select the most appropriate deposition method for each specific implant application.

\subsection{Medical imaging}

As mentioned previously, nanocrystalline apatites are nano-sized materials and the constitutive nanocrystals exhibit a highly reactive surface. Additionally, these compounds are biomimetic and show 
then a high biocompatibility. These considerations thus made of nanocrystalline apatites particularly well-suited systems in view of biomedical applications. Although most envisioned applications are related to bone engineering, the exceptional reactivity of these materials have also lately attracted attention in other biomedical fields such as medical imaging.

In this field, imaging contrast-enhancing effects by way of luminescence has been considered in the last few years, in particular using lanthanide doping, especially with europium or terbium ions [311315]. Generally speaking, lanthanide-based phosphors have indeed been used for many years in the field of optical devices [316-318] and more recently for medical applications [319-322]. In fact, systems based on luminescent lanthanide ions present several advantages over other luminescent probes: in particular, they do not lead to photobleaching issues (unlike organic fluorescent dyes like fluorescein, green fluorescent protein or rhodamine), nor to flickering effects as with quantum dots. Also, lanthanide ions give rise to fluorescence properties characterized by narrow emission bandwidths, high photochemical stability and a long fluorescence lifetime. Finally, different colors are available by varying the luminescent center used (e.g. green $\mathrm{Tb}^{3+}$, red $\left.\mathrm{Eu}^{3+}, \ldots\right)$.

Nanocrystalline calcium phosphate apatites doped with $\mathrm{Eu}^{3+}$ or $\mathrm{Tb}^{3+}$ have been prepared and investigated [311-315], exploiting the ability of the apatite structure to accommodate many types of ionic substituents. Some luminescence properties of $\mathrm{Eu}^{3+}$-doped apatites were examined in several works [323-327], unveiling the possibility to obtain a red fluorescent probe. The possibility to excite $\mathrm{Eu}^{3+}$ ions at low energy (in or near the visible domain) is indeed suitable for studying biological tissues without altering them.

The development of imaging nanoprobes in biology faces the issue of particle size, especially when interactions with cells are foreseen, either in vitro or in vivo. In this regard, the development of suspensions of nanoparticles present a mean size lower than $100 \mathrm{~nm}$ is generally sought for improving cell internalization capabilities, increasing blood circulation time, and avoiding secondary detrimental effects due to systemic inoculation. Recently, the preparation of colloidal suspensions of doped apatite nanocrystals stabilized by a phospholipid moiety has been reported [314,315], including from easily handled ionic salts, and nanoparticle sizes tailorable as needed in the range 30-100 nm were obtained. Interestingly, these systems were found to exhibit a high luminescence lifetime (of the order of a millisecond), largely greater than the autofluorescence of biological materials, therefore opening promising upcoming outcomes in the field of medical imaging, for example using time-resolved image acquisition systems.

Luminescence imaging data using intrinsically non-luminescent calcium phosphate apatite compounds but associated with a fluorescent dye have also been reported. For instance, NIR observations were made possible using associations of apatite with embedded NIR-emitting indocyanine green ICG [328]. In this case, the authors reported that the particles could accumulate in xenograft breast adenocarcinoma tumors in a nude mouse model, and ex-situ tissue imaging enabled deep-tissue NIR imaging of porcine muscle. Similarly, the encapsulation of other fluorophores has also been reported (e.g. Cy3 amidite dye [329]). Also, quantum dot-conjugated hydroxyapatite has been prepared [330], and preliminary in vivo data led to clear images from the hypodermic injected area at the emission wavelength of $600 \mathrm{~nm}$, and to NIR emission at $800 \mathrm{~nm}$ visualized after intravenous injection.

The above statements illustrate the potential use of apatite-based systems, especially with colloidal formulations, in view of the preparation of novel, highly biocompatible nanoprobes for medical imaging.

\section{Concluding remarks and perspectives}

The present review gathers general and more focused information on nanocrystalline apatiticbased systems and their applications in the biomedical field, not only in relation to bone repair but also to other broader domains such as drug delivery or medical imaging. A special attention was paid to the surface properties of biomimetic apatite nanocrystals, and major differences with stoichiometric HA were stressed. In particular, the presence (and extent) of a hydrated non-apatitic calcium-phosphate layer on the nanocrystals can be seen as a key factor that controls the interactions of biomimetic apatite nanocrystals and surrounding fluids, especially in terms of ion exchange or adsorption of organic molecules. 
There are excellent perspectives for the development of biomimetic nanoparticles with new applications based on the control of size, shape, and specific surface area, doping with new ions, even beyond bone regeneration, for example to produce photoluminescent and/or magnetic resonance imaging (MRI) contrast materials, tailoring of their surface properties by coating their surface with specific molecules and ions, or by using them to produce multifunctional engineered nanoparticles. In this respect recent advances have been done for example to produce hollow nanospheres having for instance a thickness of $45 \mathrm{~nm}$ and internal cavities of $60 \mathrm{~nm}$ [331], and the development of apatitebased colloids is in expansion [289]. The high specific surface area allows apatite nanoparticles to load drugs and enables one to envision a delivery upon stimulations such as ultrasounds. An important feature is the possibility to prepare multifunctional engineered nanoparticles by conjugation of nanocrystalline apatites with biocompatible entities such as vitamins, aminoacids, phospholipid derivatives or else monoclonal antibodies or antitumor drugs to be used for example in cancer treatment or diagnosis. One important challenge for the success of these new applications will be the scaling up of current methodologies to produce large amounts of nanoparticles with homogeneous morphological bulk and surface physico-chemical properties. In all cases mentioned here, a detailed physico-chemical characterization of the obtained materials should be seen as a major prerequisite.

\section{Acknowledgments}

M.I. would like to thank Regione Piemonte (Progetto Ricerca Sanitaria Finalizzata 2009, Grant no: 30258/DB2001) and Ministero dell'Istruzione, dell'Università e della Ricerca (MIUR) (Azioni Integrate Italia-Spagna, Grant no: IT10M4FC89) for providing financial support to this project. JGM and JMDL acknowledge Spanish MINECO (Spanish-Italian integrated action IT2009-0028, Crysfunbio project MAT2011-28543 and Factoria de Cristalización CSD2006-00015 of the Consolider-Ingenio 2010 Program) and Junta de Andalucia (Excellence project ref. RNM 5384). JMDL also thank to CSIC for his postdoctoral (JAE-DOC) research contract within the "Junta para la Ampliación de Estudios" co-founded by the European Social Found (ESF).

\section{References}

[1] S. Mann, Biomineralization: Principles and Concepts in Bioinorganic Materials Chemistry, University Press, Oxford, 2001.

[2] H.A. Lowenstam, S. Weiner, On Biomineralization, University Press, Oxford, 1989.

[3] M. Vallet-Regí, J.M. González-Calbet, Prog. Solid State Chem. 32 (2004) 1-31.

[4] C. Eichert, C. Drouet, H. Sfihi, C. Rey, C. Combes, Nanocrystalline apatite-based biomaterials: synthesis, processing and characterization, in: J.B. Kendall (Ed.), Biomaterials Research Advances, Nova Science Publishers, 2007, pp. 93-143.

[5] S.V. Dorozhkin, Acta Biomater. 6 (2010) 715-734.

[6] C. Rey, C. Combes, C. Drouet, A. Lebugle, H. Sfihi, A. Barroug, Mater.-wiss. u. Werkstofftech. 38 (2007) 996-1002.

[7] M.J. Olszta, X. Cheng, S.S. Jee, R. Kumar, Y.-Y. Kim, M.J. Kaufman, E.P. Douglas, L.B. Gower, Mater. Sci. Eng. Res. 58 (2007) 77-116.

[8] T. Kokubo, H. Takadama, Biomaterials 27 (2006) 2907-2915.

[9] C. Sanchez, H. Arribart, M.M. Giraud Guille, Nat. Mater. 4 (2005) 277-288.

[10] S. Padilla, I. Izquierdo-Barba, M. Vallet-Regi, Chem. Mater. 20 (2008) 5942-5944.

[11] S.V. Dorozhkin, M. Epple, Angew. Chem. Int. Ed. 41 (2002) 3130-3146.

[12] S.V. Dorozhkin, Biomaterials 31 (2010) 1465-1485.

[13] N. Roveri, M. Iafisco, Nanotechnol. Sci. Appl. 3 (2010) 107-125.

[14] N. Loveridge, J. Anim. Sci. 77 (1999) 190-196.

[15] A.H. Reddi, Curr. Opin. Genet. Dev. 4 (1994) 737-744.

[16] S. Weiner, H.D. Wagner, Annu. Rev. Mater. Sci. 28 (1998) 271-298.

[17] J.D. Currey, Osteoporos. Int. 14 (2003) 29-36.

[18] T. Hassenkam, G.E. Fantner, J.A. Cutroni, J.C. Weaver, D.E. Morse, P.K. Hansma, Bone 35 (2004) 4-10.

[19] S. Weiner, P.A. Price, Calcif. Tissue Int. 39 (1986) 365-375.

[20] S.A. Jackson, A.G. Cartwright, D. Lewis, Calcif. Tissue Res. 25 (1978) 217-222.

[21] A. Guagliardi, C. Giannini, A. Cedola, M. Mastrogiacomo, M. Ladisa, R. Cancedda, Tissue Eng. B Rev. 15 (2009) $423-442$.

[22] C. Rey, C. Combes, C. Drouet, H. Sfihi, A. Barroug, Mater. Sci. Eng. C 27 (2007) 198-205.

[23] Y.Y. Hu, A. Rawal, K. Schmidt-Rohr, Proc. Natl. Acad. Sci. U. S. A. 107 (2010) 22425-22429.

[24] A. López-Macipe, J. Gómez-Morales, R. Rodríguez-Clemente, Adv. Mater. 10 (1998) 49.

[25] H. Sanders, M. Iafisco, E.M. Pouget, P.H.H. Bomans, F. Nudelman, G. Falini, G. de With, M. Merkx, G.J. Strijkers, K. Nicolay, N. Sommerdijk, Chem. Commun. 47 (2011) 1503-1505.

[26] A. Gericke, C. Qin, L. Spevak, Y. Fujimoto, W.T. Butler, E.S. Sorensen, A.L. Boskey, Calcif. Tissue Int. 77 (2005) 45-54.

[27] R.T. Ingram, B.L. Clarke, L.W. Fisher, L.A. Fitzpatrick, J. Bone Miner. Res. 8 (1993) 1019-1029.

[28] T. Takano-Yamamoto, T. Takemura, Y. Kitamura, S. Nomura, J. Histochem. Cytochem. 42 (1994) 885-896. 
[29] J.H. Jang, O. Castano, H.W. Kim, Adv. Drug Deliv. Rev. 61 (2009) 1065-1083.

[30] A.L. Boskey, S.B. Doty, V. Kudryashov, P. Mayer-Kuckuk, R. Roy, I. Binderman, Bone 42 (2008) 1061-1071.

[31] M.C. Siebers, P.J. ter Brugge, X.F. Walboomers, J.A. Jansen, Biomaterials 26 (2005) 137-146.

[32] A.S. Deshpande, E. Beniash, Cryst. Growth Des. 8 (2008) 3084-3090.

[33] P.A. Price, D. Toroian, J.E. Lim, J. Biol. Chem. 284 (2009) 17092-17101.

[34] F. Nudelman, K. Pieterse, A. George, P.H.H. Bomans, H. Friedrich, L.J. Brylka, P.A.J. Hilbers, G. With, N.A.J.M. Sommerdijk, Nat. Mater. 9 (2010) 1004-1009.

[35] K. Kawasaki, Dev. Genes Evol. 219 (2009) 147-157.

[36] W.T. Butler, H. Ritchie, Int. J. Dev. Biol. 39 (1995) 169-179.

[37] K. Kawasaki, K.M. Weiss, J. Dent. Res. 87 (2008) 520-531.

[38] H.C. Margolis, E. Beniash, C.E. Fowler, J. Dent. Res. 85 (2006) 775-793.

[39] G. Daculsi, J. Menanteau, L.M. Kerebel, D. Mitre, Calcif. Tissue Int. 36 (1984) 550-555.

[40] K. Kawasaki, A.V. Buchanan, K.M. Weiss, Annu. Rev. Genet. 43 (2009) 119-142.

[41] A.G. Fincham, J. Moradian-Oldak, J.P. Simmer, J. Struct. Biol. 126 (1999) 270-299.

[42] M.U. Nylen, E.D. Eanes, K.-A. Omnell, J. Cell. Biol. 18 (1963) 109-123.

[43] A.L. Arsenault, B.W. Robinson, Calcif. Tissue Int. 45 (1989) 111-121.

[44] H. Warshawsky, A. Nanci, J. Dent. Res. 61 (1982) 1504-1514.

[45] G. Daculsi, B. Kerebel, J. Ultrastruct. Res. 65 (1978) 163-172.

[46] F.J.G. Cuisinier, P. Steuer, B. Senger, J.C. Voegel, R.M. Frank, Calcif. Tissue Int. 51 (1992) 259-268.

[47] M.J. Glimcher, E.J. Daniel, D.F. Travis, S. Kamhi, J. Ultrastruct. Res. 12 (1965) 1-77.

[48] C.E. Smith, Crit. Rev. Oral Biol. Med. 9 (1998) 128-161.

[49] D.F. Travis, M.J. Glimcher, J. Cell. Biol. 23 (1964) 447-497.

[50] C. Robinson, J. Kirkham, Dynamics of amelogenesis as revealed by protein compositional studies, in: W.T. Butler (Ed.), The Chemistry and Biology of Mineralized Tissues, EBSCO Media, Birmingham, 1985, pp. 248-263.

[51] M.L. Paine, S.N. White, W. Luo, H. Fong, M. Sarikaya, M.L. Snead, Matrix Biol. 20 (2001) 273-292.

[52] H.B. Wen, J. Moradian-Oldak, A.G. Fincham, J. Dent. Res. 79 (2000) 1902-1906.

[53] Y. Fan, Z. Sun, J. Moradian-Oldak, Biomaterials 30 (2009) 478-483.

[54] C. Du, G. Falini, S. Fermani, C. Abbott, J. Moradian-Oldak, Science 307 (2005) 1450-1454.

[55] F.-Z. Cui, Y. Li, J. Ge, Mater. Sci. Eng. Res. 57 (2007) 1-27.

[56] R.Z. Wang, S. Weiner, J. Biomech. 31 (1998) 135-141.

[57] T. Kodaka, F. Nakajima, S. Higashi, Caries Res. 23 (1989) 290-296.

[58] C. Tamerler, M. Sarikaya, MRS Bull. 33 (2008) 504-512.

[59] J. Moradian-Oldak, W. Leung, A.G. Fincham, J. Struct. Biol. 122 (1998) 320-327.

[60] J. Moradian-Oldak, M.L. Paine, Y.P. Lei, A.G. Fincham, M.L. Snead, J. Struct. Biol. 131 (2000) 27-37.

[61] A.G. Fincham, J. Moradian-Oldak, T.G.H. Diekwisch, D.M. Lyaruu, J.T. Wright, P. Bringas, H.C. Slavkin, J. Struct. Biol. 115 (1995) 50-59.

[62] C. Robinson, P. Fuchs, J.A. Weatherell, J. Cryst. Growth 53 (1981) 160-165.

[63] J.M. ten Cate, Eur. J. Oral Sci. 105 (1997) 461-465.

[64] C. Robinson, S. Connell, J. Kirkham, S.J. Brookes, R.C. Shore, A.M. Smith, Caries Res. 38 (2004) 268-276.

[65] N. Roveri, E. Battistella, C.L. Bianchi, I. Foltran, E. Foresti, M. Iafisco, M. Lelli, A. Naldoni, B. Palazzo, L. Rimondini, J. Nanomater. 2009 (2009) 1-9.

[66] G. Orsini, M. Procaccini, L. Manzoli, F. Giuliodori, A. Lorenzini, A. Putignano, J. Clin. Periodontol. 37 (2010) 510-517.

[67] M. Hannig, C. Hannig, Nat. Nanotechnol. 5 (2010) 565-569.

[68] M. Iijima, J. Moradian-Oldak, Biomaterials 26 (2005) 1595-1603.

[69] Y. Moriwaki, Y. Doi, T. Kani, T. Aoba, J. Takahashi, M. Okazaki, Synthesis of enamel-like apatite at physiological temperature and $\mathrm{pH}$ using ion-selective membranes, in: S. Suga (Ed.), Mechanisms of Tooth Enamel Formation, Quintessence Publishing Co., Tokyo, Japan, 1983, pp. 239-256.

[70] M. Iijima, Y. Moriwaki, T. Takagi, J. Moradian-Oldak, J. Cryst. Growth 222 (2001) 615-626.

[71] Y. Fan, Z. Sun, J. Moradian-Oldak, Caries Res. 43 (2009) 132-136.

[72] L.B. Gower, Chem. Rev. 108 (2008) 4551-4627.

[73] J. Mahamid, A. Sharir, L. Addadi, S. Weiner, Proc. Natl. Acad. Sci. U. S. A. 105 (2008) 12748-12753.

[74] B. Xie, G.H. Nancollas, Proc. Natl. Acad. Sci. U. S. A. 107 (2010) 22369-22370.

[75] J. Wang, L.L. Shaw, Adv. Mater. 19 (2007) 2364-2369.

[76] K. Ganesan, M. Epple, New J. Chem. 32 (2008) 1326-1330.

[77] Y. Zhang, J. Lu, J. Nanopart. Res. 9 (2007) 589-594.

[78] B. Ben-Nissan, A.H. Choi, Nanomedicine 1 (2006) 311-319.

[79] G.M. Sun, X.Z. Zhang, C.C. Chu, J. Mater. Sci.-Mater. Med. 18 (2007) 1563-1577.

[80] C.S. Chai, B. Ben-Nissan, J. Mater. Sci.-Mater. Med. 10 (1999) 465-469.

[81] A.C. Tas, Biomaterials 21 (2000) 1429-1438.

[82] X.Y. Guo, J.E. Gough, P. Xiao, J. Liu, Z.J. Shen, J. Biomed. Mater. Res. A 82A (2007) 1022-1032.

[83] A.A. Chaudhry, S. Haque, S. Kellici, P. Boldrin, I. Rehman, A.K. Fazal, J.A. Darr, Chem. Commun. (2006) 2286-2288.

[84] M. Ashok, S.N. Kalkura, N.M. Sundaram, D. Arivuoli, J. Mater. Sci.-Mater. Med. 18 (2007) 895-898.

[85] J. Gómez-Morales, J. Torrent-Burgues, T. Boix, J. Fraile, R. Rodríguez-Clemente, Cryst. Res. Technol. 36 (2001) $15-26$.

[86] K.C.B. Yeong, J. Wang, S.C. Ng, Biomaterials 22 (2001) 2705-2712.

[87] D.S.R. Krishna, A. Siddharthan, S.K. Seshadri, T.S.S. Kumar, J. Mater. Sci.-Mater. Med. 18 (2007) 1735-1743.

[88] A. Lak, M. Mazloumi, M.S. Mohajerani, S. Zanganeh, M.R. Shayegh, A. Kajbafvala, H. Arami, S.K. Sadrnezhaad, J. Am. Ceram. Soc. 91 (2008) 3580-3584.

[89] N. Rameshbabu, T.S.S. Kumar, K.P. Rao, Bull. Mater. Sci. 29 (2006) 611-615.

[90] N. Rameshbabu, K.P. Rao, T.S.S. Kumar, J. Mater. Sci. 40 (2005) 6319-6323. 
[91] M. Iafisco, J.M. Delgado-López, J. Gómez-Morales, M.A. Hernández-Hernández, I. Rodríguez-Ruiz, N. Roveri, Cryst. Res. Technol. 46 (2011) 841-846.

[92] M. Iafisco, J. Gómez-Morales, M.A. Hernández-Hernández, J.M. García-Ruiz, N. Roveri, Adv. Eng. Mater.12 (2010) B218-B223.

[93] N. Nassif, F. Martineau, O. Syzgantseva, F. Gobeaux, M. Willinger, T. Coradin, S. Cassaignon, T. Azaïs, M.M. Giraud-Guille, Chem. Mater. 22 (2010) 3653-3663.

[94] M. Iafisco, M. Marchetti, J. Gómez-Morales, M.A. Hernández-Hernández, J.M. García-Ruiz, N. Roveri, Cryst. Growth Des. 9 (2009) 4912-4921.

[95] M.J. Phillips, J.A. Darr, Z.B. Luklinska, I. Rehman, J. Mater. Sci.-Mater. Med. 14 (2003) 875-882.

[96] E. San Thian, Z. Ahmad, J. Huang, M.J. Edirisinghe, S.N. Jayasinghe, D.C. Ireland, R.A. Brooks, N. Rushton, W. Bonfield, S.M. Best, Biomaterials 29 (2008) 1833-1843.

[97] Y.Q. Wu, L.L. Hench, J. Du, K.L. Choy, J.K. Guo, J. Am. Ceram. Soc. 87 (2004) 1988-1991.

[98] K. Teshima, S. Lee, M. Sakurai, Y. Kameno, K. Yubuta, T. Suzuki, T. Shishido, M. Endo, S. Oishi, Cryst. Growth Des. 9 (2009) $2937-2940$

[99] P. Layrolle, A. Lebugle, Chem. Mater. 6 (1994) 1996-2004.

[100] F. Ye, H.F. Guo, H.J. Zhang, Nanotechnology 19 (2008).

[101] V. Uskokovic, D.P. Uskokovic, J. Biomed. Mater. Res. B 96B (2011) 152-191.

[102] B. Müller, Mater. Today 13 (2010) 58.

[103] N. Roveri, B. Palazzo, Hydroxyapatite nanocrystals as bone tissue substitute, in: Nanotechnologies for the Life Sciences, Wiley-VCH Verlag GmbH \& Co. KGaA, 2007.

[104] L. Bertinetti, C. Drouet, C. Combes, C. Rey, A. Tampieri, S. Coluccia, G. Martra, Langmuir 25 (2009) 5647-5654.

[105] Y. Sakhno, L. Bertinetti, M. Iafisco, A. Tampieri, N. Roveri, G. Martra, J. Phys. Chem. C 114 (2010) 16640-16648.

[106] L. Bertinetti, A. Tampieri, E. Landi, C. Ducati, P.A. Midgley, S. Coluccia, G. Martra, J. Phys. Chem. C 111 (2007) $4027-4035$.

[107] J.M. Delgado-López, M. Iafisco, I. Rodríguez, A. Tampieri, M. Prat, J. Gómez-Morales, Acta Biomater. 8 (2012) $3491-3499$.

[108] P.Shuk, W.L. Suchanek, T. Hao, E. Gulliver, R.E. Riman, M. Senna, K.S. TenHuisen, V.F. Janas, J. Mater. Res.16(2001) 1231 -1234.

[109] R.E. Riman, W.L. Suchanek, K. Byrappa, C.-W. Chen, P. Shuk, C.S. Oakes, Solid State Ionics 151 (2002) 393-402.

[110] C.-W. Chen, R.E. Riman, K.S. TenHuisen, K. Brown, J. Cryst. Growth 270 (2004) 615-623.

[111] Y.-S. Wu, Y.-H. Lee, H.-C. Chang, Mater. Sci. Eng. C 29 (2009) 237-241.

[112] W.L. Suchanek, P. Shuk, K. Byrappa, R.E. Riman, K.S. TenHuisen, V.F. Janas, Biomaterials 23 (2002) 699-710.

[113] W.L. Suchanek, K. Byrappa, P. Shuk, R.E. Riman, V.F. Janas, K.S. TenHuisen, Biomaterials 25 (2004) 4647-4657.

[114] H.G. Zhang, Q. Zhu, Z.H. Xie, Mater. Res. Bull. 40 (2005) 1326-1334.

[115] J. Gómez-Morales, A. Hernández-Hernandez, G. Sazaki, J.M. García-Ruiz, Cryst. Growth Des. 10 (2010) 963-969.

[116] A. Hernández-Hernandez, A.B. Rodríguez-Navarro, J. Gómez-Morales, C. Jimenez-Lopez, Y. Nys, J.M. Garcia-Ruiz, Cryst. Growth Des. 8 (2008) 1495-1502.

[117] J.H. Zhan, Y.H. Tseng, J.C.C. Chan, C.Y. Mou, Adv. Funct. Mater. 15 (2005) 2005-2010.

[118] A. Wang, H. Yin, D. Liu, H. Wu, M. Ren, T. Jiang, X. Cheng, Y. Xu, Mater. Lett. 61 (2007) 2084-2088.

[119] S.I. Stupp, P.V. Braun, Science 277 (1997) 1242-1248.

[120] X. Wang, Y. Li, J. Wei, K. de Groot, Biomaterials 23 (2002) 4787-4791.

[121] S. Mollazadeh, J. Javadpour, A. Khavandi, Ceram. Int. 33 (2007) 1579-1583.

[122] S. Liao, F. Watari, Y. Zhu, M. Uo, T. Akasaka, W. Wang, G. Xu, F. Cui, Dent. Mater. 23 (2007) 1120-1128

[123] S. Koutsopoulos, E. Dalas, J. Colloid Interf. Sci. 231 (2000) 207-212.

[124] S. Koutsopoulos, E. Dalas, J. Cryst. Growth 216 (2000) 443-449.

[125] S. Koutsopoulos, E. Dalas, Langmuir 17 (2001) 1074-1079.

[126] R. Gonzalez-McQuire, J.Y. Chane-Ching, E. Vignaud, A. Lebugle, S. Mann, J. Mater. Chem. 14 (2004) 2277-2281.

[127] E. Boanini, P. Torricelli, M. Gazzano, R. Giardino, A. Bigi, Biomaterials 27 (2006) 4428-4433.

[128] E.V. Rosseeva, O.A. Golovanova, O.V. Frank-Kamenetskaya, Glass Phys. Chem. 33 (2007) 283-286.

[129] K.S. Jack, T.G. Vizcarra, M. Trau, Langmuir 23 (2007) 12233-12242.

[130] B. Palazzo, D. Walsh, M. Iafisco, E. Foresti, L. Bertinetti, G. Martra, C.L. Bianchi, G. Cappelletti, N. Roveri, Acta Biomater. 5 (2009) 1241-1252.

[131] H. Li, M. Zhu, L. Li, C. Zhou, J. Mater. Sci. 43 (2008) 384-389.

[132] Y. Wu, S. Bose, Langmuir 21 (2005) 3232-3234.

[133] C. Lai, S. Tang, Y. Wang, K. Wei, S. Zhang, Synth. React. Inorg. Met. 35 (2005) 717-725.

[134] D. Walsh, J.D. Hopwood, S. Mann, Science 264 (1994) 1576-1578.

[135] S. Sarda, M. Heughebaert, A. Lebugle, Chem. Mater. 11 (1999) 2722-2727.

[136] M.S.-A. Johnsson, G.H. Nancollas, Crit. Rev. Oral Biol. Med. 3 (1992) 61-82.

[137] C.A. Orme, J.L. Giocondi, Model systems for formation and dissolution of calcium phosphate minerals, in: Handbook of Biomineralization, Wiley-VCH Verlag GmbH, 2008, pp. 135-157.

[138] H. Cölfen, S. Mann, Angew. Chem. Int. Ed. 42 (2003) 2350-2365.

[139] A.-W. Xu, Y. Ma, H. Cölfen, J. Mater. Chem. 17 (2007) 415-449.

[140] X. Lu, Y. Leng, Biomaterials 26 (2005) 1097-1108.

[141] M.J.J.M. van Kemenade, P.L. de Bruyn, J. Colloid Interf. Sci. 118 (1987) 564-585.

[142] E.D. Eanes, I.H. Gillessen, A.S. Posner, Nature 208 (1965) 365-367.

[143] A. Bienenstock, A.S. Posner, Arch. Biochem. Biophys. 124 (1968) 604-607.

[144] A.S. Posner, F. Betts, Acc. Chem. Res. 8 (1975) 273-281.

[145] I.V. Melikhov, Inorg. Mater. 36 (2000) 278-286.

[146] S. Lazic, J. Cryst. Growth 147 (1995) 147-154.

[147] R. Rodríguez-Clemente, A. López-Macipe, J. Gómez-Morales, J. Torrent-Burgués, V.M. Castaño, J. Eur. Ceram. Soc. 18 (1998) 1351-1356.

[148] A. Dey, P.H.H. Bomans, F.A. Müller, J. Will, P.M. Frederik, G. de With, N.A.J.M. Sommerdijk, Nat. Mater. 9 (2010) $1010-1014$.

[149] K. Onuma, A. Ito, Chem. Mater. 10 (1998) 3346-3351.

[150] G. Charlot, Chimie analytique quantitative, vol. 2, Masson, Paris, 1974. 
[151] A. Gee, V.R. Deitz, Anal. Chem. 25 (1953) 1320-1324.

[152] K.K. Chittur, Biomaterials 19 (1998) 357-369.

[153] J.L. Ong, K.K. Chittur, L.C. Lucas, J. Biomed. Mater. Res. 28 (1994) 1337-1346.

[154] N.B. Colthup, L.H. Daly, S.E. Wibereley, Introduction to IR and Raman Spectroscopy, vol. 3, Academic Press Inc., New York, 1990.

[155] B. Yan, H.U. Gremlich, Infrared and Raman Spectroscopy of Biological Materials, Marcel Dekker, New York, 2001.

[156] C. Krafft, Anal. Bioanal. Chem. 378 (2004) 60-62.

[157] C. Krafft, V. Sergo, Spectroscopy 20 (2006) 195-218.

[158] D. Eichert, Ph.D. thesis, INPT, France, 2001.

[159] C. Rey, C. Combes, C. Drouet, M.J. Glimcher, Osteoporos. Int. 20 (2009) 1013-1021.

[160] L. Winand, Ann. Chim. (Paris, Fr.) 6 (1961) 951-967.

[161] R. Legros, N. Balmain, G. Bonel, Calcif. Tissue Int. 41 (1987) 137-144.

[162] E.P. Paschalis, E. DiCarlo, F. Betts, P. Sherman, R. Mendelsohn, A.L. Boskey, Calcif. Tissue Int. 59 (1996) $480-487$.

[163] A. Carden, M.D. Morris, J. Biomed. Opt. 5 (2000) 259-268.

[164] S. Koutsopoulos, J. Biomed. Mater. Res. 62 (2002) 600-612.

[165] A. Antonakos, E. Liarokapis, T. Leventouri, Biomaterials 28 (2007) 3043-3054.

[166] Y. Bala, D. Farlay, P.D. Delmas, P.J. Meunier, G. Boivin, Bone 46 (2010) 1204-1212.

[167] C. Rey, B. Collins, T. Goehl, I. Dickson, M. Glimcher, Calcif. Tissue Int. 45 (1989) 157-164.

[168] C. Rey, M. Shimizu, B. Collins, M. Glimcher, Calcif. Tissue Int. 46 (1990) 384-394.

[169] C. Combes, C. Rey, S. Mounic, Key Eng. Mater. 192-195 (2001) 143-146.

[170] W.P. Aue, A.H. Roufosse, M.J. Glimcher, R.G. Griffin, Biochemistry 23 (1984) 6110-6114.

[171] J.L. Miquel, L. Facchini, A.P. Legrand, C. Rey, J. Lemaitre, Colloids Surf. 45 (1990) 427-433.

[172] H. Sfihi, C. Rey, 1-D and 2-D double heteronuclear magnetic resonance study of the local structure of type B carbonate fluoroapatite, in: J. Fraissard, B. Lapina (Eds.), Magnetic Resonance in Colloid and Interface Science, Nato ASI Series II, Kluwer Academic Publishers, 2002, pp. 409-418.

[173] A.H. Roufosse, W.P. Aue, J.E. Roberts, M.J. Glimcher, R.G. Griffin, Biochemistry 23 (1984) 6115-6120.

[174] J. Roberts, L. Bonar, R. Griffin, M. Glimcher, Calcif. Tissue Int. 50 (1992) 42-48.

[175] Y. Wu, M.J. Glimcher, C. Rey, J.L. Ackerman, J. Mol. Biol. 244 (1994) 423-435.

[176] M. Jarlbring, D.E. Sandstr Jam, O.N. Antzutkin, W. Forsling, Langmuir 22 (2006) 4787-4792.

[177] C. Drouet, M.-T. Carayon, C. Combes, C. Rey, Mater. Sci. Eng. C 28 (2008) 1544-1550.

[178] G. Xu, I.A. Aksay, J.T. Groves, J. Am. Chem. Soc. 123 (2001) 2196-2203.

[179] A. Hina, Ph.D. thesis, INPT, France, 1996.

[180] G. Cho, Y. Wu, J.L. Ackerman, Science 300 (2003) 1123-1127.

[181] G. Cho, J.P. Yesinowski, J. Phys. Chem. 100 (1996) 15716-15725.

[182] E. Smith, G. Dent, Modern Raman Spectroscopy, John Wiley \& Sons, Chichester, 2005.

[183] G. Gauglitz, T. Vo-Dinh, Handbook of Spectroscopy, Wiley-VCH, Weinheim, Germany, 2003.

[184] M.D. Morris, W.F. Finney, Spectroscopy 18 (2004) 155-159.

[185] M. Kazanci, P. Roschger, E.P. Paschalis, K. Klaushofer, P. Fratzl, J. Struct. Biol. 156 (2006) 489-496.

[186] S.Y. Lin, M.J. Li, W.T. Cheng, Spectroscopy 21 (2007) 1-30.

[187] G. Penel, G. Leroy, C. Rey, E. Bres, Calcif. Tissue Int. 63 (1998) 475-481.

[188] J.D. Pasteris, B. Wopenka, J.J. Freeman, K. Rogers, E. Valsami-Jones, J.A.M. van der Houwen, M.J. Silva, Biomaterials 25 (2004) 229-238.

[189] D.G.A. Nelson, J.D.B. Featherstone, Calcif. Tissue Int. 34 (1982) S69-S81.

[190] D. Nelson, B. Williamson, Aust. J. Chem. 35 (1982) 715-727.

[191] A. Awonusi, M. Morris, M. Tecklenburg, Calcif. Tissue Int. 81 (2007) 46-52.

[192] D. Grossin, S. Rollin-Martinet, C. Estournès, F. Rossignol, E. Champion, C. Combes, C. Rey, C. Geoffroy, C. Drouet, Acta Biomater. 6 (2010) 577-585.

[193] A.A. Baig, J.L. Fox, R.A. Young, Z. Wang, J. Hsu, W.I. Higuchi, A. Chhettry, H. Zhuang, M. Otsuka, Calcif. Tissue Int. 64 (1999) 437-449.

[194] S. Cazalbou, D. Eichert, X. Ranz, C. Drouet, C. Combes, M.F. Harmand, C. Rey, J. Mater, Sci. Mater. Med. 16 (2005) $405-409$.

[195] C. Drouet, F. Bosc, M. Banu, C. Largeot, C. Combes, G. Dechambre, C. Estournes, G. Raimbeaux, C. Rey, Powder Technol. 190 (2009) 118-122.

[196] S. Cazalbou, C. Combes, D. Eichert, C. Rey, M.J. Glimcher, J. Bone Miner. Metab. 22 (2004) 310-317.

[197] S. Cazalbou, C. Combes, D. Eichert, C. Rey, J. Mater. Chem. 14 (2004) 2148-2153.

[198] C. Rey, H.M. Kim, M.J. Glimcher, Maturation of poorly crystalline synthetic and biological apatites, in: P.W. Brown, B. Constantz (Eds.), Hydroxyapatite and Related Materials, CRC Press, Boca Ratón, 1994, pp. 181-187.

[199] V. Midy, C. Rey, E. Bres, M. Dard, J. Biomed. Mater. Res. 41 (1998) 405-411.

[200] S. Ouizat, A. Barroug, A. Legrouri, C. Rey, Mater. Res. Bull. 34 (1999) 2279-2289.

[201] C. Drouet, C. Largeot, G. Raimbeaux, C. Estournès, G. Dechambre, C. Combes, C. Rey, Adv. Sci. Tech. 49 (2006) 45-50.

[202] B. Bracci, P. Torricelli, S. Panzavolta, E. Boanini, R. Giardino, A. Bigi, J. Inorg. Biochem. 103 (2009) 1666-1674.

[203] P. Habibovic, T.M. Sees, M.A. van den Doel, C.A. van Blitterswijk, K. de Groot, J. Biomed. Mater. Res. A 77A (2006) 747-762.

[204] H. Autefage, F. Briand-Mésange, S. Cazalbou, C. Drouet, D. Fourmy, S. Gonçalvès, J.-P. Salles, C. Combes, P. Swider, C. Rey, J. Biomed. Mater. Res. B 91B (2009) 706-715.

[205] R. Wiesendanger, Scanning Probe Microscopy and Spectroscopy, Cambridge University Press, UK, 1994.

[206] T. Fukuma, K. Kobayashi, K. Matsushige, H. Yamada, Appl. Phys. Lett. 86 (2005) 193103-193108.

[207] H.H. Teng, P.M. Dove, C.A. Orme, J.J. De Yoreo, Science 282 (1998) 724-727.

[208] C.M. Pina, U. Becker, P. Risthaus, D. Bosbach, A. Putnis, Nature 395 (1998) 483-486.

[209] A.E.S. Van Driessche, J.M. García-Ruiz, J.M. Delgado-López, G. Sazaki, Cryst. Growth Des. 10 (2010) 3909-3916.

[210] K. Onuma, A. Ito, T. Tateishi, T. Kameyama, J. Cryst. Growth 154 (1995) 118-125.

[211] K. Onuma, Prog. Cryst. Growth Charact. 52 (2006) 223-245. 
[212] A. Bigi, E. Boanini, B. Bracci, G. Falini, K. Rubini, J. Inorg. Biochem. 95 (2003) 291-296.

[213] A. Bigi, E. Boanini, G. Cojazzi, G. Falini, S. Panzavolta, Cryst. Growth Des. 1 (2001) 239-244.

[214] L. Zhu, X. Ye, G. Tang, N. Zhao, Y. Gong, Y. Zhao, J. Zhao, X. Zhang, J. Biomed. Mater. Res. A 83A (2007) 1165-1175.

[215] M. Sato, E.B. Slamovich, T.J. Webster, Biomaterials 26 (2005) 1349-1357.

[216] J.M. Delgado, J.M. Orts, A. Rodes, Langmuir 21 (2005) 8809-8816.

[217] C.A. Siedlecki, R.E. Marchant, Biomaterials 19 (1998) 441-454.

[218] W. Jiang, H. Pan, Y. Cai, J. Tao, P. Liu, X. Xu, R. Tang, Langmuir 24 (2008) 12446-12451.

[219] M.L. Wallwork, J. Kirkham, J. Zhang, D.A. Smith, S.J. Brookes, R.C. Shore, S.R. Wood, O. Ryu, C. Robinson, Langmuir 17 (2001) 2508-2513.

[220] F. Vázquez-Hernández, C. Mendoza-Barrera, V. Altuzar, M. Meléndez-Lira, M.A. Santana-Aranda, M. de la L. Olvera, Mater. Sci. Eng. B 174 (2010) 290-295.

[221] S. Cazalbou, Ph.D. thesis, INPT, France, 2000.

[222] C. Rey, A. Hina, A. Tofighi, M.J. Glimcher, Cell Mater. 5 (1995) 345-356.

[223] F. Barrère, P. Layrolle, C.A. van Blitterswijk, K. de Groot, Bone 25 (1999) 107S-111S.

[224] M.D. O’Donnell, Y. Fredholm, A. de Rouffignac, R.G. Hill, Acta Biomater. 4 (2008) 1455-1464.

[225] A. Bigi, E. Boanini, C. Capuccini, M. Gazzano, Inorg. Chim. Acta 360 (2007) 1009-1016.

[226] F. Errassifi, A. Menbaoui, H. Autefage, L. Benaziz, S. Ouizat, V. Santran, S. Sarda, A. Lebugle, C. Combe, A. Barroug, H. Sfihi, C. Rey, Adsorption on apatitic calcium phosphates: applications to drug delivery, in: R. Narayan, M. Singh, J. McKittrick (Eds.), Advances in Bioceramics and Biotechnologies, Wiley-VCH Verlag GmbH \& Co, KGaA, 2010.

[227] X. Dong, Q. Wang, T. Wu, H. Pan, Biophys. J. 93 (2007) 750-759.

[228] T. Boix, J. Gómez-Morales, J. Torrent-Burgues, A. Monfort, P. Puigdomenech, R. Rodriguez-Clemente, J. Inorg. Biochem. 99 (2005) 1043-1050.

[229] G.H. Nancollas, R. Tang, R.J. Phipps, Z. Henneman, S. Gulde, W. Wu, A. Mangood, R.G.G. Russell, F.H. Ebetino, Bone 38 (2006) 617-627.

[230] C. Combes, C. Rey, Biomaterials 23 (2002) 2817-2823.

[231] L. Benaziz, A. Barroug, A. Legrouri, C. Rey, A. Lebugle, J. Colloid Interf. Sci. 238 (2001) 48-53.

[232] F. Errassifi, S. Sarda, A. Barroug, A. Lebugle, A. Legrouri, H. Sfihi, C. Rey, in: III Conference on the Valorization of Phosphates and Phosphorous Compounds (COVAPHOS III), Marrakech, 2009.

[233] H. Roussière, F. Fayon, B. Alonso, T. Rouillon, V. Schnitzler, E. Verron, J. Guicheux, M. Petit, D. Massiot, P. Janvier, J.-M. Bouler, B. Bujoli, Chem. Mater. 20 (2007) 182-191.

[234] L.N. Luong, S.I. Hong, R.J. Patel, M.E. Outslay, D.H. Kohn, Biomaterials 27 (2006) 1175-1186.

[235] M.I. Alam, I. Asahina, K. Ohmamiuda, K. Takahashi, S. Yokota, S. Enomoto, Biomaterials 22 (2001) 1643-1651.

[236] A. Barroug, L.T. Kuhn, L.C. Gerstenfeld, M.J. Glimcher, J. Orthop. Res. 22 (2004) 703-708.

[237] M. Iafisco, B. Palazzo, M. Marchetti, N. Margiotta, R. Ostuni, G. Natile, M. Morpurgo, V. Gandin, C. Marzano, N. Roveri, J. Mater. Chem. 19 (2009) 8385-8392.

[238] A. Barroug, A. Legrouri, C. Rey, Bioceramics 20 (1 and 2) (2008) 361-363. 79-82.

[239] B. Palazzo, M. Iafisco, M. Laforgia, N. Margiotta, G. Natile, C.Ä. Bianchi, D. Walsh, S. Mann, N. Roveri, Adv. Funct. Mater. 17 (2007) 2180-2188.

[240] M. Iafisco, B. Palazzo, G. Falini, M. Di Foggia, S. Bonora, S. Nicolis, L. Casella, N. Roveri, Langmuir 24 (2008) $4924-4930$.

[241] D. Tigani, C. Zolezzi, F. Trentani, A. Ragaini, M. Iafisco, S. Manara, B. Palazzo, N. Roveri, J. Mater. Sci.-Mater. Med. 19 (2008) $1325-1334$.

[242] M. Iafisco, E. Varoni, E. Battistella, S. Pietronave, M. Prat, N. Roveri, L. Rimondini, Int. J. Artif. Organs 33 (2010) $765-774$.

[243] N. Roveri, B. Palazzo, M. Iafisco, Expert Opin. Drug Deliv. 5 (2008) 861-877.

[244] M. Iafisco, P. Sabatino, I.G. Lesci, M. Prat, L. Rimondini, N. Roveri, Colloids Surf. B 81 (2010) 274-284.

[245] M. Iafisco, M.D. Foggia, S. Bonora, M. Prat, N. Roveri, Dalton Trans. 40 (2011) 820-827.

[246] A.H. Faraji, P. Wipf, Bioorg. Med. Chem. 17 (2009) 2950-2962.

[247] M. Kester, Y. Heakal, T. Fox, A. Sharma, G.P. Robertson, T.T. Morgan, E.I. Altinoglu, A. Tabakovic, M.R. Parette, S.M. Rouse, V. Ruiz-Velasco, J.H. Adair, Nano Lett. 8 (2008) 4116-4121.

[248] M.Z. Zhang, K. Kataoka, Nano Today 4 (2009) 508-517.

[249] S. Bisht, G. Bhakta, S. Mitra, A. Maitra, Int. J. Pharm. 288 (2005) 157-168.

[250] A. López-Macipe, J. Gómez-Morales, R. Rodríguez-Clemente, J. Colloid Interf. Sci. 200 (1998) 114-120.

[251] T. Aoba, E.C. Moreno, J. Colloid Interf. Sci. 106 (1985) 110-121.

[252] M. Stigter, J. Bezemer, K. de Groot, P. Layrolle, J. Control. Release 99 (2004) 127-137.

[253] D.N. Misra, Colloids Surf. A 141 (1998) 173-179.

[254] A. Barroug, J. Fastrez, J. Lemaitre, P. Rouxhet, J. Colloid Interf. Sci. 189 (1997) 37-42.

[255] A. Barroug, E. Lernoux, J. Lemaitre, P.G. Rouxhet, J. Colloid Interf. Sci. 208 (1998) 147-152.

[256] Y. Liu, L. Enggist, A.F. Kuffer, D. Buser, E.B. Hunziker, Biomaterials 28 (2007) 2677-2686.

[257] V. Midy, E. Hollande, C. Rey, M. Dard, J. Plouet, J. Mater. Sci.-Mater. Med. 12 (2001) 293-298.

[258] M. Yoshinari, Y. Oda, H. Ueki, S. Yokose, Biomaterials 22 (2001) 709-715.

[259] K. McLeod, S. Kumar, R.S.C. Smart, N. Dutta, N.H. Voelcker, G.I. Anderson, R. Sekel, Appl. Surf. Sci. 253 (2006) $2644-2651$.

[260] A. Lebugle, A. Rodrigues, P. Bonnevialle, J.J. Voigt, P. Canal, F. Rodriguez, Biomaterials 23 (2002) 3517-3522.

[261] G.A. Rodan, H.A. Fleisch, J. Clin. Invest. 97 (1996) 2692-2696.

[262] R.G.G. Russell, M.J. Rogers, Bone 25 (1999) 97-106.

[263] S.E. Papapoulos, Bone 38 (2006) 613-616.

[264] F.P. Coxon, K. Thompson, M.J. Rogers, Curr. Opin. Pharmacol. 6 (2006) 307-312.

[265] J. Monkkonen, J. Simila, M.J. Rogers, Life Sci. 62 (1998) PL95-PL102.

[266] S.N. Elliott, W. McKnight, N.M. Davies, W.K. MacNaughton, J.L. Wallace, Life Sci. 62 (1997) 77-91.

[267] M. Kos, J.F. Kuebler, K. Luczak, W. Engelke, J. Cranio Maxill. Surg. 38 (2010) 255-259.

[268] M. Kos, K. Luczak, Biosci. Hypotheses 2 (2009) 34-36.

[269] A. Hoffman, D. Stepensky, A. Ezra, J.M. Van Gelder, G. Golomb, Int. J. Pharm. 220 (2001) 1-11. 
[270] S. Josse, C. Faucheux, A. Soueldan, G. Grimandi, D. Massiot, B. Alonso, P. Janvier, S. Laib, P. Pilet, O. Gauthier, G. Daculsi, J. Guicheux, B. Bujoli, J.M. Bouler, Biomaterials 26 (2005) 2073-2080.

[271] A. Al-Kattan, F. Errassifi, A.M. Sautereau, S. Sarda, P. Dufour, A. Barroug, I. Dos Santos, C. Combes, D. Grossin, C. Rey, C. Drouet, Adv. Eng. Mater. 12 (2010) B224-B233.

[272] B. Peter, D.P. Pioletti, S. Laib, B. Bujoli, P. Pilet, P. Janvier, J. Guicheux, P.Y.Zambelli, J.M. Bouler, O. Gauthier, Bone 36 (2005) 52-60.

[273] E. Verron, O. Gauthier, P. Janvier, P. Pilet, J. Lesoeur, B. Bujoli, J. Guicheux, J.M. Bouler, Biomaterials 31 (2010) $7776-7784$.

[274] H. Roussiere, G. Montavon, L.B. Samia, P. Janvier, B. Alonso, F. Fayon, M. Petit, D. Massiot, J.M. Bouler, B. Bujoli, J. Mater. Chem. 15 (2005) 3869-3875.

[275] M. Balazic, J. Kopac, M.J. Jackson, W. Ahmed, Int. J. Nano Biomater. 1 (2007) 3-34.

[276] X.Y. Liu, P.K. Chu, C.X. Ding, Mater. Sci. Eng. R 47 (2004) 49-121.

[277] Y.T. Sul, C.B. Johansson, S. Petronis, A. Krozer, Y. Jeong, A. Wennerberg, T. Albrektsson, Biomaterials 23 (2002) $491-501$.

[278] K. de Groot, J.G.C. Wolke, J.A. Jansen, Proc. Inst. Mech. Eng. H - J. Eng. Med. 212 (1998) 137-147.

[279] R.G.T. Geesink, K. Degroot, C. Klein, Clin. Orthop. (1987) 147-170.

[280] K.A. Thomas, Stephen D. Cook, R.J. Haddad, J.F. Kay, M. Jarcho, J. Arthroplasty 4 (1989) 43-53.

[281] S.C.G. Leeuwenburgh, J.G.C. Wolke, M.C. Siebers, J. Schoonman, J.A. Jansen, Biomaterials 27 (2006) 3368-3378.

[282] K. Soballe, E.S. Hansen, H. Brockstedtrasmussen, C. Bunger, J. Bone Joint Surg. Br. 75 (1993) 270-278.

[283] K. Soballe, E.S. Hansen, H. Brockstedtrasmussen, V.E. Hjortdal, G.I. Juhl, C.M. Pedersen, I. Hvid, C. Bunger, Clin. Orthop. (1991) 300-307.

[284] M. Navarro, A. Michiardi, O. Castaño, J.A. Planell, J. Royal Soc. Interf. 5 (2008) 1137-1158

[285] J. Gómez-Morales, R. Rodríguez-Clemente, B. Armas, C. Combescure, R. Berjoan, J. Cubo, E. Martinez, J. Garcia Carmona, S. Garelik, J. Murtra, D.N. Muraviev, Langmuir 20 (2004) 5174-5178.

[286] D.E. MacDonald, F. Betts, M. Stranick, S. Doty, A.L. Boskey, J. Biomed. Mater. Res. 54 (2001) 480-490.

[287] Z. Zyman, J. Weng, X. Liu, X. Li, X. Zhang, Biomaterials 15 (1994) 151-155.

[288] F. Lusquinos, A. De Carlos, J. Pou, J.L. Arias, M. Boutinguiza, B. Leon, M. Perez-Amor, F.C.M. Driessens, K. Hing, I. Gibson, S. Best, W. Bonfield, J. Biomed. Mater. Res. A 64A (2003) 630-637.

[289] Y. Yang, K.-H. Kim, J.L. Ong, Biomaterials 26 (2005) 327-337.

[290] M. Wei, A.J. Ruys, M.V. Swain, S.H. Kim, B.K. Milthorpe, C.C. Sorrell, J. Mater. Sci.-Mater. Med. 10 (1999) 401-409.

[291] D.G. Wang, C.Z. Chen, H. Ting, T.Q. Lei, J. Mater. Sci.-Mater. Med. 19 (2008) 2281-2286.

[292] Y. Hashimoto, M. Kawashima, R. Hatanaka, M. Kusunoki, H. Nishikawa, S. Hontsu, M. Nakamura, J. Mater. Sci.-Mater. Med. 19 (2008) 327-333.

[293] L. Muller, E. Conforto, D. Caillard, F.A. Muller, Biomol. Eng. 24 (2007) 462-466.

[294] J.-M. Choi, H.-E. Kim, I.-S. Lee, Biomaterials 21 (2000) 469-473.

[295] H. Ishizawa, M. Fujino, M. Ogino, J. Biomed. Mater. Res. 35 (1997) 199-206.

[296] H.S. Ryu, W.-H. Song, S.-H. Hong, Curr. Appl. Phys. 5 (2005) 512-515.

[297] C.Y. Yang, T.M. Lee, C.W. Yang, L.R. Chen, M.C. Wu, T.S. Lui, J. Biomed. Mater. Res. A 83A (2007) 263-271

[298] X. Hu, H. Shen, Y. Cheng, X. Xiong, S. Wang, J. Fang, S. Wei, Surf. Coat. Technol. 205 (2010) 2000-2006.

[299] M. Lind, S. Overgaard, H. Glerup, K. Soballe, C. Bünger, Biomaterials 22 (2001) 189-193.

[300] I. Ono, H. Gunji, F. Kaneko, T. Saito, Y. Kuboki, J. Craniofac. Surg. 6 (1995) 238-244.

[301] J.M. Wozney, V. Rosen, Clin. Orthop. (1998) 26-37.

[302] L.T. de Jonge, J. Ju, S.C.G. Leeuwenburgh, Y. Yamagata, T. Higuchi, J.G.C. Wolke, K. Inoue, J.A. Jansen, Thin Solid Films 518 (2010) 5615-5621.

[303] L.T. de Jonge, S.C.G. Leeuwenburgh, J. van den Beucken, J. te Riet, W.F. Daamen, J.G.C. Wolke, D. Scharnweber, J.A. Jansen, Biomaterials 31 (2010) 2461-2469.

[304] Y.L. Liu, E.B. Hunziker, P. Layrolle, J.D. De Bruijn, K. De Groot, Tissue Eng. 10 (2004) 101-108.

[305] Y. Liu, E.B. Hunziker, N.X. Randall, K. de Groot, P. Layrolle, Biomaterials 24 (2003) 65-70.

[306] S.C.G. Leeuwenburgh, M.C. Heine, J.G.C. Wolke, S.E. Pratsinis, J. Schoonman, J.A. Jansen, Thin Solid Films 503 (2006) 69-78.

[307] I. Uematsu, H. Matsumoto, K. Morota, M. Minagawa, A. Tanioka, Y. Yamagata, K. Inoue, J. Colloid Interf. Sci. 269 (2004) 336-340.

[308] S. Leeuwenburgh, J. Wolke, J. Schoonman, J. Jansen, J. Biomed. Mater. Res. A 66A (2003) 330-334.

[309] E.S. Thian, X. Li, J. Huang, M.J. Edirisinghe, W. Bonfield, S.M. Best, Thin Solid Films 519 (2011) 2328-2331.

[310] J.A.N. Shepperd, H. Apthorp, J. Bone Jt. Surg. Br. 87B (2005) 1046-1049.

[311] A. Doat, F. Pelle, N. Gardant, A. Lebugle, J. Solid State Chem. 177 (2004) 1179-1187.

[312] M. Fanjul, A. Doat, F. Pelle, E. Hollande, A. Lebugle, In Vitro Cell. Dev. Biol. Anim. 40 (2004) 81A.

[313] S.P. Mondejar, A. Kovtun, M. Epple, J. Mater. Chem. 17 (2007) 4153-4159.

[314] J.Y. Chane-Ching, A. Lebugle, I. Rousselot, A. Pourpoint, F. Pelle, J. Mater. Chem. 17 (2007) 2904-2913.

[315] A. Al-Kattan, P. Dufour, J. Dexpert-Ghys, C. Drouet, J. Phys. Chem. C 114 (2010) 2918-2924.

[316] K.A. Franz, W.G. Kethr, A. Siggle, J. Wiieczoreck, in: B. Elvers, S. Hawkins, G. Schulz (Eds.), Ullmann's Encyclopedia of Industrial Chemistry, VCH, Weinheim, Germany, 1985.

[317] C. Görller-Walrand, K. Binnemans, Spectral intensities of f-f transitions, in: Karl A. Gschneidner Jr., E. LeRoy (Eds.), Handbook on the Physics and Chemistry of Rare Earths, Elsevier, Amsterdam, 1998, pp. 101-264.

[318] A.L. Heyes, S. Seefeldt, J.P. Feist, Opt. Laser Technol. 38 (2006) 257-265.

[319] P.R. Selvin, Annu. Rev. Biophys. Biomol. Struct. 31 (2002) 275-302.

[320] P.R. Diamente, R.D. Burke, F. van Veggel, Langmuir 22 (2006) 1782-1788.

[321] P. Huhtinen, J. Vaarno, T. Soukka, T. Lovgren, H. Harma, Nanotechnology 15 (2004) 1708-1715.

[322] X.H. Gao, Y.Y. Cui, R.M. Levenson, L.W.K. Chung, S.M. Nie, Nat. Biotechnol. 22 (2004) 969-976.

[323] R. Ternane, M. Trabelsi-Ayedi, N. Kbir-Ariguib, B. Piriou, J. Lumin. 81 (1999) 165-170.

[324] R. El Ouenzerfi, N. Kbir-Ariguib, M. Trabelsi-Ayedi, B. Piriou, J. Lumin. 85 (1999) 71-77.

[325] P. Martin, G. Carlot, A. Chevarier, C. Den-Auwer, G. Panczer, J. Nucl. Mater. 275 (1999) 268-276.

[326] A. Doat, M. Fanjul, F. Pelle, E. Hollande, A. Lebugle, Biomaterials 24 (2003) 3365-3371.

[327] E.J. Kim, S.-W. Choi, S.-H. Hong, J. Am. Ceram. Soc. 90 (2007) 2795-2798. 
[328] E.I. Altinoglu, T.J. Russin, J.M. Kaiser, B.M. Barth, P.C. Eklund, M. Kester, J.H. Adair, ACS Nano 2 (2008) 2075-2084.

[329] T.T. Morgan, H.S. Muddana, E.I. Altinoglu, S.M. Rouse, A. Tabakovic, T. Tabouillot, T.J. Russin, S.S. Shanmugavelandy, P.J. Butler, P.C. Eklund, J.K. Yun, M. Kester, J.H. Adair, Nano Lett. 8 (2008) 4108-4115.

[330] Y. Guo, D.L. Shi, J. Lian, Z.Y. Dong, W. Wang, H.S. Cho, G.K. Liu, L.M. Wang, R.C. Ewing, Nanotechnology 19 (2008).

[331] Y. Cai, H. Pan, X. Xu, Q. Hu, L. Li, R. Tang, Chem. Mater. 19 (2007) 3081-3083.

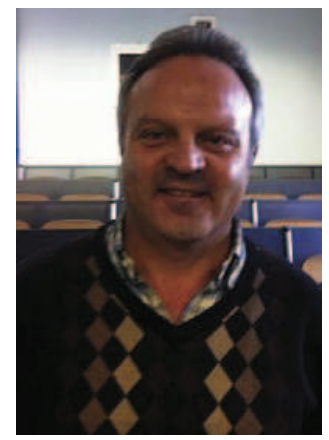

Jaime Gómez Morales received the degree in Chemistry from University of Granada in 1984 and his $\mathrm{PhD}$ in Chemistry from University of Barcelona in 1992. Since 1992 until 2003 Dr. Gómez-Morales was hired researcher at the Institute of Materials Science in Barcelona, developing his activity in crystal growth, crystallization of inorganic monodisperse particles, and lately in the field of biomaterials. During this period he was teacher of the Master Course of Crystal Growth of the Autonomous University of Barcelona. Since 2004 he is permanent staff scientist at Laboratorio de Estudios Cristalográficos (LEC) of Instituto Andaluz de Ciencias de la Tierra (IACT) in Granada, Spain. His main research activity is focused on the fields of crystallization, biomineralization of calcium carbonate and calcium phosphates and nanocrystallization for biomedical applications. Dr. Gómez-Morales actively participates in numerous managerial and academic activities including the implementation of the "Factoria Española de Cristalización (Spanish Crystallization Factory), where he is the current principal investigator of LEC; the Master of Crystallography and Crystallization of the International University Menéndez Pelayo, where he is coordinator and teacher of the Module "Fundamentals of Crystallization" and the biannual International School of Crystallization: Drugs, foods, agrochemicals, minerals and new materials, sponsored by the International Union of Crystallography, where he is the current co-director. Since 2006 Jaime Gómez is the Spanish representative in the Working Party of Crystallization of the European Federation of Chemical Engineers. Along his carrier Dr. Gómez-Morales published around 60 papers on international journals and numerous conference proceedings.

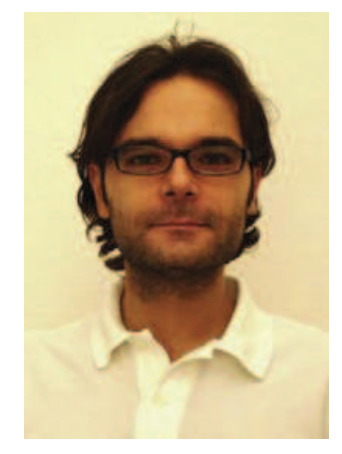

Michele Iafisco was born in 1980. In 2005 he received the degree in Chemistry at the Alma Mater Studiorum University of Bologna and at the same University he received in 2009 the Ph.D. in Chemical Science. From January 2009 to October 2011 he worked as post-doctoral researcher at the University of Piemonte Orientale. In 2009 he was the PI of a two years project "Multifunctional nanoparticles for the cancer therapy: studies in vitro and in vivo" funding by Regione Piemonte (Ricerca Sanitaria Finalizzata 2009). From October 2011 he works at ISTEC-CNR of Faenza as research fellow. Michele Iafisco collaborates and develops his scientific activities with Italian and European research groups. In 2007, 2008, 2009 and 2011 he was visiting researcher at the Laboratorio de Estudios Cristalográficos (LEC) (Granada, Spain) where he studied the processes for the control of calcium phosphates crystallization. In 2007 he was visiting researcher at the Eindhoven University of Technology Soft Matter Cryo-TEM research unit (Eindhoven, The Netherlands) where he studied the formation of collagen by using CryoTEM and in 2010 he was visiting researcher at the Department of Periodontology and Biomaterials, Radboud University Nijmegen Medical Center (Nijmegen, The Netherlands) where he studied the electrospray technique for coating production. His research interest include synthesis and characterization of inorganic and hybrid organic-inorganic nanomaterials, calcium phosphates crystallization, biomineralization and nanomedicine. He published more than 40 scientific articles and book chapters on national and international journals and he presented his researches in national and international conferences. He is referee for several international journals and member of the Italian Crystallographic Association and of the European Society of Biomaterials.

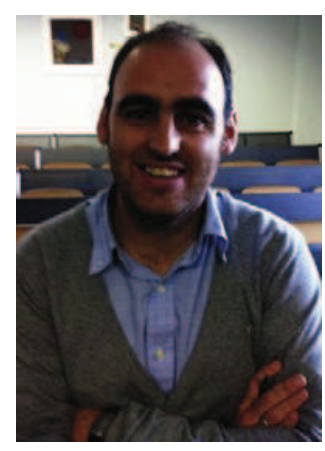

José Manuel Delgado-López is a Research Scientist at Laboratorio de Estudios Cristalográficos (IACT, CSIC-UGR), Granada, Spain. He received his degree in Chemistry (2002) from the University of Jaén and his PhD degree in Materials Science (2008) from the University of Alicante. His PhD work was awarded by the Real Sociedad Española de Química (Alicante) and by the University of Alicante. Dr. DelgadoLópez is an expert in the synthesis of nanostructured materials and their further characterization using mainly Atomic Force Microscopy (AFM), FT-IR and Raman spectroscopies. His research focuses on the synthesis and characterization of biomimetic apatite nanoparticles to be used as nanocarriers for drug delivery in cancer therapies as well as scaffolds for cells in bone. Dr. Delgado-López has published nearly 20 papers in journals and conference proceedings in the fields of chemistry, crystal growth and biomaterials. 


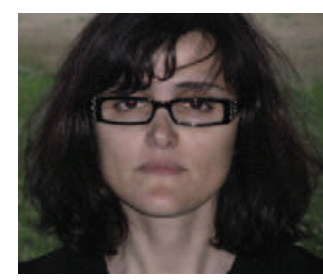

Stéphanie Sarda is Associate Professor of the University of Toulouse (France). She is a teacher in Materials Sciences in the University of Toulouse and member of "Phosphates, Pharmacotechnics, Biomaterials" research group of the CIRIMAT Carnot Institute in Toulouse. She received her PhD degree in Materials Sciences (1999) from the Institut National Polytechnique of Toulouse for her work concerning the synthesis of calcium phosphates in Organised Molecular Systems. From 2000 up to 2003, Dr. Sarda performed a post-doctorate training period in the Universitat Politècnica de Catalunya (Barcelona, Spain) dedicated to the development of calcium phosphate bone cement for biomedical application, and in the Centre de Recherche Paul Pascal (Bordeaux, France) focused on specific recognition of micrometric magnetic particles by cell surface. Her main research activity concerns the synthesis and characterization of mineral phases of biological interest, like nanocrystalline apatites and calcium pyrophosphates, and the study of mineral-organic interactions for biomedical applications. Dr. Sarda has published nearly 30 papers in journals, conference proceedings and book chapters in the fields of materials science and biomaterials.

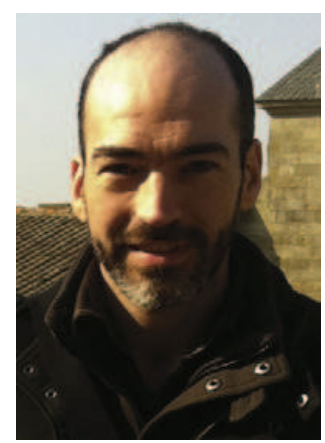

Christophe Drouet is a permanent Research Scientist hired by French governmental CNRS scientific organization. Member of the CIRIMAT Carnot Institute in Toulouse, France ("Phosphates, Pharmacotechnics, Biomaterials" research group). Ph.D. in Materials Sciences. Major research fields include the physico-chemistry and thermochemistry of natural or synthetic minerals and the study of the surface characterization and reactivity of nanomaterials. Main milestones are 3 years (2001-2003) spent in Prof. Alexandra Navrotsky's group at the University of California at Davis (UCDavis), USA, for gaining expertise in the thermochemistry of hydrated minerals, and other stays including in Prof. José-Luis G. Fierro's group at the Univ. of Madrid, Spain, for a specialization in X-ray photoelectron spectroscopy and in the study of chemisorption processes. A special focus is dedicated to the investigation of calcium phosphate compounds, in particular of biomimetic nanocrystalline apatites, as Prof. C. Rey's collaborator in view of innovative bio-medical applications (tissue engineering, intracellular drug delivery, medical imaging...) and for a better understanding of biomineralization processes. C. Drouet regularly supervises Ph.D theses in Materials Sciences and is involved in the co-direction of undergraduate students and postdoctoral fellows. Beside the publication of $45+$ articles in International journals (details on http://www.researcherid.com/rid/A-8023-2008), C. Drouet's scientific production includes the co-writing of 5 Book Chapters and the presentation of International keynote lectures. C. Drouet is a member of the Editorial Board of the International journal "Bioinspired, Biomimetic and Nanobiomaterials" (ICE Publishing), and acts as a scientific expert for the French "National Research Agency (ANR)" and the Italian "Ministero dell'istruzione, dell'universita et della ricerca (MIUR)". 